Ricardo de Godoi Mattos Ferreira

\title{
GENÉTICA EPIDEMIOLÓGICA DE MALÁRIA EM RONDÔNIA
}

Tese apresentada ao Instituto de Ciências Biomédicas da Universidade de São Paulo, para obtenção do Título de Doutor em Ciências (Biologia da relação patógeno-hospedeiro). 
Ricardo de Godoi Mattos Ferreira

GENÉTICA EPIDEMIOLÓGICA DE MALÁRIA EM RONDÔNIA

Tese apresentada ao Instituto de Ciências Biomédicas da Universidade de São Paulo, para obtenção do Título de Doutor em Ciências (Biologia da relação patógeno-hospedeiro).

Área de concentração: Biologia da relação patógeno-hospedeiro

Orientador: Professor Doutor Henrique Krieger 
DADOS DE CATALOGAÇÃO NA PUBLICAÇÃO (CIP)

Serviço de Biblioteca e Informação Biomédica do

Instituto de Ciências Biomédicas da Universidade de São Paulo

(c) reprodução total

Ferreira, Ricardo de Godoi Mattos.

Genética epidemiológica de malária em Rondônia / Ricardo de Godoi Mattos Ferreira. -- São Paulo, 2008.

Orientador: Henrique Krieger.

Tese (Doutorado) - Universidade de São Paulo. Instituto de Ciências Biomédicas. Departamento de Parasitologia. Área de concentração: Biologia da Relação Patógeno-Hospedeiro. Linha de pesquisa: Epidemiologia genética de doenças infecciosas.

Versão do título para o inglês: Genetic epidemiology of malaria infection at Rondônia.

Descritores: 1. Epidemiologia $\quad 2$. Malária $\quad 3$. Genética de populações 4. Bioestatistica 5. Polimorfismo I. Krieger, Henrique II. Universidade de São Paulo. Instituto de Ciências Biomédicas. Programa de Pós-Graduação em Biologia da Relação PatógenoHospedeiro III. Título. 


\section{UNIVERSIDADE DE SÃO PAULO \\ INSTITUTO DE CIÊNCIAS BIOMÉDICAS}

Candidato(a): $\quad$ Ricardo de Godoi Mattos Ferreira.

Título da Tese: $\quad$ Genética epidemiológica de malária em Rondônia.

Orientador(a): Henrique Krieger.

A Comissão Julgadora dos trabalhos de Defesa da Tese de Doutorado, em sessão pública realizada a ................................., considerou

\section{( ) Aprovado(a) ( ) Reprovado(a)}

Examinador(a): Assinatura:

Nome:

Instituição:

Examinador(a): $\quad$ Assinatura:

Nome:

Instituição:

Examinador(a): Assinatura:

Nome:

Instituição:

Examinador(a): Assinatura:

Nome:

Instituição:

Presidente: Assinatura:

Nome:

Instituição: 
Săo Paulo, 16 de agosto de 2007.

\section{PARECER 709/CEP}

Prozado Senhor,

Atendendo sua solicitaçăo, a Comissão de Ética em Pesquisas com Seres Humanos do ICB, em sua $77^{\mathrm{a}}$ reuniấo realizada em 15.08.07, analisou o projeto de sua responsabilidade intitulado: "Genética epidemiológrica de malária em Rondômia".

Informo a V.Sa. que, após análise e discussão, o rcferído projeto foi aprovado por csta Comissão.

Lembramos que cabe ao pesquisador elaborar e apresentar a este Comitê, relatórios anuais (parciais ou final), de acordo cum a resoluçấ 196/o6 do Conselho Nacional da Saúde, item IX.2 letra c.

O primeiro relatório deverá ser encaminhado à Secrctaria deste CEP em 15 de agosto de 2008.

Atenciosamente.

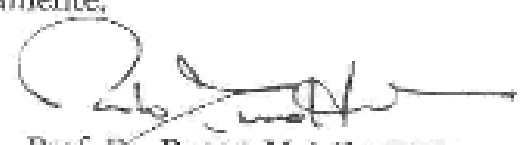

Prof. Dr. PROLO M.A ZAMCTT

Vice-Coordenador da Comissão de Ética em

Pesquisas com Seres Humanos - ICB/CSP

Ilmo, sr.

RtCando de GODCI MatTOS. FERREMGa

Departamento de Parasitologia

Instituto de Ciências Biomélic:as -USP 
Dedico aos meus pais, que sempre me incentivaram nos caminhos que tomei, com conselhos e apoio de valores inestimáveis.

À Erica, pelo amor, compreensão e companheirismo.

Aos que sofrem ou sofreram com a malária, especialmente àqueles que participaram desse estudo. 


\section{AGRADECIMENTOS}

À FAPESP e CNPq pelo apoio financeiro.

Aos colegas e professores do Departamento de Parasitologia.

Às Professoras Vera Engracia e Manuela Moura pela colaboração de campo.

Aos que trabalham para que o ICB V seja mantido, em especial ao Professor Luiz Marcelo Aranha Camargo pela coleta e grande trabalho de campo.

À Professora Mary Furlan Feitosa pela treinamento nas análises de segregação.

Às colegas Maria José Menezes e Dra. Rubiani de Cássia Pagotto pela obtenção dos dados de Portuchuelo.

À colega Ana Paula Fioretti pela ajuda na adequação da tese às diretrizes do Instituto.

Aos colegas Carlos Eduardo Malvezzi Kawamata e Leandro Garrido pelo trabalho no laboratório e grande apoio e amizade.

Ao Professor Bernardo Beiguelman pela convivência, ensinamentos e grande apoio.

Ao Professor Henrique Krieger pela orientação, incentivo e amizade. 


\section{RESUMO}

FERREIRA, R. G. M. Genética Epidemiológica de Malária em Rondônia. 2008. 114 f. Tese (Doutorado em Biologia da Relação Patógeno - Hospedeiro).Instituto de Ciências Biomédicas, Universidade de São Paulo, São Paulo, 2008.

O presente trabalho teve como objetivo investigar os mecanismos genéticos relacionados à resposta humana à malária nas populações de Portuchuelo e de Monte Negro, Rondônia. Estudos como esse podem aumentar o entendimento dos mecanismos da patogênese que são críticos para o desenvolvimento da doença. Cerca de 180 indivíduos de Portuchuelo e mais de 800 indivíduos de Monte Negro foram incluídos na amostra após assinarem o termo de consentimento consciente. Os indivíduos amostrados passaram por um levantamento epidemiológico, seguido de coleta de sangue e caracterização de marcadores sanguíneos clássicos e marcadores de STR (microssatélites). Foi realizado o estudo de mistura étnica nas duas populações utilizando marcadores clássicos. Em Portuchuelo, os componentes de mistura africano, ameríndio e europeu estimados foram $21 \%$, 44\% e 35\% respectivamente e em Monte Negro 25\%, 12\% e 64\%. Em Portuchuelo, a mistura étnica foi estimada também utilizando-se microssatélites. Não houve diferença significante entre as estimativas, entretanto os marcadores clássicos forneceram melhores resultados. Entre as características observadas, o número de episódios de malária relatado pelos indivíduos, após correção para idade e sexo, foi submetido a testes de associação com marcadores sanguíneos clássicos. A associação esperada entre indivíduos Fy- e a característica especificada acima foi encontrada nas duas populações, sem heterogeneidade significante. Análises de segregação complexa indicaram a presença de um gene principal relacionado ao acometimento de malária. Uma varredura genômica foi realizada na população de Portuchuelo utilizando-se 108 microssatélites e, na análise multiponto, foi encontrado um pico de lod score sugestivo de ligação no braço curto do cromossomo 4. Baseados nesse resultado, 9 microssatélites foram selecionados e caracterizados em 480 indivíduos da população de Monte Negro. Os resultados obtidos em Portuchuelo não puderam ser confirmados na amostra de Monte Negro, visto não ter sido detectado lod score significante entre esses 9 microssatélites e o fenótipo investigado na população de Monte Negro.

Palavras-chave: Malaria. Amazônia. Epidemiologia genética. 


\section{ABSTRACT}

FERREIRA, R. G. M. Genetic Epidemiology of Malaria infection at Rondônia Thesis. (Doctor in the Biology of the Interactions between Hosts and Pathogens). Biomedical Science Institute of the University of Sao Paulo, Sao Paulo, 2008 .

The present research aims to investigate the genetic mechanisms related to human response to malaria infection in the populations of Portuchuelo and Monte Negro, Rondonia state, Brazil. Studies like this may contribute to increase our understanding on the pathogenic mechanisms that are critical to the development of the disease. About 180 individuals from Portuchuelo population and more than 800 individuals from Monte Negro were included in the samples after agreement to a consentient term. These individuals where subjected to an epidemiological survey, followed by blood collection and characterization of classic blood groups markers and short tandem repeats markers (STRs). The ethnical admixture of both populations were estimated using classic blood groups markers. In Portuchuelo, the African, Amerindian and European components were estimated as follow: $21 \%, 44 \%$ and $35 \%$. In Monte Negro, the estimated components were $25 \%, 12 \%$ and $64 \%$. In Portuchuelo, the ethnical admixture was also studied using STR markers. Although there wasn't significant differences between the estimates, the classic blood groups markers provided better estimates. Among the characteristics surveyed, the number of malaria episodes reported by the subjects was tested for association with classic blood groups markers after correction for age and sex. The expected association with Fy- individuals was observed in both populations, without significant heterogeneity. Complex segregation analyses indicated the presence of a major gene related to the number of malaria episodes, even after the removal of Fy- individuals. A genomic scan using STRs markers was conducted at Portuchuelo sample. The multipoint linkage scan showed a lod score suggestive of linkage at the short arm of chromosome 4. Based on these results, 9 markers were selected and 480 individuals from Monte Negro were genotyped. The results found in Portuchuelo were not confirmed in Monte Negro sample, since no significant lod score were found between those 9 STRs.

Keywords: Malaria. Amazon. Genetic Epidemiology. 


\section{LISTA DE FIGURAS}

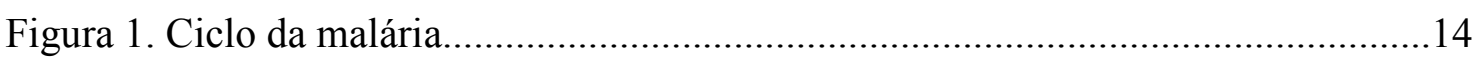

Figura 2. Distribuição dos indivíduos das populações, por sexo e idade.........................34

Figura 3. Distribuição do número de episódios de malária, em cada população, em função da idade

Figura 4. Distribuição do número de episódios de malária relatado pelos pacientes sem tratamento estatístico e após transformação logarítmica e correção para idade e sexo nas populações de Monte Negro e Portuchuelo 36

Figura 5. Resultados das análises de ligação entre 108 marcadores de microssatélites distribuídos ao longo de todo o genoma humano e o número de episódios de malária relatado pelos indivíduos em Portuchuelo .56

Figura 6. Representação gráfica dos resultados obtidos na análise de ligação em Portuchuelo (parte superior) e dos marcadores selecionados ao longo do braço curto do cromossomo 4, testados na população de Monte Negro (parte inferior) .57 


\section{LISTA DE TABELAS}

Tabela 1. Freqüências gênicas ancestrais e estimadas usadas para calcular a mistura étnica das populações de Monte Negro e Portuchuelo. .37

Tabela 2. Freqüência gênica dos STRs em Portuchuelo e nas populações ancestrais.....40 Tabela 3. Composição étnica de duas populações tri-híbridas da Amazônia ocidental utilizando marcadores clássicos e microssatélites.

Tabela 4. Teste $t$ comparando as estimativas de composição étnica obtidas na população de Portuchuelo, entre marcadores clássicos e microssatélites. .42 Tabela 5. Análise de segregação do número de episódios relatados de malária em Monte Negro. 43

Tabela 6. Análise de segregação do número de episódios relatados de malária em Portuchuelo.

Tabela 7. Associação de marcadores clássicos com o número de episódios relatados de malária corrigido nas populações de Monte Negro e Portuchuelo e nas duas populações agrupadas.

Tabela 8. Posto médio do logaritmo do número de episódios de malária relatados pelos indivíduos, corrigido para sexo e idade.

Tabela 9. Meta-análise de associação do antígeno Duffy (Fy-Fy- vs. outros genótipos) com o logaritmo do número de episódios relatados de malária na população de Portuchuelo e Monte Negro. 46

Tabela 10. Análise de segregação do número de episódios relatados de malária (sem indivíduos Duffy negativo) em Portuchuelo.....

Tabela 11. Freqüência observada dos marcadores de microssatélites estudados em Portuchuelo.

Tabela 12. Resultados da análise de ligação de dois pontos em Portuchuelo. O lod score observado para cada marcador de microssatélite (STR) é mostrado nas colunas MAL averiguando a ligação do marcador com o número de episódios de malária relatado pelos indivíduos, e na coluna MAL_LCA averiguando o logaritmo desse número, corrigido para idade e sexo (MAL_LCA) .55 


\section{SUMÁRIO}

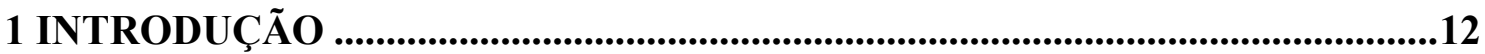

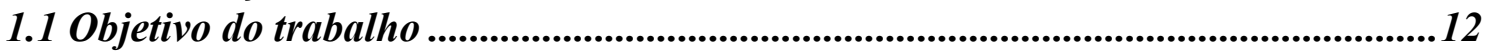

1.2 Malária ..............................................................................................................12

1.3 Epidemiologia genética, variabilidade do hospedeiro e as doenças infecciosas.... 14

1.4 Epidemiologia genética da malária..............................................................................16

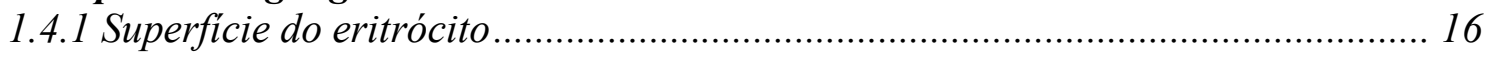

1.4.2 Variação estrutural na estrutura dos genes das globinas................................... 17

1.4.3 Variação na regulação dos genes das globinas ................................................ 17

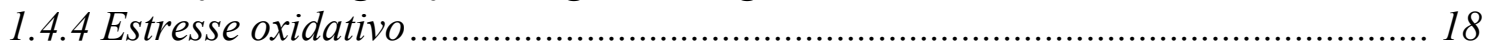

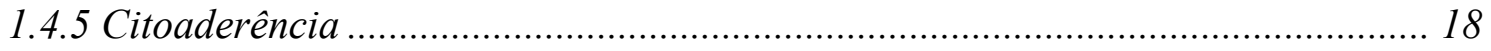

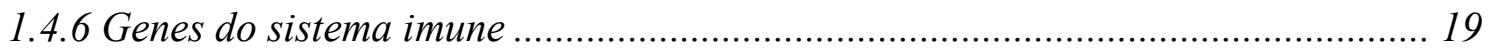

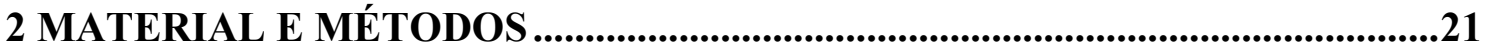

2.1 Aspectos éticos da pesquisa ...............................................................................21

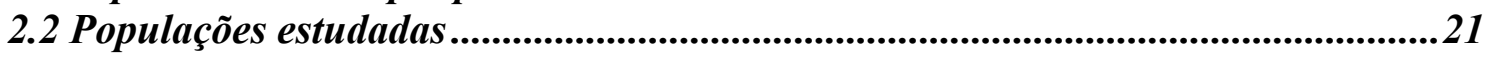

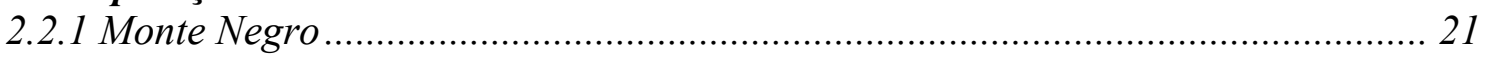

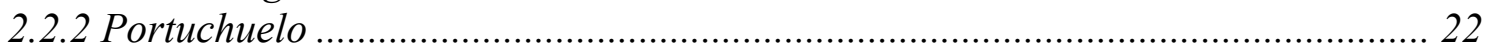

2.3 Número de episódios de malária relatado pelos indivíduos........................................22

2.4 Grupos sanguíneos eritrocitários: $\mathrm{ABO}, \mathrm{Rh}, \mathrm{MNS}$, Kell, Duffy.............................22

2.5 Enzimas eritrocitárias e proteinas séricas .........................................................................23

2.6 Caracterização genotípica da população de Portuchuelo.......................................24

2.6.1 Extração de DNA de Leucócitos para PCR ............................................................. 24

2.6.2 Marcadores de microssatélites................................................................................ 24

2.7 Caracterização genotípica da população de Monte Negro ....................................25

2.8 Programas auxiliares e banco de dados .....................................................................25

2.9 Análise descritiva, transformações e correções........................................................26

2.10 Estimativas de freqüências gênicas ..........................................................................26

2.11 Estimativas de mistura étnica......................................................................................26

2.12 Análise de segregação complexa...................................................................................26

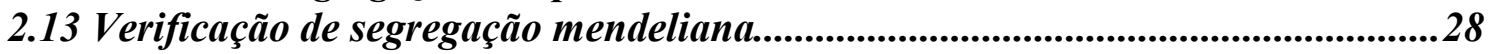

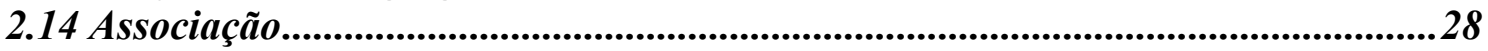

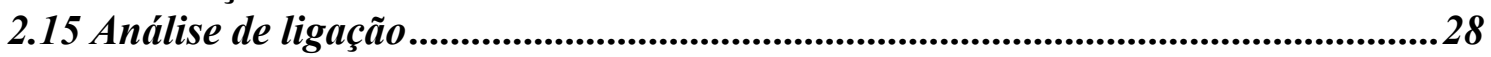

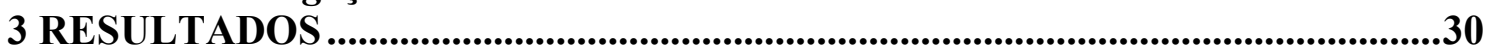

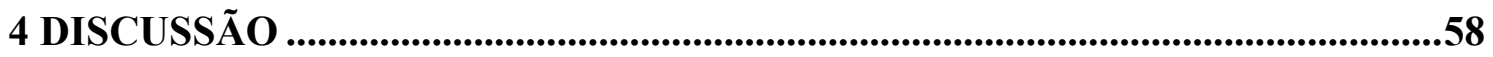

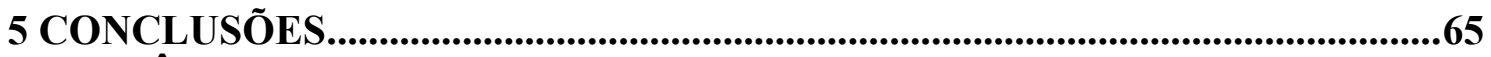

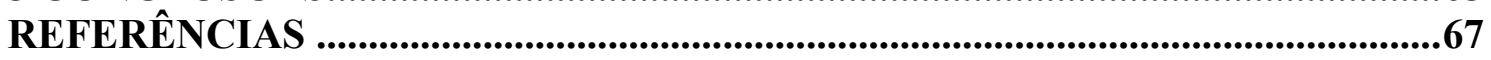

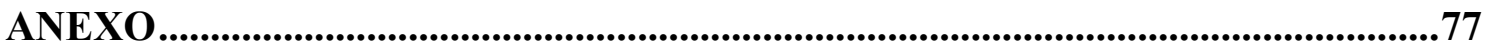




\section{INTRODUÇÃO}

\subsection{Objetivo do trabalho}

A resistência ou suscetibilidade a doenças infecciosas está fortemente associada tanto às características do ambiente quanto às características genéticas do hospedeiro e do patógeno.

Certamente alguns genes que influenciam a resistência/susceptibilidade estão associados à resposta imunológica em várias doenças parasitárias, enquanto que outros produzem ambientes inóspitos para o patógeno de modo que a identificação dos mesmos possa produzir avanços na prevenção ou cura de várias infecções. Estudos buscando esclarecer mecanismos genéticos associados à resposta humana à malária podem aumentar o entendimento dos mecanismos da patogênese que são críticos para o desenvolvimento da doença.

O objetivo principal do projeto é estabelecer a existência de mecanismos genéticos, se possível inéditos, responsáveis pela resposta humana à malária nas populações de Portuchuelo e Monte Negro, Rondônia, vez que, tratando-se de áreas com pequena densidade populacional, apresentam características epidemiológicas completamente distintas daquelas observadas na África, onde a maioria dos estudos nesse campo está sendo realizada.

\subsection{Malária}

A malária é ainda, nos dias atuais, um dos maiores problemas de saúde pública mundial. Distribui-se por todos os continentes, onde quarenta por cento da população mundial está exposta à infecção, majoritariamente pessoas que vivem nas regiões tropicais e subtropicais. Nestas regiões, entre 300 e 500 milhões de casos são diagnosticados todo ano, com 2 milhões de mortes; o dobro do número de mortes causadas pelo HIV (WORLD HEALTH ORGANIZATION e THE UNITED NATIONS CHILDREN'S FUND, 2005).

A malária é provocada por protozoários parasitas do gênero Plasmodium, sendo quatro os que habitualmente infectam o homem: Plasmodium falciparum, $P$. vivax, $P$. malariae (ou P. brazilianum) e P. ovale (limitado ao continente Africano). A doença é 
transmitida pela picada do mosquito fêmea do gênero Anófeles, também conhecido popularmente como pernilongo, mosquito-prego, carapanã, entre outros nomes (NEVES; MELO; LINARDI, 2000; REY, 2001, SILVA, 1996; USSUI e DUTRA, 2001). Um estudo recente de Cox-Singh et al. (2008) traz forte evidência de que o Plasmodium knowlesi, comumente tido como parasita de macacos apenas, também infecta seres humanos. No estudo, o DNA característico do parasita foi detectado por PCR em 266 de 960 amostras de sangue de pacientes na Malásia, incluindo entre estes, 4 casos fatais de malária.

No Brasil, cerca de setenta por cento dos casos são devido à infecção por $P$. vivax e o restante por P. falciparum. O País registra cerca de $40 \%$ do número de casos das Américas, onde 99 \% deles ocorrem na Região da Amazônia Legal (WHO e UNICEF, 2005).

Uma característica compartilhada pelos pacientes maláricos são os episódios de febre e a tendência de que esses episódios ocorram em períodos regulares. A malaria manifesta-se por episódios de calafrios seguidos de febre alta que duram de 3 a 4 horas acompanhados por mal-estar, náuseas, cefaléia e dores articulares. Quando não tratados, os pacientes podem desenvolver esplenomegalia. Quando causada pelo P. falciparum, quadros clínicos graves e risco de morte podem aparecer. A infecção causada por esse parasita pode acarretar disfunção de órgãos vitais como pulmões, rins, fígado e o cérebro, levando à malária cerebral, podendo ocorrer também anemia grave. Essas condições estão associadas aos casos de óbito relacionados à malária. Infecções crônicas por $P$. malarie podem levar a síndromes renais e eventualmente à morte. Ataques sucessivos de malária causados por qualquer espécie são, também, muito debilitantes, reduzindo tanto a qualidade quanto a duração da vida (CARTER e MENDIS, 2002). 


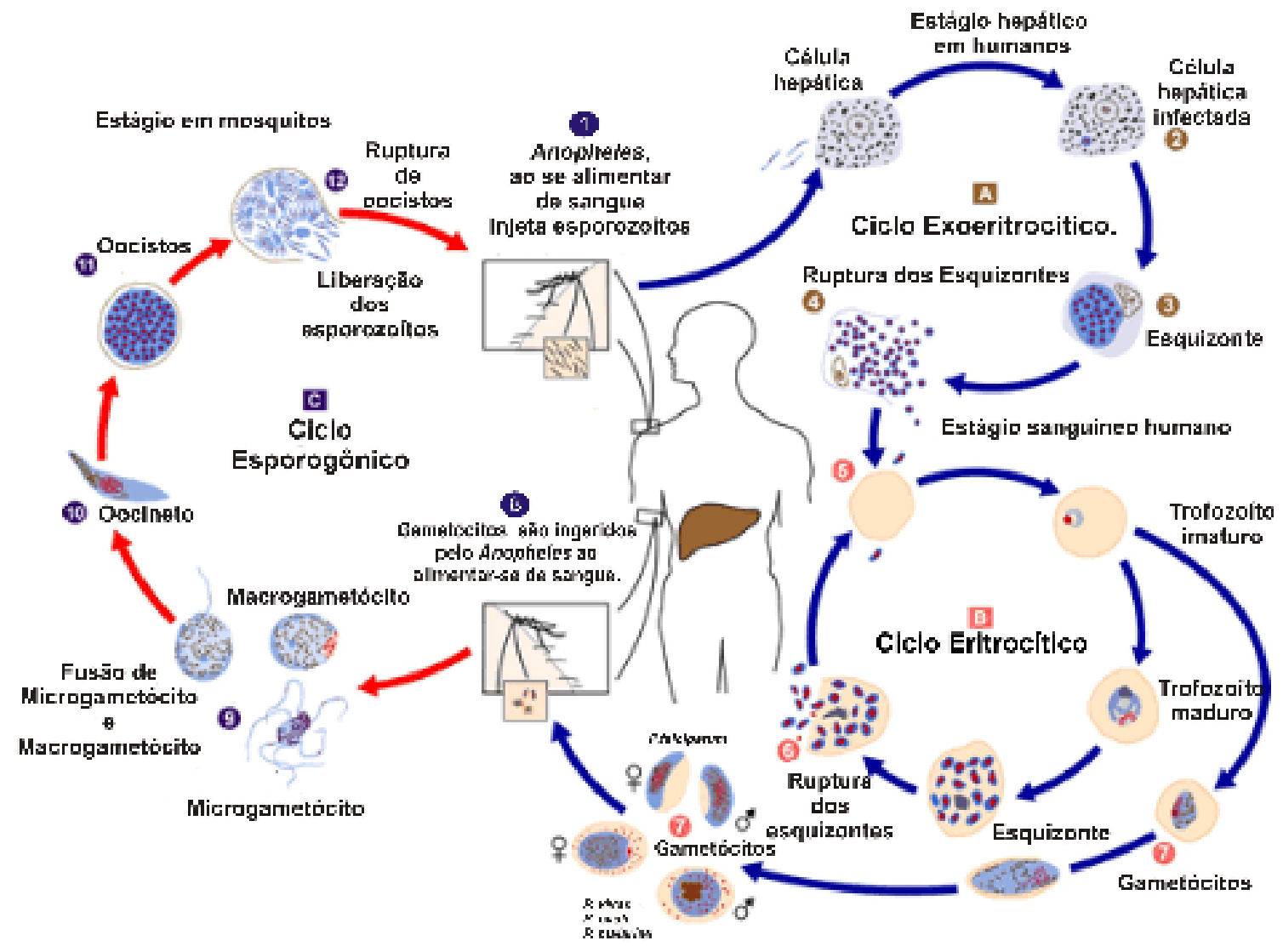

Figura 1. Ciclo da malária.

Fonte: Adaptado de <http://www.cdc.gov/malaria/biology/life_cycle.htm

\subsection{Epidemiologia genética, variabilidade do hospedeiro e as doenças infecciosas}

A publicação do trabalho pioneiro de Haldane (1949) propõe a hipótese de que a distribuição geográfica das freqüências de alguns dos polimorfismos humanos poderia resultar de seleção natural, atuando por intermédio da ação de epidemias presentes ou passadas, como fenômeno de seleção natural. Esse trabalho pode ser considerado o marco histórico do início da Epidemiologia Genética onde a Genética se une a Epidemiologia para esclarecer mecanismos hereditários causando variabilidade na resistência/suscetibilidade aos patógenos.

A hipótese de Haldane foi confirmada pelo trabalho em que Allison (1954), há mais de 50 anos e demonstra que os indivíduos do genótipo $\mathrm{HbA} / \mathrm{HbS}$ mostram-se mais resistentes à infecção do Plasmodium falciparum, agente causador da forma mais virulenta de malária humana.

Os estudos relacionados com a variabilidade da enzima G-6-PD e das talassemias, na região mediterrânea, assim como os trabalhos associados ao antígeno 
eritrocitário Duffy em consonância com a resistência à malária vivax (CARTER e MENDIS, 2002), que se seguiram, mostraram que, pelo menos no que concerne a essa doença parasitária, importantes mecanismos genéticos estavam associados à infecção e à gravidade de sua manifestação e também às variações geográficas importantes em freqüências gênicas (KWIATKOWSKI, 2005).

Em outras infecções, principalmente estudadas em modelos murinos, também se verificou que sua evolução poderia ser dependente de importantes mecanismos genéticos na espécie humana. Esses estudos, utilizando infecções experimentais de Leishmania donovani (CROCKER; BLACKWELL; BRADLEY, 1984) Mycobacterium leprae (BROWN; GLYIN; PLANT, 1982) e BCG (GROS; SKAMENE; FORGET, 1981) mostraram que as diversas linhagens isogênicas de camundongo reagiam de maneira distinta à infecção por esses microorganismos. $\mathrm{O}$ fato observado mais notável foi o de que essas diferenças entre linhagens não eram apenas dependentes do patrimônio genético como um todo, mas de mecanismos mendelianos de herança.

Como conseqüência lógica dessas observações, os pesquisadores interessados foram levados ao consenso de que a história evolutiva dos mamíferos estava intimamente relacionada com a convivência desses com doenças infecciosas e que essa convivência deve ter ditado, por meio da seleção natural, algumas importantes alterações que condicionaram as atuais freqüências gênicas de vários sistemas genéticos nas populações (KWIATKOWSKI, 2005; CARTER e MENDIS, 2002).

É de se ressaltar que a maioria desses estudos relacionados à resistência às doenças infecciosas, foi realizada em populações africanas ou então em modelos animais (CARTER e MENDIS, 2002). Particularmente, poucos trabalhos foram feitos no Brasil, apesar da alta prevalência de várias dessas doenças, em diversas regiões do nosso país.

Os estudos epidemiológico-genéticos em áreas endêmicas são importantes por fornecerem subsídios para o entendimento da História Natural desses relacionamentos interespecíficos e principalmente. Essas observações, em conjunção com informações provenientes da variabilidade do patógeno, de dados da biologia celular e molecular, da imunologia, assim como da epidemiologia clássica, poderão conduzir às medidas de controle e prevenção de algumas doenças de interesse sanitário imediato, assim como de novos processos terapêuticos. 


\subsection{Epidemiologia genética da malária}

Os mecanismos genéticos que afetam a manifestação da malária em humanos são muito diversos. Alguns desses mecanismos serão discutidos a seguir, agrupados conforme a função dos genes no homem e como estes genes afetam o desenvolvimento da doença no hospedeiro humano. O Quadro 1 mostra de forma resumida os genes que modificam a resposta humana à malária.

\subsubsection{Superfície do eritrócito}

A invasão do eritrócito pelo parasita se dá em etapas, desde o reconhecimento e ligação do merozoítas ao eritrócito, até a invasão da membrana em si, dependendo de interações entre as proteínas do merozoítas com as proteínas presentes na superfície dos eritrócitos. A variação dessas proteínas pode levar a variações no comportamento invasivo das células pelos parasitas. Em 1976 Miller et al. demonstrou que indivíduos sem o antígeno Duffy (Fy-), um receptor de quemoquina do eritrócito, não se infectam com P. vivax. Baseados nesses resultados, dezoito anos depois Chitnis e Miller (1994) descobrem a proteína de ligação ao Duffy presente no $P$. vivax. No Brasil, a resistência de indivíduos Fy- foi relatada em diversos trabalhos (CAVASINI et al., 2007a; CAVASINI et al., 2006; SOUSA et al., 2006; BEIGUELMAN et al., 2003; CAVASINI et al., 2001; PARASOL et al., 1998; COLAUTO et al., 1981). A resistência desses indivíduos ao $P$. vivax é considerada completa, porém alguns autores começam a sugerir que existem exceções (CAVASINI et al., 2007b).

A invasão do eritrócito pelo $P$. falciparum parece estar relacionada a mais de uma via, com redundância entre elas (HADLEY et al., 1987). Entre os genes que participam do processo estão os genes das glicoforinas A, B e C (GYPA, GYPB e $G Y P C)$ que mostram evidências de estarem sobre forte seleção, tanto no genoma humano, quanto no receptor EBA-175, presente no plasmodium (WANG et al., 2003). Outro gene relacionado à invasão do eritrócito, porém com mecanismo de ação ainda desconhecido é o gene de troca de ânions SLC4A1. Uma deleção nesse gene causa um tipo de ovalocitose comum em partes do sudeste asiático e está associada à resistência à infecção e à malária cerebral (CATTANI et al., 1987; FOO et al., 1992; GENTON et al., 1995; ALLEN et al., 1999). 


\subsubsection{Variação estrutural na estrutura dos genes das globinas}

A hemoglobina é a proteína presente em maior concentração nos eritrócitos. É um tetrâmero, formado por duas $\alpha$ globinas, codificadas pelos gene $H B A 1$ e $H B A 2$ e duas $\beta$ globinas, codificadas pelo gene $H B B . \mathrm{O}$ alelo $\mathrm{HbS}$ do gene da $\beta$ globina é o causador da anemia falciforme, sendo um dos primeiros alelos humanos a ser relacionado a um defeito molecular específico (PAULING, 1949). Junto ao alelo HbS, os alelos $\mathrm{HbC}$ e $\mathrm{HbE}$ da $\beta$ globina são conhecidos por causar anemias em diversos níveis de gravidade. No entanto, são importantes mecanismos de resistência a malária (KWIATKOWSKI, 2005).

Indivíduos $\mathrm{HbAS}$, heterozigotos portadores dos alelos $\mathrm{HbA}$ (selvagem) e $\mathrm{HbS}$ (causador da anemia falciforme) normalmente não apresentam problemas clínicos e tem proteção às formas letais de malária falciparum cerca de 10 vezes maior que indivíduos homozigotos saudáveis (HbA) (ALLISON, 1954; KWIATKOWSKI, 2005). Já os indivíduos $\mathrm{HbS}$, homozigotos portadores dos alelos $\mathrm{HbS}$, manifestam anemia grave e não atingem a idade reprodutiva. O $\mathrm{HbS}$ é um típico exemplo de polimorfismo balanceado. Apesar de ser letal em homozigose, a vantagem seletiva dos indivíduos heterozigotos (HbSA) mantém as freqüências do alelo $\mathrm{HbS}$ em cerca de $10 \%$ nas populações Africanas fortemente expostas à malária causada pelo P. falciparum sendo esse um dos melhores exemplos de seleção natural causada por uma doença infecciosa atuando em populações humanas.

Os mecanismos que levam à proteção à malária devido às variações na hemoglobina ainda não estão completamente esclarecidos, hipóteses variam desde a diminuição no crescimento do parasita (PASVOL et al., 1978) até ao aumento da captura de células parasitadas pelo baço (SHEAR et al., 1993).

\subsubsection{Variação na regulação dos genes das globinas}

Além das variações na estrutura das globinas, as variações na regulação desses genes também são importantes causadoras de doenças humanas monogênicas, chamadas de talassemias. O trabalho de Haldane (1949) associa a manutenção das altas freqüências da $\alpha+$ talassemia nas regiões mediterrâneas européias e africanas como sendo resultado da resistência à malária, muito freqüente na região à época. $O$ mecanismo de ação da talassemia sobre a malária ainda é incerto; entre outras hipóteses 
estão a de redução do crescimento de parasitas (PATTANAPANYASAT et al., 1999), aumento na ligação de anticorpos (WILLIAMS; WEATHERALL; NEWBOLD, 2002) e o aumento da captura de células parasitadas pelo baço (KWIATKOWSKI, 2005).

\subsubsection{Estresse oxidativo}

Uma vez no eritrócito o Plasmodium quebra as moléculas de hemoglobina e dessa quebra resultam subprodutos altamente tóxicos, como o ferro. A produção do doador de elétrons di-nucleotídeo fosfato nicotinamida adenina pela enzima glicose-6fosfato desidrogenase (G6PD) codificada pelo gene ligado ao cromossomo X G6PD, é um mecanismo natural de defesa do eritrócito ao estresse oxidativo. Diversos variantes do gene $G 6 P D$ que influenciam na atividade da enzima são conhecidos e podem levar à anemia hemolítica (KWIATKOWSKI, 2005). Em 1967, Gilles et al. mostrou correlação entre proteção à malária grave e deficiência de G6PD em crianças nigerianas. A distribuição geográfica da deficiência de G6PD coincide com a ocorrência de malária, assim como estudos da estrutura dos haplótipos do gene G6PD apóiam a hipótese de seleção positiva recente (KWIATKOWSKI, 2005).

A haptoglobina, codificada pelo gene $H P$, atua como uma proteína de ligação à hemoglobina, presente no plasma. O genótipo 1-1 da haptoglobina foi associado à susceptibilidade à malária grave causada pelo P. falciparum (ELAGIB et al., 1998; QUAYE et al., 2000) e a presença da haptoglobina inibiu, in vitro, o crescimento de parasitas (IMRIE et al., 2004).

\subsubsection{Citoaderência}

A citoaderência dos eritrócitos parasitados a diversas células e endotélios do homem, entre elas os vasos sanguíneos, plaquetas e outros eritrócitos é um dos mecanismos da patogênese da malária e contribui para a gravidade das infecções causados pelo P. falciparum (MILLER et al., 2002). Diversos são os genes humanos que demonstram associações com malária e estão relacionados a citoaderência. Entre eles podemos destacar a molécula de adesão intracelular tipo 1 (ICAM-1) e o antígeno CD36 com evidências mais fortes de apresentarem um papel importante na resistência à malária (CAMPINO; KWIATKOWSKI; DESSEIN, 2006).

Quando comparado aos fatores de resistência discutidos anteriormente, mecanismos genéticos relacionados a citoaderência são especialmente complexos 
(KWIATKOWSKI, 2005), uma vez que além da variabilidade do hospedeiro, sabe-se que o Plasmodium apresenta mecanismos específicos para gerar variabilidade nos receptores expressos na parede do eritrócito. A proteína de membrana do eritrócito de $P$. falciparum (PfEMP1), por exemplo, é codificada pela grande e diversificada família de genes var (SMITH et al., 1995).

No Brasil, o trabalho realizado por Albrecht et al. (2006) mostrou que o repertório de genes da família var é menor que o encontrado na África e Ásia, e que a repetição de genes expressos entre diversos isolados também é maior. Ainda no Brasil, foi encontrada associação entre microssatélites de $P$. falciparum com quadros assintomáticos de malária (DALLA MARTHA et al., 2007). Estudos como estes demonstram que os mecanismos de resistência em humanos, em especial os relacionados à evasão do sistema imune e adesão do eritrócito parasitado, podem sofrer variações em função da região e do padrão epidemiológico ao qual as populações estão expostas.

\subsubsection{Genes do sistema imune}

Assim como os genes envolvidos na citoaderência, os genes do sistema imune vêm apresentando diversas associações com malária e outras doenças infecciosas (BELLAMY e HILL, 1998; HILL (2006, 1999, 1998); KRIEGER e FEITOSA, 1999). Os resultados, da mesma forma que os genes relacionados à citoaderência, são mais controversos do que os obtidos com os genes relacionados aos mecanismos descritos anteriormente. Os mecanismos de evasão do parasita podem contribuir com essas variações nos resultados, vez que determinado gene humano pode atuar como um mecanismo de resistência em uma população submetida à uma variedade de Plasmodium, e em outra população, submetida a outra variedade do parasita, atuar como um mecanismo de susceptibilidade.

Entre os genes do sistema imunológico que vêm sendo associados à malária estão os genes do sistema principal de histo-compatibilidade (MHC) HLA-B, HLA-DR e TNF, as interleucinas IL1, IL4, IL10 e IL12, a citocina gama interferon IFNG (CAMPINO; KWIATKOWSKI; DESSEIN, 2006) e o gene NOS2A envolvido na geração de NO, que é um radical livre com propriedades anti-parasíticas e que também tem potencial imunossupressor (CLARK et al., 1996). 
Quadro 1. Genes com associação à malária conhecida

\begin{tabular}{|c|c|c|c|c|}
\hline Gene/Locus & Função & Efeito na resposta à Malária & Localização & Dist.(cM) \\
\hline$H B B$ & $\begin{array}{l}\text { Componente da } \\
\text { hemoglobina }\end{array}$ & $\begin{array}{l}\text { Os alelos } \mathrm{HbS} \text { e } \mathrm{HbC} \text { trazem proteção } \\
\text { contra malária grave. }\end{array}$ & $11 \mathrm{p} 15.5$ & $\sim 8 \mathrm{cM}$ \\
\hline$H B A$ & $\begin{array}{l}\text { Componente da } \\
\text { hemoglobina }\end{array}$ & $\begin{array}{l}\text { A talassemia protege contra malária } \\
\text { grave. }\end{array}$ & $16 \mathrm{p} 13.3$ & $\sim 1 \mathrm{cM}$ \\
\hline$D U F F Y-D A R C$ & $\begin{array}{l}\text { Receptor de } \\
\text { quemoquina }\end{array}$ & $\begin{array}{l}\text { O alelo FY- dá proteção total à infecção } \\
\text { causada pelo } P \text {. vivax }\end{array}$ & $1 q 21-q 22$ & $\sim 167 \mathrm{cM}$ \\
\hline$G 6 P D$ & $\begin{array}{l}\text { Enzima que proteje } \\
\text { o eritrócito do stress } \\
\text { oxidativo }\end{array}$ & $\begin{array}{l}\text { A deficiência em G6PD confere } \\
\text { proteção à malária grave }\end{array}$ & $\mathrm{Xq} 28$ & $\sim 102 \mathrm{cM}$ \\
\hline $\begin{array}{l}\text { HLA (classes } 1 e \\
\text { 2) }\end{array}$ & $\begin{array}{l}\text { Apresentação de } \\
\text { antígenos }\end{array}$ & $\begin{array}{l}\text { HLA-B53 e HLA-DRB1 foram } \\
\text { associados de forma independente à } \\
\text { proteção à malária grave na Gâmbia }\end{array}$ & $6 \mathrm{p} 21.3$ & $\sim 47 \mathrm{cM}$ \\
\hline SLC4A1 & Troca de anions & $\begin{array}{l}\text { A deleção causa Ovalocitose, que traz } \\
\text { resistência à malária cerebral }\end{array}$ & $17 q 21-q 22$ & $\sim 64 \mathrm{cM}$ \\
\hline$T N F$ & $\begin{array}{l}\text { Citocina pro- } \\
\text { inflamatória }\end{array}$ & $\begin{array}{l}\text { Diversos variantes associados } \\
\text { independentemente à malária grave e } \\
\text { risco de reinfecção. }\end{array}$ & $6 \mathrm{p} 21.3$ & $\sim 46 \mathrm{cM}$ \\
\hline$N O S 2 A$ & Produção de NO & $\begin{array}{l}\text { Diversos variantes associados } \\
\text { independentemente à malária grave }\end{array}$ & $17 q 11.2-q 12$ & $\sim 50 \mathrm{cM}$ \\
\hline ICAMI & $\begin{array}{l}\text { Molécula de adesão } \\
\text { intercellular }\end{array}$ & $\begin{array}{l}\text { Diversos variantes associados } \\
\text { independentemente à malária grave }\end{array}$ & 19 p13.3-p13.2 & $\sim 33 \mathrm{cM}$ \\
\hline$C D 36$ & $\begin{array}{l}\text { receptor de } \\
\text { trombospondina }\end{array}$ & $\begin{array}{l}\text { Diversos variantes associados } \\
\text { independentemente à malária grave }\end{array}$ & $7 \mathrm{q} 11.2$ & $\sim 67 \mathrm{cM}$ \\
\hline IFNG & $\begin{array}{l}\text { Citocina pro- } \\
\text { inflamatória }\end{array}$ & $\begin{array}{l}\text { Associado com malária grave na } \\
\text { Gâmbia e redução do risco de malaria } \\
\text { cerebral em Mali }\end{array}$ & $12 \mathrm{q} 14$ & $\sim 77 \mathrm{cM}$ \\
\hline IL4 & $\begin{array}{l}\text { Estimula a } \\
\text { promoção de } \\
\text { anticorpos por } \\
\text { células B }\end{array}$ & $\begin{array}{l}\text { Associado com níveis elevados de } \\
\text { anticorpos contra antígenos maláricos. } \\
\text { (Burquina Faso) }\end{array}$ & $5 \mathrm{q} 31.1$ & $\sim 136 \mathrm{cM}$ \\
\hline
\end{tabular}

Adaptado de CAMPINO et al. (2006). Localização e distância genética no cromossomo, a partir de seu início no braço curto, em centimorgans (mapa do instituto Marshfield) obtidas usando o "Map Viewer", ferramenta disponível em http://www.ncbi.nih.gov.

Diante desse panorama, cercado de tantas questões de grande interesse e meio a outras tantas incertezas é que esta proposta de trabalho foi implementada e suas conseqüências serão mostradas a seguir. 


\section{MATERIAL E MÉTODOS}

\subsection{Aspectos éticos da pesquisa}

O presente estudo foi aprovado pela Comissão de Ética em Pesquisas com Seres Humanos do ICB/USP segundo o parecer 799/CEP.

As amostras utilizadas foram obtidas pela equipe participante do amplo programa de pesquisas na Amazônia ocidental brasileira, intitulado "Investigação científica da etiologia e clínica de algumas doenças tropicais na região de Monte Negro, Rondônia” e que vem sendo conduzido pelo Departamento de Parasitologia do Instituto de Ciências Biomédicas (ICB) da Universidade de São Paulo (USP). O projeto foi aprovado pelo Comitê de Ética do Conselho Regional de Medicina desse Estado (parecer 322/CEP).

As amostras coletadas atualmente estão sob os cuidados do Laboratório de Epidemiologia Genética do Instituto de Ciências Biomédicas da Universidade de São Paulo. Todas as medidas necessárias foram tomadas tanto para garantir o anonimato dos indivíduos participantes do projeto, quanto em relação à preservação do material colhido e seu uso de maneira ética.

\subsection{Populações estudadas}

\subsubsection{Monte Negro}

Município situado a cerca de $260 \mathrm{~km}$ ao sudoeste de Porto Velho $\left(10^{\circ} 15^{\prime} \mathrm{S}\right.$, $63^{\circ} 18^{\prime} \mathrm{W}$ ) com aproximadamente 10.000 habitantes, sendo que cerca de $60 \%$ habitam a área rural do município. Nessa localidade, a amostra foi coletada ao acaso seguindo um modelo de averiguação completa, reunindo dados de 900 indivíduos, compreendendo cerca de 250 famílias nucleares. Foram coletadas informações pessoais, familiares e sobre a saúde de cada indivíduo, seguidos de exame médico e coleta de sangue. Mais detalhes sobre os padrões demográficos e epidemiológicos dessa população podem ser encontrados no trabalho de Camargo et al. (2002). 


\subsubsection{Portuchuelo}

É um vilarejo ribeirinho, à margem direita do Rio Madeira ( $\left.8^{\circ} 37^{\prime} \mathrm{S}, 63^{\circ} 49^{\prime} \mathrm{W}\right)$, ao qual se pode chegar por barco, durante todo o ano, ou por terra, durante a estação de seca (maio a setembro). A pequena comunidade de Portuchuelo não atinge 200 pessoas e é composta por descendentes dos europeus que ali se estabeleceram no século 19 e começo do século 20 e que se miscigenaram com os índios que viviam nessa região banhada pelo Rio Madeira. Durante o período áureo da extração da borracha e da construção da estrada de ferro Madeira-Mamoré, essa área recebeu trabalhadores oriundos do nordeste brasileiro bem como de trabalhadores procedentes de Granada e Barbados, os quais foram responsáveis pelo fluxo de genes africanos na população de Portuchuelo (CAMARGO et al., 1999). A principal ocupação da maioria dos homens dessa comunidade é a pesca e a agricultura de subsistência, cabendo às mulheres as atividades domésticas e agrícolas.

Assim como em Monte Negro, foram coletadas informações pessoais, familiares e sobre a saúde de cada indivíduo, seguidos de exame médico e coleta de sangue. Praticamente todos os habitantes do local aderiram ao projeto, totalizando cerca de 30 famílias nucleares.

\subsection{Número de episódios de malária relatado pelos indivíduos}

O principal fenótipo estudado foi o número de episódios de malária relatados pelos indivíduos, corrigidos pelas co-variáveis idade e sexo dos indivíduos segundo modelo de regressão a ser discutido nos resultados.

\subsection{Grupos sanguíneos eritrocitários: $A B O, R h, M N S, K e l l$, Duffy.}

Os procedimentos a seguir foram realizados pela equipe do Laboratório de Epidemiologia Genética, com participação local da Profa. Dra. Vera Engracia e da Profa. Dra. Maria Manuela Moura, em Porto Velho. Os grupos sangüíneos foram classificadas por meio de um kit de microtipagem da "DiaMed - ID Micro Typing 
System", em que um gel de sephadex G100, superfino, é colocado em microtúbulos inseridos em cartões. Esse gel é apresentado em três preparações básicas, mas, no caso de grupos sangüíneos, é usada uma mistura de gel/anti-soro. Reagentes padronizados foram colocados, juntamente com uma pequena amostra de sangue na extremidade superior do tubo, permitindo a incubação da amostra, antes de ser efetuada a centrifugação que separa as hemácias sensibilizadas por anticorpos. As hemácias sensibilizadas ficam aglutinadas em algum ponto do gel ou, em caso de resultado negativo, sedimentam-se no fundo do microtúbulo.

Os antígenos pesquisados foram: A e B do sistema $\mathrm{ABO}$; c, e, D, C e E do Rh; M, N, S, s, do MNSs; Cellano e Kell do Kell e Fy e Fy ${ }^{\mathrm{b}}$ do sistema Duffy.

\subsection{Enzimas eritrocitárias e proteinas séricas}

Os procedimentos a seguir foram realizados pela equipe do Laboratório de Epidemiologia Genética, com participação local da Profa. Dra. Vera Engracia e da Profa. Dra. Maria Manuela Moura, em Porto Velho.

Esterase D (ES D): foi identificada pelo método de Kühnl; Schwabenland; Spielmann (1977) em um gel de agarose, com tampão TRIS (0,1M)/ácido cítrico $(0,028 \mathrm{M})$, em pH 7,7. O mesmo foi usado para o gel, mas diluído na proporção 1:4, em câmara úmida, a uma voltagem de $8-10 \mathrm{~V} / \mathrm{cm}$, por 2 horas e vinte minutos a $4{ }^{\circ} \mathrm{C}$. Na coloração para ESD foi utilizado acetato de 4-metil umbeliferona como substrato, diluído em tampão acetato $(0,1 \mathrm{M})$ em $\mathrm{pH} 5,2$, preparados no momento de uso. Esta solução foi colocada em um papel de filtro, a $2 \mathrm{~cm}$ da origem do lado anódico do gel, posteriormente observado sob luz ultravioleta.

Anidrase carbônica (CaII): foi classificada pelo método de Kühnl; Schwabenland; Spielmann (1977) em um gel de agarose, com tampão TRIS $(0,1 \mathrm{M})$ /ácido cítrico $(0,028 \mathrm{M})$, em $\mathrm{pH}$ 7,7. O mesmo foi usado para o gel, mas diluído na proporção 1:4, em câmara úmida, a uma voltagem de $8-10 \mathrm{~V} / \mathrm{cm}$, por 2 horas e vinte minutos a $4{ }^{\circ} \mathrm{C}$. Na solução de coloração foi empregado o diacetato de fluoresceína e acetona diluídos em tampão fosfato $(0,1 \mathrm{M})$ sob $\mathrm{pH} 7,8$. Esta solução foi colocada em um papel de filtro, por todo o lado catódico do gel e posteriormente observado sob luz ultravioleta.

Glioxalase (GLO): foi classificada pelo método de Kühnl; Schwabenland; Spielmann (1977) em um gel de agarose, com tampão TRIS (0,1M)/ácido cítrico 
(0,028M), em pH 7,7. O mesmo foi usado para o gel, mas diluído na proporção 1:4, em câmara úmida, a uma voltagem de $8-10 \mathrm{~V} / \mathrm{cm}$, por 2 horas e vinte minutos a $4{ }^{\circ} \mathrm{C}$. Na coloração, a parte anódica do gel foi revelada por uma solução com MTT e DCIP (diclorofenolindofenol) dissolvidos em tampão TRIS $(0,1 \mathrm{M})$, à qual foi adicionada ágar a 2\%, também em tampão TRIS $(0,1 \mathrm{M})$, havendo necessidade de incubação por 20 minutos a $37^{\circ} \mathrm{C}$, para a revelação das bandas.

Hemoglobinas: foram examinadas em gel de amido, a 10\%, com tampão, TRISEDTA-borato (SMITH, 1968) nas seguintes condições: $2,8 \mathrm{~V} / \mathrm{cm}$, durante 7 horas a 4 ${ }^{\circ} \mathrm{C}$. Após a migração, o gel foi cortado longitudinalmente, sendo que uma das metades foi corada com uma solução de benzidina e outra com uma solução de amido "black 10B".

\subsection{Caracterização genotípica da população de Portuchuelo}

\subsubsection{Extração de DNA de Leucócitos para PCR}

O DNA foi extraído do creme leucocitário, previamente tratado com glicerol tamponado e armazenado em congelador segundo a metodologia descrita por Higuchi (1989). Após a extração, o DNA foi armazenado a $-20{ }^{\circ} \mathrm{C}$ até o momento da análise.

\subsubsection{Marcadores de microssatélites}

Os marcadores de microssatélites foram caracterizados pela equipe do Laboratório de Epidemiologia Genética, com a participação da Dra. Rubiani de Cassia Pagotto. Basicamente, depois de extraído, o DNA dos indivíduos da amostra foi amplificado por meio da técnica de PCR, para 108 marcadores de microssatélites, distribuídos ao longo do genoma nuclear. Após a amplificação, os fragmentos foram analisados em um gel de poliacrilamida, sob condições denaturantes, no equipamento de sequenciamento ALF-Blue (Amersham Biosciences Inc.) e, os arquivos com extensão

*.ALX foram editados e analisados no programa Alellelinks, do mesmo fabricante que o seqüenciador.

Após a edição dos arquivos dos géis, as genotipagens referentes a cada sistema analisado foram exportadas para um arquivo e inseridas no banco de dados do laboratório para análises posteriores. 


\subsection{Caracterização genotípica da população de Monte Negro}

Os marcadores de microssatélites foram caracterizados pela equipe do Laboratório de Epidemiologia Genética. Para a obtenção dos resultados foram realizadas extrações de DNA das amostras de sangue dos indivíduos estudados com o Illustra Blood Genomic Prep Mini Spin Kit (GE Healthcare). O DNA obtido foi posteriormente utilizado como molde para amplificação de regiões de microssatélites presentes no braço curto do cromossomo 4 com iniciadores de reação (primers) da ABI PRISM Linkage Map Set v2.5. Os marcadores escolhidos foram: D4S391, D4S403, D4S405, D4S412, D4S419, D4S 1587, D4S2366, D4S2983, D4S3022. Depois de amplificados, os fragmentos referentes aos microssatélites estudados foram separados por eletroforese capilar, realizada com o equipamento MegaBACE 1500 DNA analysis system da GE Healthcare e analisados com o programa MegaBACE fragment profiler v1.2 fornecido pela mesma companhia.

\subsection{Programas auxiliares e banco de dados}

Em virtude do grande número de dados gerados foi estabelecido um banco de dados possibilitando a consulta e utilização de todas as informações obtidas. Pequenos programas, chamados comumente de "scripts" foram elaborados.

O banco de dados foi criado na plataforma MySQL. Nesse banco foram inseridas informações como os genótipos obtidos (mais de 8000 registros), dados epidemiológicos e da estrutura familial dos indivíduos e dados sobre os marcadores de microssatélites utilizados. As informações sobre os microssatélites incluem a posição do marcador no cromossomo, a freqüências de cada alelo em populações ancestrais entre outras.

Os scripts foram programados na linguagem Pearl. Esses programas foram empregados na organização dos dados para entrada nos programas de análise, na organização das saídas dos programas, na realização de operações de banco de dados como consultas, inserções, exclusões e alterações de registros, na verificação da integridade dos dados bem como em cálculos de algumas análises.

Para uma visão mais aprofundada sobre Bioinformática e alguns exemplos de sua aplicação, o leitor pode consultar o trabalho "Bioinformática: Manual do Usuário" ANEXO dessa tese. 


\subsection{Análise descritiva, transformações e correções}

O pacote estatístico SPSS, nas versões 11 e 13, foi utilizado na análise descritiva das características estudadas, transformações logarítmicas, regressões e correções do efeito de co-variáveis. O pacote foi utilizado também para a criação de gráficos.

\subsection{Estimativas de freqüências gênicas}

As freqüências gênicas dos marcadores clássicos foram feitas pelo programa GENIOC (CABELLO e KRIEGER, 1997) utilizando-se o método de verossimilhança máxima e levam em conta a proporção de mistura racial.

As freqüências gênicas dos microssatélites foram estimadas pelo programa SOLAR 2, que faz correção para desvios gerados por indivíduos relacionados.

\subsection{Estimativas de mistura étnica}

As estimativas de mistura étnica foram calculadas utilizando-se o método de Krieger et al. (1965), implementado no programa Mistura do pacote GENIOC (CABELLO e KRIEGER, 1997). Este método usa as freqüências gênicas de diversos sistemas polimórficos para estimar, por verossimilhança máxima, a composição racial da população em estudo (no caso tri-híbridas). A estimativa da mistura depende das freqüências gênicas ancestrais fornecidas ao programa. As fontes consultadas para a obtenção das freqüências gênicas ancestrais dos marcadores clássicos são fornecidas na tabela de resultados e no ANEXO "Ethnic admixture composition of two western Amazonian populations", sendo específicas para cada marcador ou grupo de marcadores. As freqüências gênicas ancestrais dos microssatélites foram obtidas do sítio na internet do Marshfield Research (MARSHFIELD CLINIC RESEARCH FOUNDATION, 2007).

O programa Mistura precisou ter seu código fonte alterado para que pudesse lidar com o número de alelos encontrado nos marcadores de microssatélites utilizados.

\subsection{Análise de segregação complexa}

A análise de segregação complexa é uma das ferramentas da epidemiologia genética que permite investigar se determinada característica em estudo, chamada de agora em diante de fenótipo, apresenta evidências de ter sua distribuição populacional 
influenciada por mecanismos genéticos. Para testar a hipótese de existência de um mecanismo genético atuando na manifestação do fenótipo, é necessário averiguar a distribuição nas famílias do fenótipo em estudo. Os resultados de uma análise de segregação podem ser úteis na tomada de decisões sobre os rumos da investigação populacional. A evidência de um mecanismo genético importante detectado pela análise de segregação apóia a busca de genes relacionados ao acometimento do fenótipo.

O modelo de análise de segregação empregado, proposto por Lalouel et al. (1983) pressupõe que contribuem para a distribuição do fenótipo em estudo, de modo independente, um loco autossômico principal, um componente multifatorial e, ainda, fatores aleatórios do ambiente. No loco autossômico principal supõe-se um par de alelos $A$, $a$ com freqüências $p$ e $q$, respectivamente, sendo $p+q=1$, e com os genótipos $A A, A a$ e $a a$ resultantes, os quais, se distribuem na população segundo a lei de Hardy e Weinberg, isto é, segundo $(p+q)^{2}$. A distância entre as médias dos dois genótipos homozigotos ( $A A$ e $a a$ ) é denominada deslocamento e representada por $t$. A posição da média do genótipo heterozigoto $(A a)$ em relação às médias dos homozigotos é designada por grau de dominância e representada por $d$. No caso de um dos fenótipos em estudo ser completamente dominante $(A A=A a), d$ será igual a $1 \mathrm{e}$, em havendo codominância, $d$ será igual a 0,5 . Se a dominância for parcial ter-se-á $0,5<d<1$.

Aceita-se que a variação em torno da média de cada um desses genótipos tem distribuição normal, com uma variância comum $\mathrm{C}+\mathrm{E}$ a todos, sendo $\mathrm{C}$ a variância devida a efeitos multifatoriais transmissíveis e E o componente da variância residual do ambiente que não é transmitido dentro das famílias. A variância fenotípica total é designada por $\mathrm{V}$ e a razão $(\mathrm{C} / \mathrm{V})=\mathrm{H}$ é a herdabilidade, que reflete a transmissão poligênica. Parâmetros adicionais podem ser estimados para testar desvios da transmissão mendeliana do efeito principal de pais aos filhos. Esses parâmetros, indicados por $\tau_{\mathrm{AA}}, \tau_{\mathrm{Aa}}$ e $\tau_{\mathrm{aa}}$ indicam, respectivamente, as probabilidades de os genótipos $A A, A a$ e $a a$ transmitirem o alelo $A$ e que dentro da hipótese mendeliana são respectivamente $1,0,5$ e 0 . As diferentes alternativas são testadas por fixação ou estimação de parâmetros do modelo completo, sendo os testes das hipóteses realizados por intermédio do quociente de verossimilhança.

A análise de segregação complexa foi conduzida com a utilização do programa POINTER, baseado no modelo unificado Lalouel et al. (1983) e com a finalidade de investigar a existência de um gene que, eventualmente, condiciona as características em 
estudo. O modelo unificado incorpora as freqüências de transmissão de Elston e Stewart (1971) ao modelo misto de Morton e MacLean (1974).

\subsection{Verificação de segregação mendeliana}

Os genótipos obtidos foram submetidos a testes de verificação de segregação mendeliana ao longo das genealogias, utilizando-se o programa SIMWALK 2 (SOBEL e LANGE, 1996; SOBEL; PAPP; LANGE, 2002; SOBEL; SENGUL; WEEKS, 2001). Esses testes permitem a verificação da integridade dos dados e das informações obtidas sobre os indivíduos e são necessários para a execução dos programas de análise de ligação.

\subsection{Associação}

Os estudos de associação foram efetuados usando-se o programa SPSS. O clássico teste não-paramétrico de Kruskal-Wallis foi empregado para averiguar associação do número de episódios de malária com marcadores clássicos (cf. ANEXO "The association of genetic markers and malaria infection in the Brazilian Western Amazonian region.”). Mais detalhes sobre estudos de associação podem ser encontrado no ANEXO "Genes em indivíduos e famílias".

\subsection{Análise de ligação}

O estudo de ligação foi realizado com o programa SOLAR 2 (ALMASY; e BLANGERO, 1998) que permite a análise de ligação quando se estudam fenótipos quantitativos resultantes de locus múltiplos, efeitos de dominância e epistasia. Mais detalhes sobre estudos de ligação podem ser encontrado ANEXO "Genes em indivíduos e famílias".

Os fenótipos estudados na análise de ligação foram o número de episódios de malárias relatados pelos sujeitos amostrais bem como esse mesmo número após transformação logarítmica e correção para sexo e idade. Na população de Portuchuelo foi realizada a análise de ligação usando 108 marcadores de microssatélites ao longo dos cromossomos autossômicos humanos, totalizando 6.793 genótipos após verificação de segregação mendeliana. Foram realizadas análise de ligação de dois pontos, onde a 
segregação nas famílias de cada marcador é comparada independentemente nas famílias e análise de ligação multiponto, onde a posição dos marcadores nos mapas genéticos é levada em conta nos cálculos, bem como a relação entre eles.

Baseado em resultados obtidos na população de Portuchuelo, conforme discutido mais adiante nessa tese, nove marcadores de microssatélites foram selecionados para caracterização genotípica em 480 indivíduos de Monte Negro. Os mesmos fenótipos investigados em Portuchuelo foram estudados em Monte Negro, assim como as análises aplicadas utilizaram os mesmos métodos. 


\section{RESULTADOS}

Na Figura 2 é mostrada a distribuição dos indivíduos divididos pelo sexo e agrupados por faixa etária (pirâmide etária) nas populações de Monte Negro e Portuchuelo. Em Monte Negro, foram estudados 924 indivíduos, sendo 431 (46,6\%) do sexo feminino e $493(53,4 \%)$ do sexo masculino, o que mostra um excesso masculino ( $P$ do teste exato $=0,045)$. Em Portuchuelo, foram estudados 203 indivíduos, sendo 91 $(44,8 \%)$ do sexo feminino e $112(55,2 \%)$ do sexo masculino, porém o excesso masculino não é significante $(P$ do teste exato $=0,16)$. A distribuição observada é típica da encontrada em populações de países em desenvolvimento, com grande número de indivíduos mais jovens e decréscimo acentuado do número de indivíduos com idade mais avançada.

A Figura 3 mostra como o número de episódios de malária relatados pelos indivíduos se distribui nas populações em função da idade.

A Figura 4 mostra a distribuição desse mesmo fenótipo sem tratamento estatístico e é claramente leptocúrtica nas duas populações. A distribuição da mesma característica também é apresentada após transformação logarítmica e correção para idade e sexo nas populações de Monte Negro, segundo a equação:

Mal_Cor_MN $=\log ($ Num. de episódios de malária $)-\left[3,575^{*} 10^{-2}+3,526 * 10^{-2} *\right.$ idade $-4,023 * 10^{-4} *$ idade $2+4,023 * 10^{-3} *$ idade* $\operatorname{sexo}$;

obtida por regressão múltipla escalonada, bem como em Portuchuelo, segundo a equação:

Mal_Cor_Pc $=\log ($ Num. de episódios de malária $)-\left[0,634+8,503 * 10^{-5}\right.$ $*(\text { idade })^{2} *$ sexo];

obtida da mesma maneira. Após a correção, a curtose da distribuição em Monte Negro foi 0,325 e a assimetria 0,528; em Portuchuelo 0,269 de curtose e -0,384 de assimetria. Pode-se considerar então que as distribuições observadas ajustam-se bem à distribuição normal.

$\mathrm{Na}$ Tabela 1 são mostradas as freqüências gênicas ancestrais dos marcadores clássicos utilizadas no cálculo de mistura étnica bem como as obtidas no estudo atual e, na Tabela 2, os mesmos dados são mostrados para os marcadores de microssatélites na população de Portuchuelo. 
A Tabela 3 traz os resultados obtidos na análise de composição étnica utilizando marcadores clássicos na população de Monte Negro e Portuchuelo e marcadores de microssatélites na população de Portuchuelo. Em Monte Negro, foi observado um componente de mistura africano de $25 \%$, seguido de $12 \%$ de mistura ameríndia e $63 \%$ de origem européia. Já em Portuchuelo, o componente de mistura africano estimado foi de $21 \%$, seguido de $44 \%$ de mistura ameríndia e $35 \%$ de origem européia, considerando as análises realizadas com marcadores clássicos e, considerando os resultados obtidos usando microssatélites, foram estimados o componente de mistura africano de $12 \%$, seguido de $32 \%$ de mistura ameríndia e $56 \%$ de origem européia.

Na Tabela 4 são apresentados os resultados do teste $t$ comparando as estimativas obtidas utilizando marcadores clássicos com aquelas obtidas utilizando microssatélites. Esses resultados mostram que não houve diferença significativa observada entre as análises realizadas utilizando marcadores clássicos e microssatélites.

A Tabela 5 mostra os resultados da análise de segregação utilizando o logaritmo do número de episódios de malária relatado pelos indivíduos, corrigido para idade e ajustado à distribuição normal na população de Monte Negro. A coluna "-2 ln $L$ ” é a medida de ajuste dos dados aos modelos de segregação testados. Os modelos que consideram a inexistência de um gene principal atuando na distribuição do fenótipo estudado (modelo aleatório -2- e sem gene principal -3-) são rejeitados quando comparados ao modelo misto -1- ( 2 vs. $1, \chi^{2}=210,679, p<0,001 ; 3$ vs. $1, \chi^{2}=26,806$, $p<0,001)$. O melhor modelo obtido pode ser considerado o modelo 10 , utilizando o critério de Akaike (1974) - AIC. É importante salientar que os valores estimados de transmissão $(\tau \mathrm{s})$ encontrados diferem dos esperados pela segregação mendeliana $\left(\tau_{\mathrm{AA}}=\right.$ $1,0, \tau_{\mathrm{Aa}}=0,5$ e $\left.\tau_{\mathrm{aa}}=0,0\right)$. Esses valores divergentes do esperado devem refletir características epidemiológicas não medidas em nossas análises. De qualquer maneira, a presença de um gene principal na população de Monte Negro fica apoiada pela análise, uma vez que os modelos "aleatório" e sem "gene principal" foram rejeitados.

A Tabela 6 mostra os resultados da análise de segregação utilizando o logaritmo do número de episódios de malária relatado pelos indivíduos, corrigido para idade e ajustado à distribuição normal na população de Portuchuelo. Os resultados podem ser interpretados da mesma maneira que os da Tabela 5. Os modelos que consideram a inexistência de um gene principal atuando na distribuição do número de episódios relatados de malária também são rejeitados quando comparados ao modelo misto -1- ( 2 vs. $1, \chi^{2}=31,36, p<0,001 ; 3$ vs. $\left.1, \chi^{2}=16,53, p<0,001\right)$. O melhor modelo obtido, 
baseado no AIC, pode ser considerado o modelo 6, onde o gene principal estimado teria efeito aditivo. Os valores estimados de transmissão $(\tau s)$ encontrados estão próximos aos valores pela segregação mendeliana $\left(\tau_{\mathrm{AA}}=1,0, \tau_{\mathrm{Aa}}=0,5\right.$ e $\left.\tau_{\mathrm{aa}}=0,0\right)$. Assim como na população de Monte Negro, a análise de segregação apóia a presença de um gene principal atuando na distribuição do fenótipo na população de Portuchuelo.

A Tabela 7 traz o resultado da análise de associação entre marcadores clássicos e o número de episódios de malária corrigido por sexo e idade nas populações de Portuchuelo e Monte Negro e em ambas agrupadas. No ANEXO "The association of genetic markers and malaria infection in the Brazilian Western Amazonian region." dados similares são apresentados apenas para a população de Portuchuelo, com a diferença que no trabalho em ANEXO, o fenótipo estudado não foi corrigido para sexo e idade.

Nas tabelas 8 e 9 foi dado destaque ao antígeno Duffy, onde foi detectada uma associação esperada entre a ausência do antígeno Duffy (indivíduos Fy-Fy-) e um menor número de episódio de malária relatados pelos indivíduos altamente significante nas duas populações $\left(\chi_{1}^{2}=10,954 ; P<0,001\right.$ para as populações agrupadas.) e sem heterogeneidade entre elas $\left(\chi_{1}^{2}=1,974 ; P>0,05\right)$.

As freqüências gênicas observadas dos marcadores de microssatélites estudados em Portuchuelo, bem como o número de indivíduos utilizado para realização da análise de ligação são apresentados na Tabela 10. Duas linhas são utilizadas para cada marcador, a superior com o número do alelo e a inferior com a freqüência observada.

Na Tabela 11 são mostrados os resultados da análise de ligação de dois pontos em Portuchuelo. Duas variáveis foram usadas nas análises. O número de episódios de malária relatado pelos indivíduos sem qualquer tratamento estatístico foi chamado de MAL. O logaritmo desse número, corrigido para idade e sexo dos indivíduos e ajustado à distribuição normal foi chamado de MAL_LCA. Na análise utilizando-se a variável MAL foram observados 8 lod scores maiores que $3(p<0,01)$, que indicam ligação. $\mathrm{O}$ número de resultados significantes observado foi maior do que o esperado por acaso em 108 testes utilizando-se 0,01 como nível de significância é de cerca de 3. Não foram observados lod scores maiores que 3 nas análises utilizando a variável MAL_LCA.

Os resultados obtidos nas análises de ligação multiponto são representados nas figuras 4 e 5 . Na figura 5 são mostrados os resultados das análises multiponto e de dois 
pontos obtidos ao longo de todo o genoma, posicionados de acordo com o a distância entre eles, obtida no mapa genético do Instituto Marshfield. As variáveis MAL e MAL_LCA foram testadas. Diversos lod scores maiores que 3 foram encontrados e as implicações desses resultados serão discutidas posteriormente.

$\mathrm{Na}$ figura 6 é mostrado apenas os resultados obtidos no braço curto do cromossomo 4, onde foi encontrado um pico de lod score de 2,8, sugestivo de ligação, na variável MAL_LCA. Esses resultados levaram à seleção dos marcadores utilizados na análise em Monte Negro, mostrados na parte inferior da figura.

Na população de Monte Negro não foram observados lod scores sugestivos de ligação para as duas variáveis utilizadas (MAL e MAL_LCA) em nenhuma das análises realizadas. 

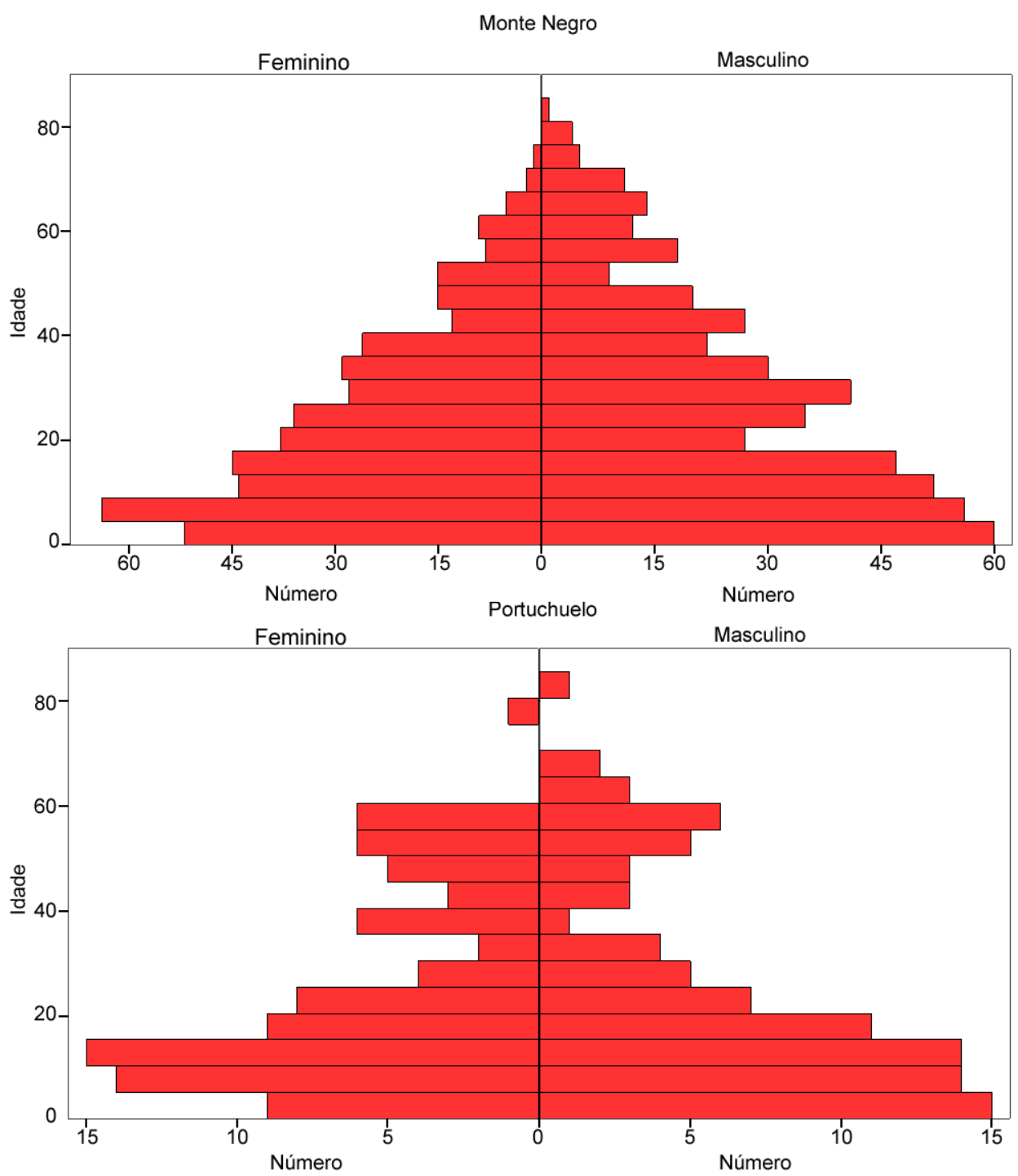

Figura 2. Distribuição dos indivíduos das populações, por sexo e idade. 

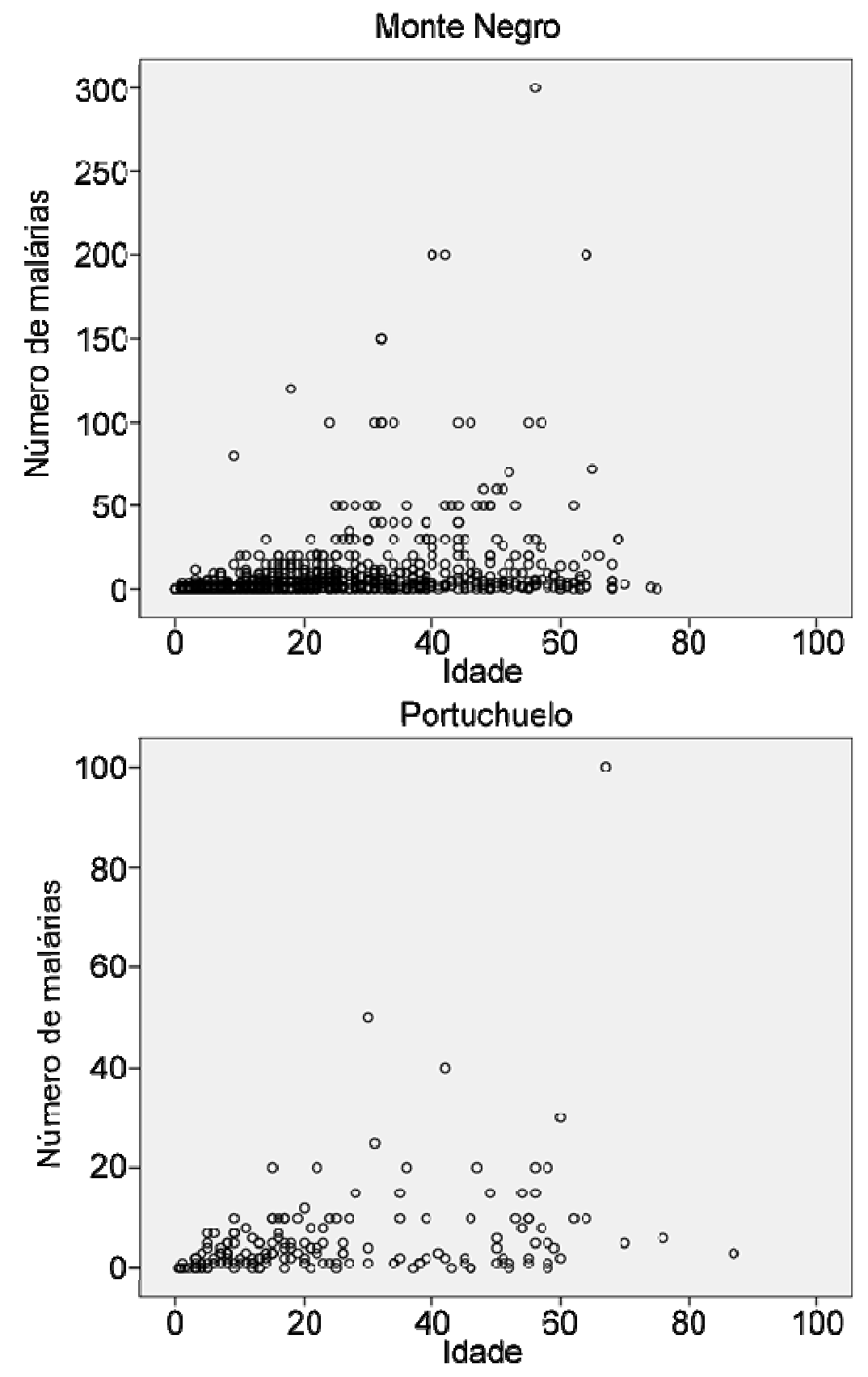

Figura 3. Distribuição do número de episódios de malária, em cada população, em função da idade. 

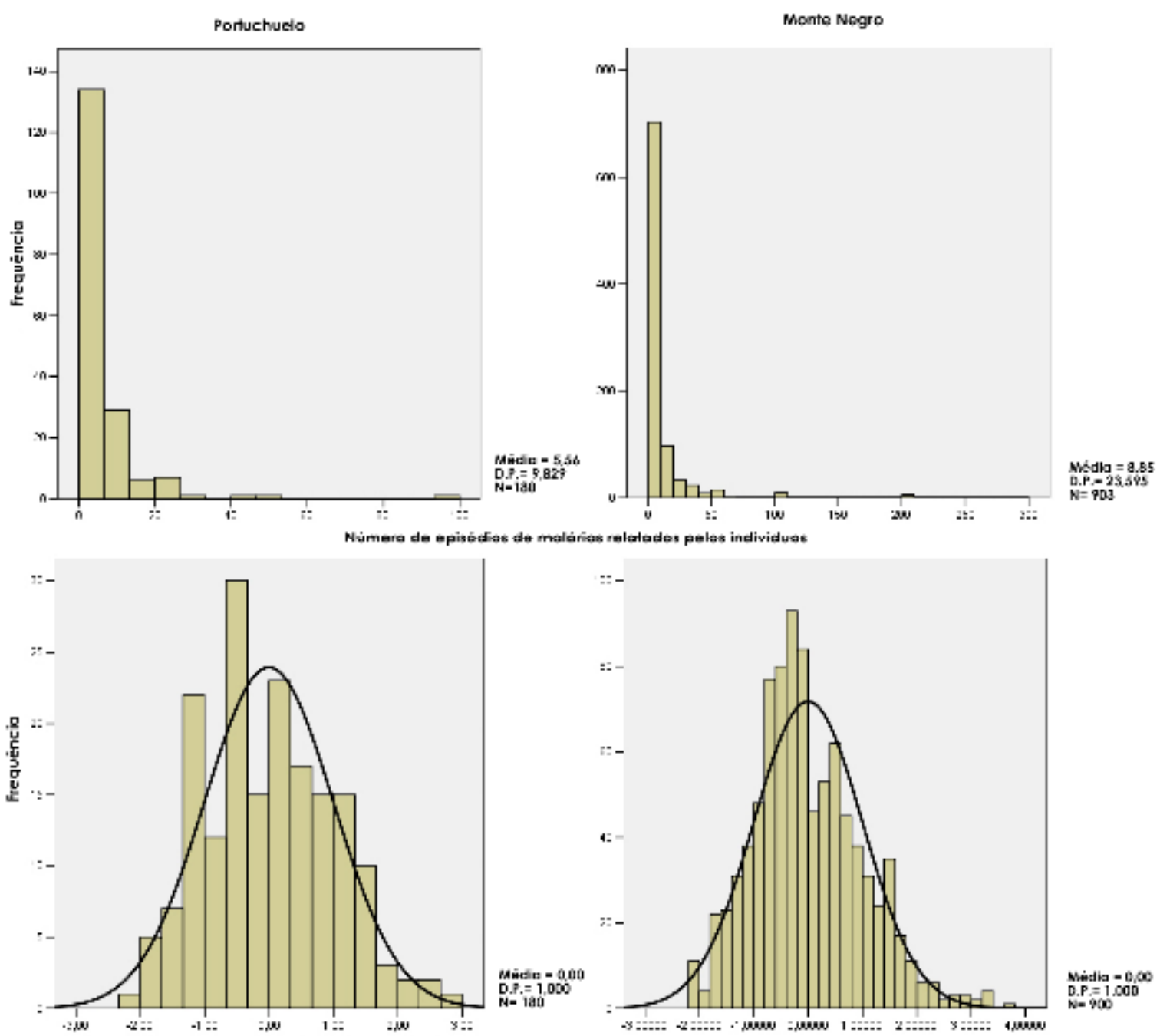

logarítmo do número de eplsbdlos de malánas relotados pelos Indlviduos ajustado para Idade e sexo

Figura 4. Distribuição do número de episódios de malária relatado pelos pacientes sem tratamento estatístico e após transformação logarítmica e correção para idade e sexo nas populações de Monte Negro e Portuchuelo. 
Tabela 1. Freqüências gênicas ancestrais e estimadas usadas para calcular a mistura étnica das populações de Monte Negro e Portuchuelo. $(\mathrm{AF}=$ Africanos, $\mathrm{AM}=$ Ameríndios, $\mathrm{E}=$ Europeus $)$

\begin{tabular}{|c|c|c|c|c|c|c|c|c|c|c|}
\hline Sistema & Grupo étnico & \multicolumn{8}{|c|}{ Frequencias gênicas } & \multirow[t]{2}{*}{ Referências } \\
\hline \multirow{6}{*}{$\mathrm{ABO}$} & & \multicolumn{2}{|c|}{$\mathbf{A}$} & \multicolumn{2}{|c|}{$\mathbf{B}$} & \multicolumn{2}{|c|}{$\mathbf{O}$} & & & \\
\hline & $\mathrm{AF}$ & \multicolumn{2}{|c|}{0,151} & \multicolumn{2}{|c|}{0,128} & \multicolumn{2}{|c|}{0,721} & & & Franco; Weimer; Salzano, (1982) \\
\hline & AM & \multicolumn{2}{|c|}{-} & \multicolumn{2}{|c|}{-} & \multicolumn{2}{|c|}{1} & & & Franco; Weimer; Salzano, (1982) \\
\hline & $\mathrm{E}$ & \multicolumn{2}{|c|}{0,298} & \multicolumn{2}{|c|}{0,057} & \multicolumn{2}{|c|}{0,645} & & & Lessa $(1970)$ \\
\hline & Portuchuelo & \multicolumn{2}{|c|}{0,135} & \multicolumn{2}{|c|}{0,047} & \multicolumn{2}{|c|}{0,819} & & & \multirow{2}{*}{ Estudo atual } \\
\hline & Monte Negro & \multicolumn{2}{|c|}{0,226} & \multicolumn{2}{|c|}{0,068} & \multicolumn{2}{|c|}{0,706} & & & \\
\hline \multirow{6}{*}{$\mathrm{Rh}$} & & $\overline{R^{0}}$ & $\mathbf{R}^{1}$ & $\mathbf{R}^{2}$ & $\overline{\mathbf{R}}$ & $\mathbf{r}$ & $\mathbf{R}^{\mathbf{Z}}$ & r" & $\mathrm{r}^{\mathrm{y}}$ & \\
\hline & $\mathrm{AF}$ & 0,555 & 0,096 & 0,070 & 0,270 & 0,005 & 0,001 & 0,003 & - & Franco; Weimer; Salzano, (1982) \\
\hline & AM & 0,052 & 0,542 & 0,341 & 0,006 & - & 0,056 & 0,001 & 0,002 & Salzano; Weimer; Franco, (1998) \\
\hline & $\mathrm{E}$ & 0,030 & 0,428 & 0,139 & 0,384 & 0,010 & 0,005 & 0,004 & - & Franco; Weimer; Salzano, (1982) \\
\hline & Portuchuelo & 0,150 & 0,409 & 0,214 & 0,192 & 0,005 & 0,027 & 0,002 & 0,001 & Estudo atual \\
\hline & Monte Negro & 0,178 & 0,357 & 0,156 & 0,285 & 0,007 & 0,013 & 0,003 & 0,001 & Estudo atual \\
\hline \multirow{6}{*}{ MNSs } & & MS & Ms & $\mathrm{MS}^{\mathrm{u}}$ & NS & Ns & $\mathrm{NS}^{\mathrm{u}}$ & & & \\
\hline & $\mathrm{AF}$ & 0,159 & 0,328 & 0,066 & 0,088 & 0,265 & 0,093 & & & Mourant; Kopec; Domaniewska-Sobczak, (1976) \\
\hline & AM & 0,244 & 0,510 & - & 0,073 & 0,173 & - & & & Salzano; Weimer; Franco, (1998) \\
\hline & $\mathrm{E}$ & 0,214 & 0,300 & - & 0,071 & 0,374 & - & & & Cunha; Morais, (1966) \\
\hline & Portuchuelo & 0,219 & 0,405 & 0,014 & 0,077 & 0,266 & 0,020 & & & Estudo atual \\
\hline & Monte Negro & 0,209 & 0,341 & 0,017 & 0,078 & 0,331 & 0,024 & & & Estudo atual \\
\hline \multirow{6}{*}{ Kell } & & & $\mathbf{K}$ & & & $\bar{K}$ & & & & \\
\hline & $\mathrm{AF}$ & & 0,013 & & & 0,987 & & & & \\
\hline & AM & & 0,001 & & & 0,999 & & & & Salzano; Weimer; Franco, (1998) \\
\hline & $\mathrm{E}$ & & 0,038 & & & 0,962 & & & & Cunha; Morais, (1966) \\
\hline & Portuchuelo & & 0,016 & & & 0,984 & & & & Estudo atual \\
\hline & Monte Negro & & 0,027 & & & 0,973 & & & & Estudo atual \\
\hline & & & $\mathrm{Fy}^{\mathrm{a}}$ & & & $\mathbf{F y} \mathbf{y}^{\mathbf{b}}$ & & Fy & & \\
\hline & $\mathrm{AF}$ & & 0,020 & & & 0,020 & & 0,960 & & Mourant; Kopec; Domaniewska-Sobczak, (1976) \\
\hline Duffy & AM & & 0,669 & & & 0,331 & & - & & Salzano; Weimer; Franco, (1998) \\
\hline & $\mathrm{E}$ & & 0,369 & & & 0,631 & & - & & Cunha; Morais, (1966) \\
\hline & Portuchuelo & & 0,429 & & & 0,370 & & 0,201 & & Estudo atual \\
\hline & Monte Negro & & 0,315 & & & 0,440 & & 0,245 & & Estudo atual \\
\hline
\end{tabular}


Tabela 1. Continuação.

\begin{tabular}{|c|c|c|c|c|c|}
\hline Sistema & Grupo étnico & & acias g & & Referências \\
\hline \multirow{6}{*}{ Haptoglobina } & & $\mathrm{Hp}^{1}$ & $\mathrm{Hp}^{2}$ & $\mathrm{Hp}^{2 \mathrm{~m}}$ & \\
\hline & $\mathrm{AF}$ & 0,633 & 0,335 & 0,032 & Franco; Weimer; Salzano, (1982) \\
\hline & $\mathrm{AM}$ & 0,660 & 0,340 & - & Franco; Weimer; Salzano, (1982) \\
\hline & $\mathrm{E}$ & 0,403 & 0,597 & - & Franco; Weimer; Salzano, (1982) \\
\hline & Portuchuelo & 0,554 & 0,428 & 0,007 & Estudo atual \\
\hline & Monte Negro & 0,481 & 0,511 & 0,008 & Estudo atual \\
\hline \multirow{6}{*}{ Hemoglobina } & & $\overline{\mathbf{A}}$ & $\mathbf{C}$ & $\overline{\mathbf{S}}$ & \\
\hline & $\mathrm{AF}$ & 0,900 & 0,016 & 0,084 & Franco; Weimer; Salzano, (1982) \\
\hline & $\mathrm{AM}$ & 1 & - & - & Franco; Weimer; Salzano, (1982) \\
\hline & $\mathrm{E}$ & 1 & - & - & Franco; Weimer; Salzano, (1982) \\
\hline & Portuchuelo & 0,979 & 0,003 & 0,018 & Estudo atual \\
\hline & Monte Negro & 0,973 & 0,004 & 0,023 & Estudo atual \\
\hline \multirow{6}{*}{$\mathrm{ACP}$} & & $\mathbf{A}$ & $\mathbf{B}$ & $\mathbf{C}$ & \\
\hline & $\mathrm{AF}$ & 0,171 & 0,829 & - & Arpini-Sampaio et al. (1999) \\
\hline & $\mathrm{AM}$ & 0,152 & 0,848 & - & Arpini-Sampaio et al. (1999) \\
\hline & $\mathrm{E}$ & 0,358 & 0,522 & 0,121 & Arpini-Sampaio et al. (1999) \\
\hline & Portuchuelo & 0,227 & 0,731 & 0,042 & Estudo atual \\
\hline & Monte Negro & - & - & - & Estudo atual \\
\hline \multirow{6}{*}{ PGM1 } & & PGM1*1 & & PGM1*2 & \\
\hline & $\mathrm{AF}$ & 0,837 & & 0,163 & Arpini-Sampaio et al. (1999) \\
\hline & $\mathrm{AM}$ & 0,785 & & 0,215 & Arpini-Sampaio et al. (1999) \\
\hline & $\mathrm{E}$ & 0,735 & & 0,265 & Arpini-Sampaio et al. (1999) \\
\hline & Portuchuelo & 0,779 & & 0,221 & Estudo atual \\
\hline & Monte Negro & 0,767 & & 0,233 & Estudo atual \\
\hline \multirow{6}{*}{ GLO I } & & 1 & & 2 & \\
\hline & $\mathrm{AF}$ & 0,306 & & 0,694 & Arpini-Sampaio et al. (1999) \\
\hline & $\mathrm{AM}$ & 0,273 & & 0,727 & Arpini-Sampaio et al. (1999) \\
\hline & $\mathrm{E}$ & 0,426 & & 0,574 & Arpini-Sampaio et al. (1999) \\
\hline & Portuchuelo & 0,333 & & 0,667 & Estudo atual \\
\hline & Monte Negro & 0,378 & & 0,622 & Estudo atual \\
\hline
\end{tabular}


Tabela 1. Continuação.

\begin{tabular}{clccc}
\hline Sistema & Grupo étnico & Frequencias gênicas & Referências \\
\hline \multirow{6}{*}{ CAII } & $\mathbf{1}$ & $\mathbf{2}$ & Arpini-Sampaio et al. (1999) \\
& AF & 1 & 0,076 & Arpini-Sampaio et al. (1999) \\
& AM & 1 & - & Arpini-Sampaio et al. (1999) \\
& E & 0,984 & - & Estudo atual \\
& Portuchuelo & 0,981 & 0,016 & Estudo atual \\
\hline
\end{tabular}

Conclusão 


\begin{tabular}{|c|c|c|c|c|c|c|c|c|c|c|c|c|}
\hline Microssatélite & População & & & & & Fre & quenci & a gênic & & & & \\
\hline \multirow{5}{*}{$\begin{array}{c}\text { D2S2968 } \\
19943\end{array}$} & & 171 & 175 & 179 & 183 & 187 & 191 & 195 & 199 & 203 & 207 & \\
\hline & Portuchuelo & 0,015 & 0,002 & 0,052 & 0,520 & 0,352 & 0,035 & 0,017 & 0,002 & 0,003 & 0,000 & \\
\hline & Africana & 0,000 & 0,000 & 0,104 & 0,228 & 0,348 & 0,192 & 0,080 & 0,020 & 0,024 & 0,004 & \\
\hline & Ameríndia & 0,000 & 0,000 & 0,014 & 0,760 & 0,226 & 0,000 & 0,000 & 0,000 & 0,000 & 0,000 & \\
\hline & Européia & 0,027 & 0,004 & 0,063 & 0,447 & 0,424 & 0,022 & 0,013 & 0,000 & 0,000 & 0,000 & \\
\hline \multirow{5}{*}{$\begin{array}{c}\text { D3S2460 } \\
21182\end{array}$} & & 143 & 147 & 151 & 155 & 159 & 163 & 167 & 171 & & & \\
\hline & Portuchuelo & 0,008 & 0,017 & 0,018 & 0,239 & 0,232 & 0,401 & 0,062 & 0,023 & & & \\
\hline & Africana & 0,004 & 0,012 & 0,095 & 0,063 & 0,195 & 0,440 & 0,171 & 0,020 & & & \\
\hline & Ameríndia & 0,000 & 0,000 & 0,005 & 0,097 & 0,306 & 0,556 & 0,037 & 0,000 & & & \\
\hline & Européia & 0,014 & 0,027 & 0,009 & 0,356 & 0,198 & 0,306 & 0,054 & 0,036 & & & \\
\hline \multirow{5}{*}{$\begin{array}{c}\text { D4S2366 } \\
67015\end{array}$} & & 120 & 124 & 128 & 132 & 136 & 140 & 144 & & & & \\
\hline & Portuchuelo & 0,225 & 0,125 & 0,123 & 0,267 & 0,127 & 0,127 & 0,006 & & & & \\
\hline & Africana & 0,072 & 0,326 & 0,204 & 0,330 & 0,055 & 0,009 & 0,004 & & & & \\
\hline & Ameríndia & 0,163 & 0,005 & 0,199 & 0,316 & 0,087 & 0,219 & 0,010 & & & & \\
\hline & Européia & 0,291 & 0,150 & 0,064 & 0,227 & 0,164 & 0,100 & 0,004 & & & & \\
\hline \multirow{5}{*}{$\begin{array}{c}\text { D6S474 } \\
74530\end{array}$} & & 147 & 151 & 155 & 159 & 163 & 167 & 171 & & & & \\
\hline & Portuchuelo & 0,014 & 0,311 & 0,193 & 0,139 & 0,225 & 0,105 & 0,013 & & & & \\
\hline & Africana & 0,013 & 0,250 & 0,174 & 0,152 & 0,321 & 0,080 & 0,009 & & & & \\
\hline & Ameríndia & 0,040 & 0,370 & 0,170 & 0,170 & 0,105 & 0,140 & 0,005 & & & & \\
\hline & Européia & 0,000 & 0,291 & 0,209 & 0,118 & 0,273 & 0,091 & 0,018 & & & & \\
\hline \multirow{5}{*}{$\begin{array}{c}\text { D7S2846 } \\
67557\end{array}$} & & 168 & 172 & 176 & 180 & 184 & 188 & 192 & 196 & & & \\
\hline & Portuchuelo & 0,001 & 0,049 & 0,218 & 0,318 & 0,193 & 0,210 & 0,009 & 0,002 & & & \\
\hline & Africana & 0,008 & 0,016 & 0,228 & 0,354 & 0,211 & 0,163 & 0,020 & 0,000 & & & \\
\hline & Ameríndia & 0,000 & 0,094 & 0,227 & 0,227 & 0,189 & 0,259 & 0,005 & 0,000 & & & \\
\hline & Européia & 0,000 & 0,031 & 0,210 & 0,362 & 0,192 & 0,192 & 0,009 & 0,004 & & & \\
\hline \multirow{5}{*}{$\begin{array}{c}\text { D8S1132 } \\
53216\end{array}$} & & 131 & 135 & 139 & 143 & 147 & 151 & 155 & 159 & 163 & 167 & 171 \\
\hline & Portuchuelo & 0,005 & 0,054 & 0,111 & 0,181 & 0,189 & 0,166 & 0,104 & 0,094 & 0,080 & 0,015 & 0,003 \\
\hline & Africana & 0,024 & 0,129 & 0,173 & 0,141 & 0,109 & 0,105 & 0,154 & 0,048 & 0,080 & 0,028 & 0,008 \\
\hline & Ameríndia & 0,000 & 0,065 & 0,084 & 0,117 & 0,220 & 0,234 & 0,094 & 0,140 & 0,037 & 0,005 & 0,005 \\
\hline & Européia & 0,004 & 0,032 & 0,113 & 0,225 & 0,188 & 0,140 & 0,099 & 0,077 & 0,104 & 0,018 & 0,000 \\
\hline
\end{tabular}




\begin{tabular}{|c|c|c|c|c|c|c|c|c|c|c|c|c|c|c|}
\hline $\begin{array}{c}\text { Microssatélite } \\
\text { UNISTS }\end{array}$ & População & & & & & & Frequ & iencia g & jênica & & & & & \\
\hline \multirow{5}{*}{$\begin{array}{c}\text { D9S934 } \\
\mathbf{8 1 8 1 6}\end{array}$} & & 206 & 210 & 214 & 218 & 222 & 226 & 230 & 234 & & & & & \\
\hline & Portuchuelo & 0,006 & 0,146 & 0,293 & 0,267 & 0,201 & 0,079 & 0,006 & 0,003 & & & & & \\
\hline & Africana & 0,008 & 0,138 & 0,319 & 0,362 & 0,157 & 0,012 & 0,004 & 0,000 & & & & & \\
\hline & Ameríndia & 0,000 & 0,146 & 0,335 & 0,170 & 0,272 & 0,078 & 0,000 & 0,000 & & & & & \\
\hline & Européia & 0,009 & 0,148 & 0,264 & 0,301 & 0,171 & 0,093 & 0,009 & 0,005 & & & & & \\
\hline \multirow{5}{*}{$\begin{array}{c}\text { D12S1045 } \\
14863\end{array}$} & & 73 & 76 & 79 & 82 & 85 & 88 & 91 & 94 & 97 & 100 & & & \\
\hline & Portuchuelo & 0,001 & 0,118 & 0,117 & 0,018 & 0,036 & 0,067 & 0,479 & 0,104 & 0,051 & 0,008 & & & \\
\hline & Africana & 0,008 & 0,437 & 0,017 & 0,008 & 0,046 & 0,126 & 0,181 & 0,118 & 0,050 & 0,008 & & & \\
\hline & Ameríndia & 0,000 & 0,010 & 0,053 & 0,000 & 0,000 & 0,053 & 0,808 & 0,077 & 0,000 & 0,000 & & & \\
\hline & Européia & 0,000 & 0,112 & 0,174 & 0,031 & 0,054 & 0,063 & 0,357 & 0,116 & 0,080 & 0,013 & & & \\
\hline \multirow{5}{*}{$\begin{array}{c}\text { D14S617 } \\
82795\end{array}$} & & 137 & 141 & 145 & 149 & 153 & 157 & 161 & 165 & 169 & 173 & 177 & & \\
\hline & Portuchuelo & 0,015 & 0,249 & 0,066 & 0,089 & 0,014 & 0,055 & 0,215 & 0,239 & 0,046 & 0,011 & 0,002 & & \\
\hline & Africana & 0,124 & 0,128 & 0,058 & 0,095 & 0,016 & 0,124 & 0,215 & 0,136 & 0,037 & 0,046 & 0,021 & & \\
\hline & Ameríndia & 0,000 & 0,289 & 0,000 & 0,077 & 0,005 & 0,005 & 0,149 & 0,423 & 0,043 & 0,010 & 0,000 & & \\
\hline & Européia & 0,000 & 0,252 & 0,104 & 0,095 & 0,018 & 0,068 & 0,252 & 0,158 & 0,049 & 0,004 & 0,000 & & \\
\hline \multirow{5}{*}{$\begin{array}{c}\text { D18S877 } \\
\mathbf{4 5 9 4 7}\end{array}$} & & 109 & 113 & 117 & 121 & 125 & 129 & 133 & 137 & 141 & & & & \\
\hline & Portuchuelo & 0,002 & 0,004 & 0,051 & 0,045 & 0,179 & 0,375 & 0,315 & 0,026 & 0,004 & & & & \\
\hline & Africana & 0,000 & 0,008 & 0,069 & 0,134 & 0,284 & 0,333 & 0,150 & 0,020 & 0,000 & & & & \\
\hline & Ameríndia & 0,005 & 0,000 & 0,079 & 0,042 & 0,171 & 0,306 & 0,366 & 0,028 & 0,005 & & & & \\
\hline & Européia & 0,000 & 0,005 & 0,032 & 0,028 & 0,161 & 0,422 & 0,321 & 0,027 & 0,005 & & & & \\
\hline \multirow{5}{*}{$\begin{array}{c}\text { D22S689 } \\
63378\end{array}$} & & 194 & 198 & 202 & 206 & 210 & 214 & 216 & 218 & 220 & 222 & 224 & 226 & 230 \\
\hline & Portuchuelo & 0,005 & 0,002 & 0,025 & 0,045 & 0,081 & 0,300 & 0,002 & 0,346 & 0,003 & 0,154 & 0,000 & 0,033 & 0,004 \\
\hline & Africana & 0,041 & 0,014 & 0,027 & 0,092 & 0,046 & 0,294 & 0,014 & 0,289 & 0,023 & 0,078 & 0,000 & 0,069 & 0,014 \\
\hline & Ameríndia & 0,000 & 0,000 & 0,000 & 0,000 & 0,062 & 0,333 & 0,000 & 0,371 & 0,000 & 0,214 & 0,000 & 0,019 & 0,000 \\
\hline & Européia & 0,000 & 0,000 & 0,038 & 0,061 & 0,099 & 0,283 & 0,000 & 0,344 & 0,000 & 0,137 & 0,000 & 0,033 & 0,005 \\
\hline
\end{tabular}


Tabela 3. Composição étnica de duas populações tri-híbridas da Amazônia ocidental estimadas utilizando-se marcadores clássicos e microssatélites.

\begin{tabular}{llccc}
\hline População & Tipo de marcador & Africana & Ancestralidade & Ameríndia \\
\hline Monte Negro & Marcadores clássicos & $0,25 \pm 0,032$ & $0,12 \pm 0,046$ & $0,63 \pm 0,054$ \\
Portuchuelo & Marcadores clássicos & $0,21 \pm 0,046$ & $0,44 \pm 0,064$ & $0,35 \pm 0,069$ \\
Portuchuelo & Microssatélites & $0,12 \pm 0,059$ & $0,32 \pm 0,087$ & $0,56 \pm 0,106$ \\
\hline
\end{tabular}

Tabela 4. Teste $t$ comparando as estimativas de composição étnica obtidas na população de Portuchuelo, entre marcadores clássicos e microssatélites.

\begin{tabular}{lcc}
\hline \multirow{2}{*}{ Ancestralidade } & \multicolumn{2}{c}{ Estatística } \\
& $\boldsymbol{t}$ & $\boldsymbol{P}$ \\
\hline Africana & 1,182 & 0,24 \\
Ameríndia & 1,224 & 0,224 \\
Européia & 1,732 & 0,086 \\
\hline
\end{tabular}


Tabela 5. Análise de segregação do número de episódios relatados de malária em Monte Negro, no estado de Rondônia.

\begin{tabular}{|c|c|c|c|c|c|c|c|c|c|c|c|c|}
\hline Modelo & $d$ & $t$ & $q$ & $\bar{H}$ & $\tau 1$ & $\tau 2$ & $\tau 3$ & $-2 \ln L$ & $\chi^{2}$ & $P$ & teste & AIC \\
\hline 1.Misto & 1,000 & 1,099 & 0,175 & 0,141 & [1] & {$[0,5]$} & [0] & 978,653 & & & & 990,653 \\
\hline 2.Aleatório & {$[0]$} & {$[0]$} & [0] & [0] & - & - & - & 1189,332 & 210,679 & 0,000 & 2 vs. 1 & 1193,332 \\
\hline $\begin{array}{l}\text { 3.Sem gene } \\
\text { principal }\end{array}$ & {$[0]$} & {$[0]$} & [0] & 0,438 & [1] & {$[0,5]$} & [0] & 1005,458 & 26,806 & 0,000 & 3 vs. 1 & 1011,458 \\
\hline $\begin{array}{l}\text { 4.Sem componente } \\
\text { multifatorial }\end{array}$ & 0,383 & 1,557 & 0,355 & [0] & [1] & {$[0,5]$} & [0] & 995,103 & 16,450 & 0,000 & 4 vs. 1 & 1005,103 \\
\hline 5.Recessivo $(\mathrm{d}=0)$ & {$[0]$} & 1,870 & 0,119 & 0,454 & [1] & {$[0,5]$} & [0] & 978,262 & 0,390 & 0,532 & 5 vs. 1 & 988,262 \\
\hline 6.Aditivo $(\mathrm{d}=0.5)$ & {$[0,5]$} & 1,378 & 0,240 & 0,111 & [1] & {$[0,5]$} & [0] & 991,420 & 12,767 & 0,000 & 6 vs. 1 & 1001,420 \\
\hline 7. Dominante $(\mathrm{d}=1)$ & [1] & 1,096 & 0,174 & 0,141 & [1] & {$[0,5]$} & [0] & 978,646 & 0,007 & 0,933 & 7 vs. 1 & 988,646 \\
\hline 8. $\tau$ s livre $(d=0)$ & [0] & 1,098 & 0,193 & 0,317 & 1,000 & 0,056 & 0,000 & $\mathbf{9 5 5 , 8 2 5}$ & 22,438 & $\mathbf{0 , 0 0 0}$ & 8 vs. 5 & 971,825 \\
\hline 9. $\tau$ s iguais $(\mathrm{d}=0)$ & {$[0]$} & - & - & [0] & - & - & - & N.C & - & - & 9 vs. 8 & - \\
\hline 10. $\tau$ s livre $(d=1)$ & [1] & 1,077 & 0,449 & 0,190 & $1 *$ & $1 *$ & $\mathbf{0 , 0 0 0}$ & 940,192 & & & 10 vs. 7 & 956,192 \\
\hline 11. $\tau \mathrm{s}$ iguais $(\mathrm{d}=1)$ & [1] & - & - & [0] & - & - & - & N.C & - & - & 11 vs. 10 & - \\
\hline
\end{tabular}

$\mathrm{V}=$ variância; $\mu$ = média: $d=$ grau de dominância; $t=$ deslocamento; $q=$ freqüência alélica; $H=$ herdabilidade multifatorial;

$\tau \mathrm{s}=$ parâmetros de probabilidades de transmissão (\#8 e \#10 são os modelos com $\tau$ s livres, enquanto nos modelos \#9 e \#11 os $\tau \mathrm{s}$ são iguais);

$-2 \ln \mathrm{L}=$ menos duas vezes o logarítimo neperiano do likelihood. N.C. - modelo não convergiu. 
Tabela 6. Análise de segregação do número de episódios relatados de malária em Portuchuelo, no estado de Rondônia.

\begin{tabular}{|c|c|c|c|c|c|c|c|c|c|c|c|c|c|c|}
\hline Modelo & $\mathrm{V}$ & $\mu$ & $d$ & $t$ & $q$ & $H$ & $\tau 1$ & $\overline{\tau 2}$ & $\tau 3$ & $-2 \ln L$ & $\chi^{2}$ & $\bar{P}$ & Teste & $\mathrm{AIC}$ \\
\hline 1.Misto & 0,93 & 0,02 & 0,44 & 3,27 & 0,15 & 0,08 & [1] & {$[0,5]$} & {$[0]$} & 297,77 & & & & 309,8 \\
\hline 2.Aleatório & 0,87 & 0,05 & {$[0]$} & {$[0]$} & {$[0]$} & {$[0]$} & - & - & - & 329,13 & 31,36 & $<, 001$ & $\begin{array}{c}2 \text { vs. } \\
1\end{array}$ & 333,1 \\
\hline $\begin{array}{l}\text { 3.Sem gene } \\
\text { principal }\end{array}$ & 0,97 & 0,07 & {$[0]$} & {$[0]$} & {$[0]$} & 0,71 & {$[1]$} & {$[0,5]$} & {$[0]$} & 314,3 & 16,53 & $<, 001$ & $\begin{array}{c}3 \mathrm{vs} . \\
1\end{array}$ & 318,3 \\
\hline $\begin{array}{l}\text { 4.Sem } \\
\text { componente } \\
\text { multifatorial }\end{array}$ & 0,88 & 0 & 0,44 & 3,13 & 0,15 & {$[0]$} & [1] & {$[0,5]$} & {$[0]$} & 298,74 & 0,97 & 0,325 & $\begin{array}{c}4 \mathrm{vs} . \\
1\end{array}$ & 308,7 \\
\hline 5.Recessivo $(\mathrm{d}=0)$ & 0,83 & $-0,01$ & {$[0]$} & 1,41 & 0,51 & {$[0]$} & {$[1]$} & {$[0,5]$} & {$[0]$} & 314,08 & 15,34 & $<, 001$ & $\begin{array}{c}5 \text { vs. } \\
4\end{array}$ & 322,1 \\
\hline 6.Aditivo $(d=0.5)$ & 0,86 & 0 & {$[0,5]$} & 2,82 & 0,15 & {$[0]$} & {$[1]$} & {$[0,5]$} & {$[0]$} & 299,22 & 0,48 & 0,488 & $\begin{array}{c}6 \mathrm{vs} . \\
4\end{array}$ & 307,2 \\
\hline $\begin{array}{l}\text { 7. Dominante } \\
\qquad(d=1)\end{array}$ & 0,81 & $-0,05$ & {$[1]$} & 1,49 & 0,13 & {$[0]$} & {$[1]$} & {$[0,5]$} & {$[0]$} & 304,59 & 5,85 & 0,016 & $\begin{array}{c}7 \text { vs. } \\
4\end{array}$ & 312,6 \\
\hline 8. $\tau \mathrm{s}$ livre $(\mathrm{d}=0.5)$ & 0,7 & $-0,17$ & {$[0,5]$} & 2,72 & 0,1 & {$[0]$} & $1,0^{*}$ & 0,28 & $0,0 *$ & 296,76 & 2,46 & 0,483 & $\begin{array}{c}6 \mathrm{vs} . \\
8\end{array}$ & 310,8 \\
\hline 9. $\tau \mathrm{s}$ iguais $(\mathrm{d}=0.5)$ & 0,89 & $-0,05$ & {$[0,5]$} & 2,47 & 0,23 & {$[0]$} & 0,77 & 0,77 & 0,77 & 324,53 & 27,77 & $<, 001$ & $\begin{array}{c}9 \text { vs. } \\
8\end{array}$ & 338,5 \\
\hline
\end{tabular}

* Parâmetro estimado atingiu o limite. $\quad$ Parâmetros entre conchetes foram fixados no valor indicado.

$\mathrm{V}=$ variância; $\mu$ = média: $d=$ grau de dominância; $t=$ deslocamento; $q=$ freqüência alélica; $H=$ herdabilidade multifatorial;

$\tau \mathrm{s}=$ parâmetros de probabilidades de transmissão (\#8 é o modelo com $\tau$ s livres, enquanto no modelo \#9 os $\tau$ s são iguais);

$-2 \ln \mathrm{L}=$ menos duas vezes o logarítimo neperiano do likelihood. 
Tabela 7. Associação de marcadores clássicos com o número de episódios de malária corrigido nas populações de Monte Negro e Portuchuelo e nas duas populações agrupadas.

\begin{tabular}{|c|c|c|c|c|c|c|c|c|c|c|c|c|}
\hline & \multicolumn{4}{|c|}{ Portuchuelo } & \multicolumn{4}{|c|}{ Monte Negro } & \multicolumn{4}{|c|}{ Populações agrupadas } \\
\hline & $\mathrm{N}$ & $\chi^{2}$ & G.L. & sig & $\mathrm{N}$ & $\chi^{2}$ & G.L. & $\operatorname{sig}$ & $\mathrm{N}$ & $\chi^{2}$ & G.L. & sig \\
\hline ABO & 178 & 1,387 & 3 & 0,709 & 851 & 19,727 & 3 & 0,000 & 1029 & 17,651 & 3 & 0,001 \\
\hline Duffy & 178 & 6,719 & 3 & 0,081 & 850 & 7,244 & 3 & 0,065 & 1028 & 11,335 & 3 & 0,010 \\
\hline Duffy - negativos & 178 & 6,155 & 1 & 0,013 & 850 & 6,773 & 1 & 0,009 & 1028 & 10,954 & 1 & 0,001 \\
\hline Haptoglobina & 173 & 1,186 & 3 & 0,756 & 614 & 0,043 & 3 & 0,998 & 787 & 0,408 & 3 & 0,939 \\
\hline Hemoglobina & 176 & 0,000 & 1 & 0,990 & 900 & 2,893 & 3 & 0,408 & 1076 & 2,646 & 3 & 0,449 \\
\hline MN & 178 & 0,784 & 2 & 0,676 & 850 & 5,376 & 3 & 0,146 & 1028 & 4,065 & 3 & 0,255 \\
\hline Ssp & 178 & 1,988 & 2 & 0,370 & 850 & 6,563 & 3 & 0,087 & 1028 & 6,151 & 3 & 0,104 \\
\hline MNSs & 178 & 4,162 & 8 & 0,842 & 850 & 26,330 & 15 & 0,035 & 1028 & 25,330 & 15 & 0,046 \\
\hline $\mathrm{Rh}$ & 178 & 7,444 & 7 & 0,384 & 848 & 22,169 & 11 & 0,023 & 1026 & 12,652 & 11 & 0,317 \\
\hline $\mathrm{Rh} \mathrm{C} / \mathrm{c}$ & 178 & 2,372 & 2 & 0,305 & 854 & 2,759 & 2 & 0,252 & 1032 & 1,952 & 2 & 0,377 \\
\hline $\mathrm{Rh} E / \mathrm{e}$ & 178 & 5,121 & 2 & 0,077 & 852 & 12,020 & 2 & 0,002 & 1030 & 4,163 & 2 & 0,125 \\
\hline Kell & 178 & 1,304 & 1 & 0,253 & 854 & 4,288 & 1 & 0,038 & 1032 & 1,137 & 1 & 0,286 \\
\hline G6PD $(m$ & 88 & 1,178 & 2 & 0,555 & & & & & & & & \\
\hline G6PD (feminino) & 87 & 2,146 & 3 & 0,543 & & & & & & & & \\
\hline Esterase D & 176 & 7,600 & 2 & 0,022 & & & & & & & & \\
\hline CAll & 176 & 0,802 & 1 & 0,370 & & & & & & & & \\
\hline GLO & 176 & 1,211 & 2 & 0,546 & & & & & & & & \\
\hline PGM & 176 & 0,990 & 2 & 0,610 & & & & & & & & \\
\hline
\end{tabular}


Tabela 8. Posto médio do logaritmo do número de episódios de malária relatado pelos indivíduos, corrigido para sexo e idade.

\begin{tabular}{lcccccc}
\hline & \multicolumn{2}{c}{$\begin{array}{c}\text { Populações } \\
\text { agrupadas }\end{array}$} & \multicolumn{2}{c}{ Portuchuelo } & \multicolumn{2}{c}{ Monte Negro } \\
\hline Duffy A e/ou B & N & Posto Médio & N & Posto Médio & N & Posto Médio \\
\hline Fy-Fy- & 59 & 390,30 & 7 & 42,14 & 52 & 339,64 \\
Não Fy-Fy- & 969 & 522,06 & 171 & 91,44 & 798 & 431,09 \\
Total & 1.028 & & 178 & & 850 & \\
\hline
\end{tabular}

Tabela 9. Meta-análise de associação do antígeno Duffy (Fy-Fy- vs. outros genótipos) com o logaritmo do número de episódios de malária na população de Portuchuelo e Monte Negro, RO.

\begin{tabular}{lccc}
\hline & $\chi^{\mathbf{2}}$ & Graus de liberdade & Significância \\
\hline Populações agrupadas & 10,954 & 1 & 0,001 \\
Portuchuelo & 6,155 & 1 & 0,013 \\
Monte Negro & 6,773 & 1 & 0,009 \\
Heterogeneidade & 1,974 & 1 & 0,160 \\
\hline
\end{tabular}

n.s.= não significante; ${ }^{*}, * * * * *$, significantes aos níveis de $0,05,0,01$ e 0,001 respectivamente. 
Tabela 10. Análise de segregação do número de episódios relatados de malária (sem indivíduos Duffy negativo) em Portuchuelo, no estado de Rondônia.

\begin{tabular}{|c|c|c|c|c|c|c|c|c|c|c|c|c|}
\hline Modelo & $\bar{d}$ & $t$ & $q$ & $\bar{H}$ & $\tau 1$ & $\tau 2$ & $\tau 3$ & $-2 \ln L$ & $\chi^{2}$ & $\bar{P}$ & teste & $\overline{\mathrm{AIC}}$ \\
\hline 1.Misto & 0,24 & 6,19 & 0,09 & 0,17 & {$[1]$} & $\overline{[0,5]}$ & [0] & 243,56 & & & & 251,56 \\
\hline 2.Aleatório & {$[0]$} & {$[0]$} & {$[0]$} & {$[0]$} & - & - & - & 270,67 & 27,11 & 0,0000 & 2 vs. 1 & 270,67 \\
\hline $\begin{array}{c}\text { 3.Sem gene } \\
\text { principal } \\
\text { 4.Sem }\end{array}$ & {$[0]$} & [0] & {$[0]$} & 0,72 & [1] & {$[0,5]$} & [0] & 253,52 & 9,96 & 0,0189 & 3 vs. 1 & 255,52 \\
\hline $\begin{array}{l}\text { componente } \\
\text { multifatorial }\end{array}$ & 0,43 & 3,12 & 0,18 & {$[0]$} & [1] & {$[0,5]$} & {$[0]$} & 246,83 & 3,28 & 0,0703 & 4 vs. 1 & 254,83 \\
\hline 5.Recessivo $(\mathrm{d}=0)$ & {$[0]$} & 1,53 & 0,55 & {$[0]$} & [1] & {$[0,5]$} & [0] & 258,71 & 11,88 & 0,0006 & 5 vs. 4 & 262,71 \\
\hline 6.Aditivo $(d=0,5)$ & {$[0,5]$} & 2,83 & 0,18 & [0] & [1] & {$[0,5]$} & [0] & 247,41 & $\mathbf{0 , 5 8}$ & 0,4473 & 6 vs. 4 & 251,41 \\
\hline $\begin{array}{l}\text { 7.Dominante } \\
(\mathrm{d}=1)\end{array}$ & {$[1]$} & 1,58 & 0,15 & {$[0]$} & [1] & {$[0,5]$} & [0] & 253,55 & 6,72 & 0,0095 & 7 vs. 4 & 257,55 \\
\hline
\end{tabular}

$\mathrm{V}=$ variância; $\mathrm{m}=$ média: $d=$ grau de dominância; $t=$ deslocamento; $q=$ freqüência alélica; $H=$ herdabilidade multifatorial; $\tau \mathrm{s}=$ parâmetros de probabilidades de transmissão; $-2 \ln \mathrm{L}=$ menos duas vezes o logarítimo neperiano do likelihood. 
Tabela 11. Freqüência observada dos marcadores de microssatélites estudados em Portuchuelo

\begin{tabular}{|c|c|c|c|c|c|c|c|c|c|c|c|c|c|c|}
\hline \multirow[t]{21}{*}{ Cromossomo } & \multirow{3}{*}{$\begin{array}{c}\text { Posição } \\
16\end{array}$} & \multirow{3}{*}{$\frac{N}{57}$} & \multirow{3}{*}{$\begin{array}{l}\text { STR } \\
\text { D1S1612 }\end{array}$} & \multicolumn{2}{|c|}{ Alelos/Freqüências } & \multirow[b]{2}{*}{98} & \multirow[b]{2}{*}{102} & \multirow[b]{2}{*}{106} & \multirow[b]{2}{*}{110} & \multirow[b]{2}{*}{114} & & & & \\
\hline & & & & 90 & 94 & & & & & & & & & \\
\hline & & & & 0,018 & 0,395 & 0,246 & 0,175 & 0,018 & 0,123 & 0,026 & & & & \\
\hline & 30 & 57 & D1S1597 & 155 & 159 & 163 & 167 & 171 & 175 & & & & & \\
\hline & 30 & 51 & יו & 0,070 & 0,096 & 0,132 & 0,430 & 0,254 & 0,018 & & & & & \\
\hline & 76 & 30 & D1S2134 & 253 & 265 & 281 & 285 & 289 & 293 & & & & & \\
\hline & 10 & 30 & 5102104 & 0,050 & 0,167 & 0,100 & 0,467 & 0,200 & 0,017 & & & & & \\
\hline & & & & 219 & 223 & 227 & 231 & 235 & 239 & & & & & \\
\hline & 102 & 109 & U1S1665 & 0,046 & 0,358 & 0,399 & 0,110 & 0,069 & 0,018 & & & & & \\
\hline & 126 & 73 & D1S1588 & 118 & 127 & 130 & 133 & 139 & & & & & & \\
\hline & $1<0$ & 10 & 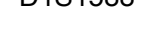 & 0,089 & 0,082 & 0,527 & 0,260 & 0,041 & & & & & & \\
\hline & 152 & 64 & D1S534 & 192 & 196 & 200 & 204 & 208 & 212 & 216 & & & & \\
\hline & 102 & 04 & S10004 & 0,016 & 0,125 & 0,273 & 0,367 & 0,156 & 0,047 & 0,016 & & & & \\
\hline & & & & 144 & 148 & 152 & 156 & 160 & 164 & 168 & 172 & & & \\
\hline & 171 & 100 & DTSTo/y & 0,009 & 0,231 & 0,099 & 0,085 & 0,340 & 0,094 & 0,085 & 0,057 & & & \\
\hline & 202 & 92 & D1S518 & 187 & 191 & 195 & 199 & 203 & 207 & 211 & 215 & 219 & 223 & \\
\hline & 202 & 92 & ע15010 & 0,016 & 0,076 & 0,185 & 0,207 & 0,163 & 0,136 & 0,130 & 0,043 & 0,022 & 0,022 & \\
\hline & & & & 226 & 230 & 234 & 238 & 242 & 246 & & & & & \\
\hline & 212 & 94 & D1S1660 & 0,027 & 0,186 & 0,213 & 0,106 & 0,314 & 0,154 & & & & & \\
\hline & 275 & 86 & D1S1609 & 176 & 180 & 184 & 188 & 192 & 196 & 200 & 208 & & & \\
\hline & 215 & 00 & Disious & 0,209 & 0,285 & 0,244 & 0,116 & 0,017 & 0,047 & 0,041 & 0,041 & & & \\
\hline & 28 & 32 & D2S1400 & 111 & 115 & 119 & 127 & 131 & 135 & 139 & 147 & & & \\
\hline & $\angle 0$ & 32 & $5 \angle S 1400$ & 0,428 & 0,227 & 0,174 & 0,049 & 0,024 & 0,049 & 0,025 & 0,024 & & & \\
\hline & 64 & 22 & 2S1356 & 227 & 230 & 233 & 239 & 242 & 245 & 254 & 257 & & & \\
\hline & 04 & 24 & DLU & 0,033 & 0,066 & 0,165 & 0,099 & 0,190 & 0,283 & 0,132 & 0,033 & & & \\
\hline & 91 & 63 & 251394 & 154 & 158 & 162 & 166 & 170 & 174 & & & & & \\
\hline & (9) & 03 & 5231094 & 0,171 & 0,266 & 0,300 & 0,220 & 0,028 & 0,014 & & & & & \\
\hline 2 & 114 & 69 & D2S2972 & 216 & 220 & 224 & 228 & 232 & 236 & 240 & 244 & 248 & & \\
\hline 2 & 174 & 69 & $\mathrm{U} \angle \mathrm{S} \angle \mathrm{Y} / \angle$ & 0,027 & 0,014 & 0,014 & 0,271 & 0,290 & 0,217 & 0,111 & 0,044 & 0,014 & & \\
\hline & & & & 127 & 135 & 139 & 143 & 147 & 151 & 155 & 159 & 163 & 171 & 175 \\
\hline & 152 & 22 & D2S1399 & 0,032 & 0,096 & 0,183 & 0,096 & 0,064 & 0,160 & 0,104 & 0,128 & 0,073 & 0,032 & 0,032 \\
\hline & 186 & 24 & & 109 & 113 & 117 & 121 & 125 & 129 & & & & & \\
\hline & 180 & $\angle 4$ & ULST391 & 0,063 & 0,063 & 0,080 & 0,475 & 0,288 & 0,032 & & & & & \\
\hline & 200 & 19 & D2S1384 & 137 & 141 & 145 & 149 & 153 & 157 & 161 & & & & \\
\hline & 200 & 19 & 0201004 & 0,070 & 0,157 & 0,305 & 0,152 & 0,210 & 0,035 & 0,070 & & & & \\
\hline
\end{tabular}


Tabela 11. Continuação.

\begin{tabular}{|c|c|c|c|c|c|c|c|c|c|c|c|c|c|c|}
\hline Cromossomo & Posição & $\mathrm{N}$ & STR & Alelos/Fr & ências & & & & & & & & & \\
\hline \multirow{4}{*}{2} & \multirow{2}{*}{227} & \multirow{2}{*}{38} & \multirow{2}{*}{ D2S1363 } & 168 & 169 & 172 & 176 & 180 & 184 & 188 & 192 & 196 & 204 & \\
\hline & & & & 0,020 & 0,041 & 0,040 & 0,139 & 0,312 & 0,246 & 0,100 & 0,063 & 0,020 & 0,020 & \\
\hline & \multirow{2}{*}{252} & \multirow{2}{*}{88} & \multirow{2}{*}{ D2S2968 } & 171 & 175 & 179 & 183 & 187 & 191 & 195 & & & & \\
\hline & & & & 0,058 & 0,012 & 0,097 & 0,379 & 0,397 & 0,023 & 0,035 & & & & \\
\hline \multirow{14}{*}{3} & \multirow{2}{*}{6} & \multirow{2}{*}{42} & \multirow{2}{*}{ D3S2387 } & 177 & 181 & 185 & 189 & 191 & 193 & 195 & 197 & 199 & 201 & 205 \\
\hline & & & & 0,212 & 0,218 & 0,039 & 0,039 & 0,019 & 0,281 & 0,039 & 0,039 & 0,039 & 0,039 & 0,039 \\
\hline & \multirow{2}{*}{26} & \multirow{2}{*}{19} & \multirow{2}{*}{ D3S4545 } & 200 & 204 & 220 & 224 & 228 & & & & & & \\
\hline & & & & 0,036 & 0,312 & 0,293 & 0,288 & 0,072 & & & & & & \\
\hline & \multirow{2}{*}{58} & \multirow{2}{*}{64} & \multirow{2}{*}{ D3S2432 } & 120 & 124 & 134 & 138 & 142 & 146 & 150 & 154 & & & \\
\hline & & & & 0,031 & 0,032 & 0,031 & 0,046 & 0,127 & 0,275 & 0,302 & 0,156 & & & \\
\hline & \multirow{2}{*}{79} & \multirow{2}{*}{74} & \multirow{2}{*}{ D3S1766 } & 204 & 208 & 212 & 216 & 220 & 224 & 228 & 232 & 236 & & \\
\hline & & & & 0,012 & 0,059 & 0,162 & 0,256 & 0,141 & 0,120 & 0,144 & 0,082 & 0,024 & & \\
\hline & \multirow{2}{*}{135} & \multirow{2}{*}{94} & \multirow{2}{*}{ D3S2460 } & 151 & 155 & 159 & 163 & 167 & 171 & & & & & \\
\hline & & & & 0,023 & 0,238 & 0,308 & 0,313 & 0,107 & 0,011 & & & & & \\
\hline & 161 & & R3S1744 & 135 & 139 & 143 & 147 & 151 & 155 & 159 & 163 & 167 & & \\
\hline & 101 & 88 & D3ST/44 & 0,054 & 0,045 & 0,080 & 0,160 & 0,207 & 0,227 & 0,118 & 0,099 & 0,011 & & \\
\hline & & & & 93 & 96 & 99 & 102 & 105 & 108 & 111 & 114 & 117 & & \\
\hline & 216 & 53 & D3S2418 & 0,074 & 0,322 & 0,093 & 0,019 & 0,020 & 0,081 & 0,280 & 0,093 & 0,019 & & \\
\hline & 13 & & D4S2366 & 120 & 124 & 128 & 132 & 136 & 140 & 144 & & & & \\
\hline & 13 & 99 & $045 \angle 300$ & 0,296 & 0,060 & 0,075 & 0,169 & 0,216 & 0,155 & 0,030 & & & & \\
\hline & & & & 160 & 164 & 168 & 172 & 173 & 176 & 180 & 184 & & & \\
\hline & 33 & 86 & D4S2639 & 0,052 & 0,239 & 0,112 & 0,254 & 0,043 & 0,072 & 0,058 & 0,170 & & & \\
\hline 4 & 60 & 39 & D4S1627 & 181 & 185 & 189 & 193 & 197 & 201 & & & & & \\
\hline 4 & 00 & 39 & 0451021 & 0,073 & 0,154 & 0,330 & 0,322 & 0,097 & 0,024 & & & & & \\
\hline & & & & 152 & 155 & 158 & 161 & 164 & & & & & & \\
\hline & 93 & 38 & D4S2361 & 0,136 & 0,405 & 0,349 & 0,087 & 0,022 & & & & & & \\
\hline & & & & 226 & 230 & 234 & 238 & 242 & 246 & 250 & & & & \\
\hline & $1 / 6$ & 42 & $043<431$ & 0,019 & 0,056 & 0,056 & 0,147 & 0,229 & 0,342 & 0,150 & & & & \\
\hline & 0 & 69 & R5s 2488 & 218 & 221 & 224 & 227 & 230 & 233 & 236 & 239 & 242 & 245 & 248 \\
\hline & 0 & 09 & $050<400$ & 0,078 & 0,026 & 0,043 & 0,087 & 0,065 & 0,266 & 0,123 & 0,135 & 0,138 & 0,026 & 0,013 \\
\hline & & & & 145 & 149 & 153 & 157 & 165 & & & & & & \\
\hline 5 & 36 & 26 & D5S2845 & 0,082 & 0,374 & 0,427 & 0,060 & 0,056 & & & & & & \\
\hline & 69 & 61 & D5S2500 & 149 & 153 & 157 & 161 & 165 & 169 & 173 & & & & \\
\hline & 0 & & 503200 & 0,102 & 0,239 & 0,239 & 0,093 & 0,041 & 0,186 & 0,099 & & & & \\
\hline
\end{tabular}


Tabela 11. Continuação

\begin{tabular}{|c|c|c|c|c|c|c|c|c|c|c|c|c|c|c|c|}
\hline Cromossomo & Posição & $\mathrm{N}$ & STR & Alelos/Fr & iências & & & & & & & & & & \\
\hline \multirow{8}{*}{5} & \multirow{2}{*}{98} & \multirow{2}{*}{111} & \multirow{2}{*}{ D5S1725 } & 180 & 184 & 188 & 192 & 196 & 200 & 204 & & & & & \\
\hline & & & & 0,009 & 0,355 & 0,049 & 0,057 & 0,213 & 0,221 & 0,095 & & & & & \\
\hline & \multirow{2}{*}{130} & \multirow{2}{*}{94} & \multirow{2}{*}{ D5S1505 } & 235 & 239 & 243 & 247 & 251 & 255 & 259 & 263 & 267 & 271 & 279 & \\
\hline & & & & 0,011 & 0,053 & 0,120 & 0,053 & 0,235 & 0,316 & 0,066 & 0,052 & 0,042 & 0,042 & 0,011 & \\
\hline & \multirow{2}{*}{160} & \multirow{2}{*}{121} & \multirow{2}{*}{ D5S820 } & 182 & 186 & 190 & 194 & 198 & 202 & 206 & 210 & & & & \\
\hline & & & & 0,009 & 0,037 & 0,057 & 0,246 & 0,315 & 0,143 & 0,129 & 0,064 & & & & \\
\hline & \multirow{2}{*}{175} & \multirow{2}{*}{48} & \multirow{2}{*}{ D5S1456 } & 191 & 195 & 199 & 203 & 207 & 211 & & & & & & \\
\hline & & & & 0,129 & 0,150 & 0,176 & 0,419 & 0,084 & 0,042 & & & & & & \\
\hline \multirow{8}{*}{6} & \multirow{2}{*}{9} & \multirow{2}{*}{74} & \multirow{2}{*}{$\mathrm{F} 13 \mathrm{~A} 1$} & 177 & 181 & 185 & 189 & 193 & 197 & 225 & 229 & 233 & & & \\
\hline & & & & 0,022 & 0,278 & 0,146 & 0,124 & 0,219 & 0,132 & 0,034 & 0,022 & 0,022 & & & \\
\hline & \multirow{2}{*}{80} & \multirow{2}{*}{58} & \multirow{2}{*}{ D6S1053 } & 289 & 293 & 297 & 301 & 305 & 309 & 313 & 317 & 321 & & & \\
\hline & & & & 0,077 & 0,015 & 0,123 & 0,237 & 0,145 & 0,203 & 0,138 & 0,046 & 0,016 & & & \\
\hline & \multirow{2}{*}{103} & \multirow{2}{*}{2} & \multirow{2}{*}{ D6S1056 } & 246 & 250 & 258 & & & & & & & & & \\
\hline & & & & 0,250 & 0,500 & 0,250 & & & & & & & & & \\
\hline & \multirow{2}{*}{119} & & & 151 & 155 & 159 & 163 & 167 & 171 & & & & & & \\
\hline & & 109 & D6S474 & 0,284 & 0,136 & 0,209 & 0,218 & 0,115 & 0,038 & & & & & & \\
\hline & & & & 170 & 174 & 178 & 182 & 186 & & & & & & & \\
\hline & 7 & 56 & D7S3056 & 0,016 & 0,154 & 0,191 & 0,463 & 0,175 & & & & & & & \\
\hline & & & & 142 & 146 & 150 & 154 & 158 & 162 & 166 & 170 & 174 & 178 & 182 & 186 \\
\hline & 29 & 35 & D7S3051 & 0,037 & 0,092 & 0,111 & 0,096 & 0,074 & 0,065 & 0,184 & 0,203 & 0,065 & 0,018 & 0,037 & 0,018 \\
\hline & & & & 172 & 176 & 180 & 184 & 188 & 192 & & & & & & \\
\hline & 58 & 109 & D7S2846 & 0,099 & 0,180 & 0,386 & 0,151 & 0,145 & 0,039 & & & & & & \\
\hline 7 & & & & 124 & 128 & 132 & 136 & 140 & 144 & 148 & 152 & 156 & & & \\
\hline & 128 & 36 & D7S3061 & 0,104 & 0,050 & 0,210 & 0,308 & 0,050 & 0,104 & 0,099 & 0,025 & 0,050 & & & \\
\hline & 150 & & & 163 & 167 & 171 & 175 & 179 & 183 & 187 & 191 & 195 & 199 & & \\
\hline & 150 & 67 & D7S1824 & 0,083 & 0,163 & 0,146 & 0,260 & 0,059 & 0,029 & 0,203 & 0,028 & 0,014 & 0,014 & & \\
\hline & & & & 205 & 209 & 213 & 217 & 221 & 225 & 229 & 233 & & & & \\
\hline & 174 & 89 & D7S3058 & 0,208 & 0,193 & 0,100 & 0,089 & 0,239 & 0,092 & 0,045 & 0,033 & & & & \\
\hline & & & & 139 & 143 & 147 & 151 & 155 & 159 & 163 & 167 & 171 & & & \\
\hline & 60 & 56 & D8S1477 & 0,015 & 0,015 & 0,015 & 0,074 & 0,183 & 0,264 & 0,316 & 0,075 & 0,044 & & & \\
\hline & & & & 135 & 139 & 143 & 147 & 151 & 155 & 159 & 163 & 167 & 171 & & \\
\hline 8 & 119 & 69 & D8S1132 & 0,035 & 0,082 & 0,128 & 0,074 & 0,209 & 0,225 & 0,129 & 0,047 & 0,047 & 0,023 & & \\
\hline & & & & 197 & 201 & 205 & 209 & 213 & 217 & & & & & & \\
\hline & 164 & 68 & D8S373 & 0,103 & 0,287 & 0,151 & 0,209 & 0,172 & 0,077 & & & & & & \\
\hline
\end{tabular}


Tabela 11. Continuação.

\begin{tabular}{|c|c|c|c|c|c|c|c|c|c|c|c|c|}
\hline \multirow[t]{9}{*}{ Cromossomo } & \multirow{3}{*}{$\frac{\text { Posição }}{32}$} & \multirow{3}{*}{$\frac{N}{48}$} & \multirow{3}{*}{$\begin{array}{l}\text { STR } \\
\text { D9S925 }\end{array}$} & \multicolumn{9}{|c|}{ Alelos/Freqüências } \\
\hline & & & & 167 & 171 & 175 & 179 & 183 & 187 & 191 & 195 & 199 \\
\hline & & & & 0,033 & 0,033 & 0,050 & 0,066 & 0,052 & 0,320 & 0,297 & 0,116 & 0,033 \\
\hline & \multirow{5}{*}{80} & \multirow{2}{*}{62} & \multirow{2}{*}{ D9S1118 } & 141 & 145 & 149 & 157 & 161 & 165 & 169 & 173 & 177 \\
\hline & & & & 0,117 & 0,151 & 0,034 & 0,084 & 0,088 & \multirow{3}{*}{0,084} & \multirow{3}{*}{0,125} & \multirow[t]{5}{*}{0,284} & \multirow[t]{3}{*}{0,034} \\
\hline & & & Rosa?? & 251 & 255 & 259 & 263 & 267 & & & & \\
\hline & & 12 & D9S922 & 0,147 & 0,192 & 0,186 & 0,366 & 0,108 & & & & \\
\hline & & \multirow{2}{*}{83} & \multirow{2}{*}{ D9S934 } & 206 & 210 & 214 & 218 & 222 & 226 & \multirow{2}{*}{$\begin{array}{c}230 \\
0,012\end{array}$} & & \\
\hline & 128 & & & 0,012 & 0,148 & 0,356 & 0,296 & 0,111 & 0,064 & & & \\
\hline \multirow{12}{*}{10} & \multirow{2}{*}{4} & \multirow{2}{*}{30} & \multirow{2}{*}{ D10S1435 } & 256 & 260 & 264 & 268 & 272 & 276 & & & \\
\hline & & & & 0,154 & 0,378 & 0,288 & 0,077 & 0,051 & 0,051 & & & \\
\hline & \multirow{2}{*}{59} & \multirow{2}{*}{73} & \multirow{2}{*}{ D10S1426 } & 152 & 156 & 160 & 164 & 168 & & & & \\
\hline & & & & 0,032 & 0,215 & 0,253 & 0,372 & 0,127 & & & & \\
\hline & \multirow{2}{*}{94} & \multirow{2}{*}{54} & D10S1432 & 157 & 161 & 165 & 169 & 173 & 177 & 181 & & \\
\hline & & & DIUS1432 & 0,018 & 0,018 & 0,286 & 0,275 & 0,369 & 0,018 & 0,018 & & \\
\hline & 117 & 61 & D10\$677 & 197 & 201 & 205 & 209 & 213 & 217 & 221 & & \\
\hline & 111 & 01 & ז1080 & 0,142 & 0,164 & 0,100 & 0,076 & 0,204 & 0,252 & 0,061 & & \\
\hline & & & & 156 & 160 & 168 & 172 & 176 & 180 & & & \\
\hline & 125 & 46 & D10S1239 & 0,079 & 0,020 & 0,060 & 0,099 & 0,433 & 0,309 & & & \\
\hline & 148 & 82 & D10S1213 & 101 & 105 & 109 & 113 & 117 & 121 & 125 & & \\
\hline & 148 & 82 & 01051213 & 0,023 & 0,195 & 0,500 & 0,131 & 0,058 & 0,070 & 0,023 & & \\
\hline & 2 & & & 170 & 174 & 178 & 182 & 186 & 190 & 194 & 198 & 202 \\
\hline & 2 & 71 & D11S1984 & 0,030 & 0,032 & 0,030 & 0,254 & 0,207 & 0,075 & 0,155 & 0,126 & 0,092 \\
\hline & 43 & 45 & D11S1392 & 200 & 204 & 208 & 212 & 216 & & & & \\
\hline 11 & 40 & 45 & Dו101092 & 0,172 & 0,394 & 0,262 & 0,155 & 0,017 & & & & \\
\hline 11 & & & & 197 & 201 & 205 & 209 & 213 & 217 & 221 & 225 & 229 \\
\hline & 101 & 77 & D11S2000 & 0,110 & 0,090 & 0,039 & 0,035 & 0,351 & 0,140 & 0,129 & 0,070 & 0,035 \\
\hline & 123 & 80 & 011S4464 & 229 & 233 & 237 & 241 & 245 & 249 & 253 & & \\
\hline & 123 & 80 & DTTS4464 & 0,059 & 0,094 & 0,417 & 0,263 & 0,072 & 0,047 & 0,047 & & \\
\hline & 6 & 87 & D12S372 & 174 & 178 & 182 & 186 & 190 & & & & \\
\hline & 0 & - & & 0,105 & 0,464 & 0,259 & 0,116 & 0,056 & & & & \\
\hline 12 & 26 & 37 & D12S391 & 211 & 215 & 219 & 223 & 227 & 231 & 235 & 239 & 243 \\
\hline 12 & $\angle 0$ & $3 r$ & 0123391 & 0,041 & 0,083 & 0,104 & 0,266 & 0,187 & 0,062 & 0,174 & 0,041 & 0,041 \\
\hline & & & & 115 & 118 & 121 & 124 & 127 & 130 & 133 & & \\
\hline & 49 & 15 & 01251042 & 0,048 & 0,143 & 0,095 & 0,249 & 0,099 & 0,249 & 0,118 & & \\
\hline
\end{tabular}


Tabela 11. Continuação.

\begin{tabular}{|c|c|c|c|c|c|c|c|c|c|c|c|c|c|c|c|c|}
\hline Cromossomo & Posição & $\mathrm{N}$ & STR & Alelos/Fr & Üências & & & & & & & & & & & \\
\hline \multirow{6}{*}{12} & \multirow{2}{*}{81} & \multirow{2}{*}{57} & \multirow{2}{*}{ D12S375 } & 157 & 161 & 165 & 169 & 173 & 177 & 181 & 185 & & & & & \\
\hline & & & & 0,058 & 0,014 & 0,070 & 0,164 & 0,305 & 0,169 & 0,163 & 0,056 & & & & & \\
\hline & \multirow{2}{*}{109} & \multirow{2}{*}{52} & \multirow{2}{*}{ PAH } & 229 & 233 & 237 & 241 & 245 & 249 & 253 & 257 & & & & & \\
\hline & & & & 0,033 & 0,306 & 0,218 & 0,102 & 0,195 & 0,114 & 0,016 & 0,016 & & & & & \\
\hline & \multirow{2}{*}{161} & \multirow{2}{*}{92} & \multirow{2}{*}{ D12S1045 } & 76,000 & 79,000 & 85,000 & 88,000 & 91,000 & 94,000 & & & & & & & \\
\hline & & & & 0,101 & 0,099 & 0,033 & 0,151 & 0,481 & 0,135 & & & & & & & \\
\hline \multirow{6}{*}{13} & \multirow[b]{2}{*}{9} & \multirow{2}{*}{77} & \multirow{2}{*}{ D13S787 } & 251 & 255 & 259 & 263 & 267 & 271 & 275 & & & & & & \\
\hline & & & & 0,034 & 0,105 & 0,147 & 0,170 & 0,272 & 0,153 & 0,118 & & & & & & \\
\hline & \multirow{2}{*}{33} & \multirow{2}{*}{102} & \multirow{2}{*}{ D13S894 } & 188 & 192 & 196 & 200 & 204 & 208 & & & & & & & \\
\hline & & & & 0,098 & 0,257 & 0,235 & 0,304 & 0,097 & 0,010 & & & & & & & \\
\hline & \multirow{2}{*}{64} & \multirow{2}{*}{94} & \multirow{2}{*}{ D13S317 } & 171 & 175 & 179 & 183 & 187 & 191 & 195 & 199 & & & & & \\
\hline & & & & 0,134 & 0,074 & 0,185 & 0,249 & 0,166 & 0,108 & 0,021 & 0,063 & & & & & \\
\hline \multirow{12}{*}{14} & \multirow[b]{2}{*}{26} & \multirow[b]{2}{*}{55} & \multirow{2}{*}{ D14S1280 } & 285 & 289 & 293 & 297 & 301 & & & & & & & & \\
\hline & & & & 0,098 & 0,199 & 0,189 & 0,465 & 0,049 & & & & & & & & \\
\hline & & & & 190 & 194 & 198 & 202 & 206 & 210 & & & & & & & \\
\hline & 44 & 44 & D14S306 & 0,152 & 0,276 & 0,154 & 0,175 & 0,179 & 0,064 & & & & & & & \\
\hline & & & & 219 & 222 & 225 & 228 & 231 & 234 & 237 & 240 & 243 & & & & \\
\hline & 67 & 69 & D14S592 & 0,024 & 0,112 & 0,073 & 0,167 & 0,370 & 0,181 & 0,037 & 0,024 & 0,012 & & & & \\
\hline & & & & 262 & 270 & 274 & 278 & 282 & & & & & & & & \\
\hline & 92 & 12 & D14S606 & 0,203 & 0,527 & 0,135 & 0,068 & 0,068 & & & & & & & & \\
\hline & & & & 137 & 141 & 149 & 157 & 161 & 165 & 169 & & & & & & \\
\hline & 106 & 102 & D14S617 & 0,019 & 0,405 & 0,048 & 0,086 & 0,173 & 0,260 & 0,010 & & & & & & \\
\hline & & & & 131 & 135 & 139 & 143 & 147 & 151 & 155 & & & & & & \\
\hline & 126 & 45 & D14S1426 & 0,206 & 0,128 & 0,020 & 0,142 & 0,202 & 0,282 & 0,020 & & & & & & \\
\hline & & & & 256 & 260 & 264 & 268 & 272 & 276 & 280 & 284 & 288 & & & & \\
\hline & 12 & 42 & D15S822 & 0,065 & 0,162 & 0,175 & 0,065 & 0,043 & 0,242 & 0,139 & 0,043 & 0,065 & & & & \\
\hline & & & & 193 & 195 & 199 & 201 & 203 & 205 & 207 & 209 & 211 & 213 & 215 & 219 & 223 \\
\hline & 52 & 95 & D15S643 & 0,019 & 0,010 & 0,019 & 0,019 & 0,039 & 0,010 & 0,080 & 0,062 & 0,122 & 0,245 & 0,160 & 0,195 & 0,020 \\
\hline 15 & 83 & & & 234 & 237 & 240 & 243 & 246 & 249 & 252 & 255 & & & & & \\
\hline & 83 & 108 & D15S655 & 0,061 & 0,229 & 0,159 & 0,132 & 0,153 & 0,126 & 0,130 & 0,010 & & & & & \\
\hline & & & & 196 & 202 & 204 & 206 & 208 & 210 & 212 & 214 & 216 & & & & \\
\hline & 122 & 65 & D15S642 & 0,134 & 0,047 & 0,139 & 0,149 & 0,257 & 0,119 & 0,095 & 0,045 & 0,015 & & & & \\
\hline
\end{tabular}


Tabela 11. Continuação.

\begin{tabular}{|c|c|c|c|c|c|c|c|c|c|c|c|c|c|c|c|}
\hline Cromossomo & Posição & $\mathrm{N}$ & STR & Alelos/Fr & Üências & & & & & & & & & & \\
\hline \multirow{8}{*}{16} & \multirow{2}{*}{11} & \multirow{2}{*}{70} & \multirow{2}{*}{ ATA41E04 } & 112 & 115 & 118 & 121 & 124 & 127 & 130 & 133 & 136 & 142 & 145 & 148 \\
\hline & & & & 0,012 & 0,024 & 0,092 & 0,069 & 0,221 & 0,216 & 0,194 & 0,023 & 0,092 & 0,035 & 0,012 & 0,012 \\
\hline & \multirow{2}{*}{30} & \multirow{2}{*}{73} & \multirow{2}{*}{ D16S764 } & 94 & 98 & 102 & 106 & 110 & 114 & & & & & & \\
\hline & & & & 0,026 & 0,068 & 0,421 & 0,308 & 0,149 & 0,028 & & & & & & \\
\hline & \multirow{2}{*}{58} & \multirow{2}{*}{39} & \multirow{2}{*}{ D16S753 } & 248 & 256 & 260 & 264 & 268 & 272 & 276 & 284 & & & & \\
\hline & & & & 0,020 & 0,093 & 0,130 & 0,261 & 0,258 & 0,174 & 0,043 & 0,020 & & & & \\
\hline & \multirow{2}{*}{125} & \multirow{2}{*}{77} & \multirow{2}{*}{ D16S539 } & 148 & 150 & 154 & 156 & 158 & 160 & 162 & 164 & 166 & & & \\
\hline & & & & 0,157 & 0,090 & 0,087 & 0,104 & 0,136 & 0,165 & 0,152 & 0,059 & 0,050 & & & \\
\hline \multirow{10}{*}{17} & \multirow{2}{*}{1} & \multirow{2}{*}{75} & \multirow{2}{*}{ D17S1308 } & 292 & 296 & 300 & 304 & 308 & 312 & 316 & & & & & \\
\hline & & & & 0,034 & 0,023 & 0,129 & 0,369 & 0,231 & 0,202 & 0,011 & & & & & \\
\hline & \multirow{2}{*}{24} & \multirow{2}{*}{35} & \multirow{2}{*}{ D17S1303 } & 225 & 229 & 233 & 237 & 241 & 245 & & & & & & \\
\hline & & & & 0,260 & 0,027 & 0,109 & 0,444 & 0,106 & 0,053 & & & & & & \\
\hline & \multirow{2}{*}{56} & \multirow{2}{*}{58} & \multirow{2}{*}{ D17S1293 } & 262 & 266 & 270 & 274 & 276 & 278 & 282 & 286 & 290 & & & \\
\hline & & & & 0,130 & 0,198 & 0,111 & 0,111 & 0,056 & 0,038 & 0,204 & 0,095 & 0,058 & & & \\
\hline & \multirow{2}{*}{100} & & & 135 & 139 & 143 & 147 & 151 & 155 & 159 & 163 & & & & \\
\hline & & 50 & D17S1301 & 0,014 & 0,014 & 0,015 & 0,014 & 0,446 & 0,365 & 0,117 & 0,014 & & & & \\
\hline & 126 & 12 & R175928 & 135 & 137 & 143 & 145 & 147 & 149 & 151 & 153 & 155 & 157 & 159 & 161 \\
\hline & 126 & 42 & D1/5928 & 0,048 & 0,032 & 0,016 & 0,064 & 0,096 & 0,181 & 0,160 & 0,144 & 0,160 & 0,032 & 0,048 & 0,017 \\
\hline & & & & 173 & 176 & 179 & 182 & 185 & 188 & 191 & & & & & \\
\hline & 28 & 47 & D18S843 & 0,019 & 0,019 & 0,038 & 0,171 & 0,479 & 0,236 & 0,038 & & & & & \\
\hline 18 & 54 & 65 & 18S877 & 117 & 121 & 125 & 129 & 133 & 137 & & & & & & \\
\hline 18 & 54 & 65 & Di8s8/ & 0,017 & 0,017 & 0,166 & 0,373 & 0,280 & 0,148 & & & & & & \\
\hline & 99 & & & 160 & 164 & 168 & 172 & 176 & 180 & 184 & 188 & 192 & & & \\
\hline & 99 & 33 & D18S1364 & 0,121 & 0,097 & 0,204 & 0,159 & 0,103 & 0,170 & 0,024 & 0,097 & 0,024 & & & \\
\hline & 10 & 07 & & 96 & 98 & 100 & 102 & 104 & 106 & 108 & 112 & & & & \\
\hline & 10 & 91 & D19S591 & 0,020 & 0,010 & 0,535 & 0,020 & 0,133 & 0,031 & 0,241 & 0,010 & & & & \\
\hline & & & & 230 & 234 & 238 & 241 & 242 & 246 & 250 & & & & & \\
\hline & 33 & 45 & D19S586 & 0,020 & 0,222 & 0,249 & 0,337 & 0,019 & 0,096 & 0,057 & & & & & \\
\hline & & & & 199 & 203 & 205 & 207 & 209 & 211 & 213 & 215 & 217 & & & \\
\hline 19 & 52 & 68 & D19S433 & 0,183 & 0,301 & 0,064 & 0,172 & 0,096 & 0,053 & 0,039 & 0,051 & 0,039 & & & \\
\hline & & & & 181 & 185 & 189 & 193 & 201 & 205 & 209 & 213 & 217 & 221 & 225 & 229 \\
\hline & 78 & 63 & D19S246 & 0,230 & 0,049 & 0,017 & 0,033 & 0,033 & 0,136 & 0,033 & 0,142 & 0,138 & 0,084 & 0,089 & 0,016 \\
\hline & & & & 114 & 118 & 122 & 126 & 130 & 134 & 138 & 142 & & & & \\
\hline & 101 & 57 & D19S254 & 0,354 & 0,056 & 0,043 & 0,042 & 0,070 & 0,246 & 0,159 & 0,030 & & & & \\
\hline
\end{tabular}


Tabela 11. Continuação.

\begin{tabular}{|c|c|c|c|c|c|c|c|c|c|c|c|c|c|c|c|c|c|c|c|}
\hline Cromossomo & Posição & $\mathrm{N}$ & STR & Alelos/F & reqüênci & & & & & & & & & & & & & & \\
\hline \multirow{4}{*}{20} & \multirow{2}{*}{39} & \multirow{2}{*}{23} & \multirow{2}{*}{ D20S470 } & 266 & 290 & 294 & 298 & 302 & 306 & 310 & & & & & & & & & \\
\hline & & & & 0,030 & 0,091 & 0,187 & 0,126 & 0,281 & 0,254 & 0,030 & & & & & & & & & \\
\hline & \multirow{2}{*}{80} & \multirow{2}{*}{45} & \multirow{2}{*}{ D20S480 } & 278 & 282 & 286 & 290 & 294 & 298 & 302 & 314 & 318 & & & & & & & \\
\hline & & & & 0,041 & 0,103 & 0,210 & 0,247 & 0,254 & 0,021 & 0,062 & 0,041 & 0,021 & & & & & & & \\
\hline \multirow{6}{*}{21} & \multirow{2}{*}{3} & \multirow{2}{*}{76} & \multirow{2}{*}{ D21S1432 } & 131 & 135 & 139 & 143 & 147 & & & & & & & & & & & \\
\hline & & & & 0,065 & 0,187 & 0,593 & 0,116 & 0,039 & & & & & & & & & & & \\
\hline & \multirow{2}{*}{40} & \multirow{2}{*}{78} & \multirow{2}{*}{ D21S2055 } & 115 & 119 & 127 & 131 & 135 & 147 & 151 & 155 & 159 & 167 & 175 & 179 & 183 & 187 & 191 & 199 \\
\hline & & & & 0,011 & 0,034 & 0,057 & 0,069 & 0,011 & 0,023 & 0,206 & 0,176 & 0,091 & 0,011 & 0,058 & 0,103 & 0,080 & 0,046 & 0,012 & 0,011 \\
\hline & \multirow{2}{*}{58} & \multirow{2}{*}{59} & \multirow{2}{*}{$\mathrm{D} 21 \mathrm{~S} 1446$} & 201 & 205 & 209 & 213 & 217 & 221 & 225 & & & & & & & & & \\
\hline & & & & 0,048 & 0,285 & 0,080 & 0,127 & 0,112 & 0,331 & 0,016 & & & & & & & & & \\
\hline \multirow{4}{*}{22} & \multirow{2}{*}{29} & \multirow{2}{*}{98} & \multirow{2}{*}{ D22S689 } & 202 & 206 & 210 & 214 & 218 & 222 & 226 & 230 & & & & & & & & \\
\hline & & & & 0,011 & 0,067 & 0,097 & 0,229 & 0,207 & 0,277 & 0,101 & 0,011 & & & & & & & & \\
\hline & \multirow{2}{*}{36} & \multirow{2}{*}{45} & \multirow{2}{*}{ D22S683 } & 168 & 172 & 174 & 176 & 178 & 180 & 182 & 184 & 188 & 196 & 198 & 202 & & & & \\
\hline & & & & 0,076 & 0,053 & 0,107 & 0,171 & 0,178 & 0,161 & 0,035 & 0,070 & 0,018 & 0,018 & 0,077 & 0,038 & & & & \\
\hline
\end{tabular}

Conclusão. 
Tabela 12. Resultados da análise de ligação de dois pontos em Portuchuelo. O lod score observado para cada marcador de microssatélite (STR) é mostrado nas colunas MAL averiguando a ligação do marcador com o número de episódios de malária relatado pelos indivíduos, e na coluna MAL_LCA averiguando o logaritmo desse número, corrigido para idade e sexo (MAL_LCA).

\begin{tabular}{|c|c|c|c|c|c|c|c|c|c|}
\hline Crom. & $\begin{array}{l}\text { Posição } \\
\text { (cM) }\end{array}$ & STR & MAL & MAL_LCA & Crom. & $\begin{array}{c}\text { Posição } \\
\text { (cM) }\end{array}$ & STR & MAL & MAL_LCA \\
\hline \multirow{10}{*}{1} & 16 & D1S1612 & 2,039 & 0,002 & \multirow{6}{*}{10} & 4 & D10S1435 & 0,000 & 0,270 \\
\hline & 30 & D1S1597 & 1,209 & 0,009 & & 59 & D10S1426 & 1,490 & 0,000 \\
\hline & 76 & D1S2134 & 0,000 & 0,250 & & 94 & D10S1432 & 4,332 & 0,464 \\
\hline & 102 & D1S1665 & 0,000 & 0,236 & & 117 & D10S677 & 0,000 & 0,178 \\
\hline & 126 & D1S1588 & 3,995 & 0,000 & & 125 & D10S1239 & 0,000 & 0,334 \\
\hline & 152 & D1S534 & 0,000 & 0,264 & & 148 & D10S1213 & 0,816 & 0,000 \\
\hline & 171 & D1S1679 & 0,000 & 0,038 & \multirow{4}{*}{11} & 2 & D11S1984 & 0,000 & 0,772 \\
\hline & 202 & D1S518 & 0,000 & 0,000 & & 43 & D11S1392 & 0,000 & 0,113 \\
\hline & 212 & D1S1660 & 0,000 & 0,000 & & 101 & D11S2000 & 0,000 & 0,000 \\
\hline & 275 & D1S1609 & 3,856 & 0,492 & & 123 & D11S4464 & 0,000 & 0,000 \\
\hline \multirow{9}{*}{2} & 28 & D2S1400 & 0,000 & 0,110 & \multirow{6}{*}{12} & 6 & D12S372 & 1,172 & 0,000 \\
\hline & 64 & D2S1356 & 0,212 & 0,000 & & 26 & D12S391 & 3,761 & 0,626 \\
\hline & 91 & D2S1394 & 0,000 & 0,000 & & 49 & D12S1042 & 0,648 & 0,000 \\
\hline & 114 & D2S2972 & 0,546 & 0,000 & & 81 & D12S375 & 1,821 & 0,000 \\
\hline & 152 & D2S1399 & 0,243 & 0,000 & & 109 & PAH & 0,000 & 0,016 \\
\hline & 186 & D2S1391 & 0,000 & 0,000 & & 161 & D12S1045 & 0,000 & 0,000 \\
\hline & 200 & D2S1384 & 0,000 & 0,000 & \multirow{3}{*}{13} & 9 & D13S787 & 0,000 & 0,884 \\
\hline & 227 & D2S1363 & 0,551 & 0,035 & & 33 & D13S894 & 1,853 & 0,170 \\
\hline & 252 & D2S2968 & 2,284 & 0,000 & & 64 & D13S317 & 0,000 & 0,000 \\
\hline \multirow{7}{*}{3} & 6 & D3S2387 & 0,000 & 0,000 & \multirow{6}{*}{14} & 26 & D14S1280 & 0,000 & 0,000 \\
\hline & 26 & D3S4545 & 0,000 & 0,171 & & 44 & D14S306 & 0,000 & 0,000 \\
\hline & 58 & D3S2432 & 1,994 & 0,000 & & 67 & D14S592 & 0,000 & 0,744 \\
\hline & 79 & D3S1766 & 0,000 & 0,084 & & 92 & D14S606 & 0,000 & 0,000 \\
\hline & 135 & D3S2460 & 1,366 & 0,048 & & 106 & D14S617 & 0,000 & 0,269 \\
\hline & 161 & D3S1744 & 0,000 & 0,000 & & 126 & D14S1426 & 0,000 & 0,139 \\
\hline & 216 & D3S2418 & 0,586 & 1,275 & \multirow{4}{*}{15} & 12 & D15S822 & 0,000 & 0,721 \\
\hline \multirow{5}{*}{4} & 13 & D4S2366 & 2,536 & 1,163 & & 52 & D15S643 & 0,000 & 0,158 \\
\hline & 33 & D4S2639 & 0,000 & 0,943 & & 83 & D15S655 & 3,252 & 0,005 \\
\hline & 60 & D4S1627 & 0,000 & 0,000 & & 122 & D15S642 & 0,000 & 0,000 \\
\hline & 93 & D4S2361 & 0,000 & 0,000 & \multirow{4}{*}{16} & 11 & ATA41E04 & 0,257 & 0,000 \\
\hline & 176 & D4S2431 & 0,000 & 0,300 & & 30 & D16S764 & 0,000 & 0,000 \\
\hline \multirow{7}{*}{5} & 0 & D5S2488 & 1,168 & 0,000 & & 58 & D16S753 & 0,000 & 0,000 \\
\hline & 36 & D5S2845 & 0,470 & 1,044 & & 125 & D16S539 & 4,213 & 0,389 \\
\hline & 69 & D5S2500 & 0,000 & 0,063 & \multirow{5}{*}{17} & 1 & D17S1308 & 0,000 & 0,988 \\
\hline & 98 & D5S1725 & 4,003 & 0,000 & & 24 & D17S1303 & 0,686 & 0,166 \\
\hline & 130 & D5S1505 & 2,051 & 0,000 & & 56 & D17S1293 & 2,347 & 0,485 \\
\hline & 160 & D5S820 & 0,000 & 0,000 & & 100 & D17S1301 & 0,636 & 0,000 \\
\hline & 175 & D5S1456 & 0,000 & 0,000 & & 126 & D17S928 & 0,000 & 0,000 \\
\hline \multirow{4}{*}{6} & 9 & F13A1 & 0,000 & 0,273 & \multirow{3}{*}{18} & 28 & D18S843 & 0,000 & 0,000 \\
\hline & 80 & D6S1053 & 0,000 & 0,432 & & 54 & D18S877 & 1,142 & 0,101 \\
\hline & 103 & D6S1056 & 0,000 & 0,000 & & 99 & D18S1364 & 1,269 & 0,698 \\
\hline & 119 & D6S474 & 0,000 & 0,002 & & 10 & D19S591 & 2,227 & 0,019 \\
\hline \multirow{6}{*}{7} & 7 & D7S3056 & 0,000 & 0,000 & & 33 & D19S586 & 0,000 & 0,000 \\
\hline & 29 & D7S3051 & 0,000 & 0,501 & 19 & 52 & D19S433 & 0,624 & 0,052 \\
\hline & 58 & D7S2846 & 0,000 & 0,000 & & 78 & D19S246 & 0,000 & 0,000 \\
\hline & 128 & D7S3061 & 0,000 & 0,081 & & 101 & D19S254 & 0,160 & 0,000 \\
\hline & 150 & D7S1824 & 2,042 & 0,000 & 20 & 39 & D20S470 & 0,341 & 0,000 \\
\hline & 174 & D7S3058 & 0,920 & 0,000 & 20 & 80 & D20S480 & 0,000 & 0,694 \\
\hline & 60 & D8S1477 & 0,000 & 0,000 & & 3 & D21S1432 & 0,000 & 0,000 \\
\hline 8 & 119 & D8S1132 & 1,406 & 0,373 & 21 & 40 & D21S2055 & 0,000 & 0,000 \\
\hline & 164 & D8S373 & 1,808 & 0,643 & & 58 & D21S1446 & 0,000 & 0,000 \\
\hline & 32 & D9S925 & 2,209 & 0,109 & 22 & 29 & D22S689 & 0,000 & 0,363 \\
\hline 9 & 58 & D9S1118 & 0,000 & 0,007 & 22 & 36 & D22S683 & 1,720 & 0,355 \\
\hline 9 & 80 & D9S922 & 3,294 & 0,861 & & & & & \\
\hline & 128 & D9S934 & 0,000 & 0,116 & & & & & \\
\hline
\end{tabular}




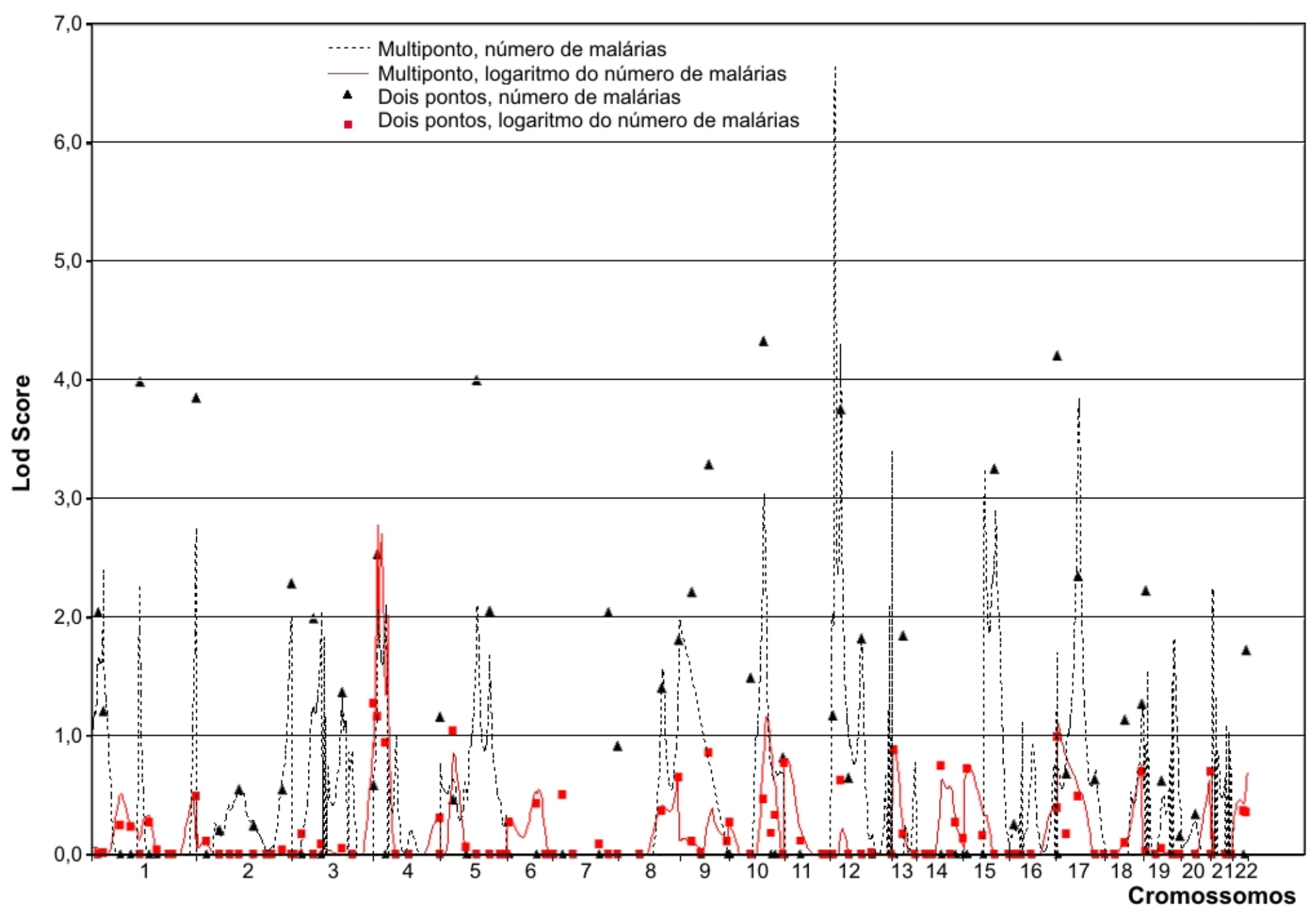

Figura 5. Resultados das análises de ligação entre 108 marcadores de microssatélites distribuídos ao longo de todo o genoma humano e o número de episódios de malária relatado pelos indivíduos em Portuchuelo. 


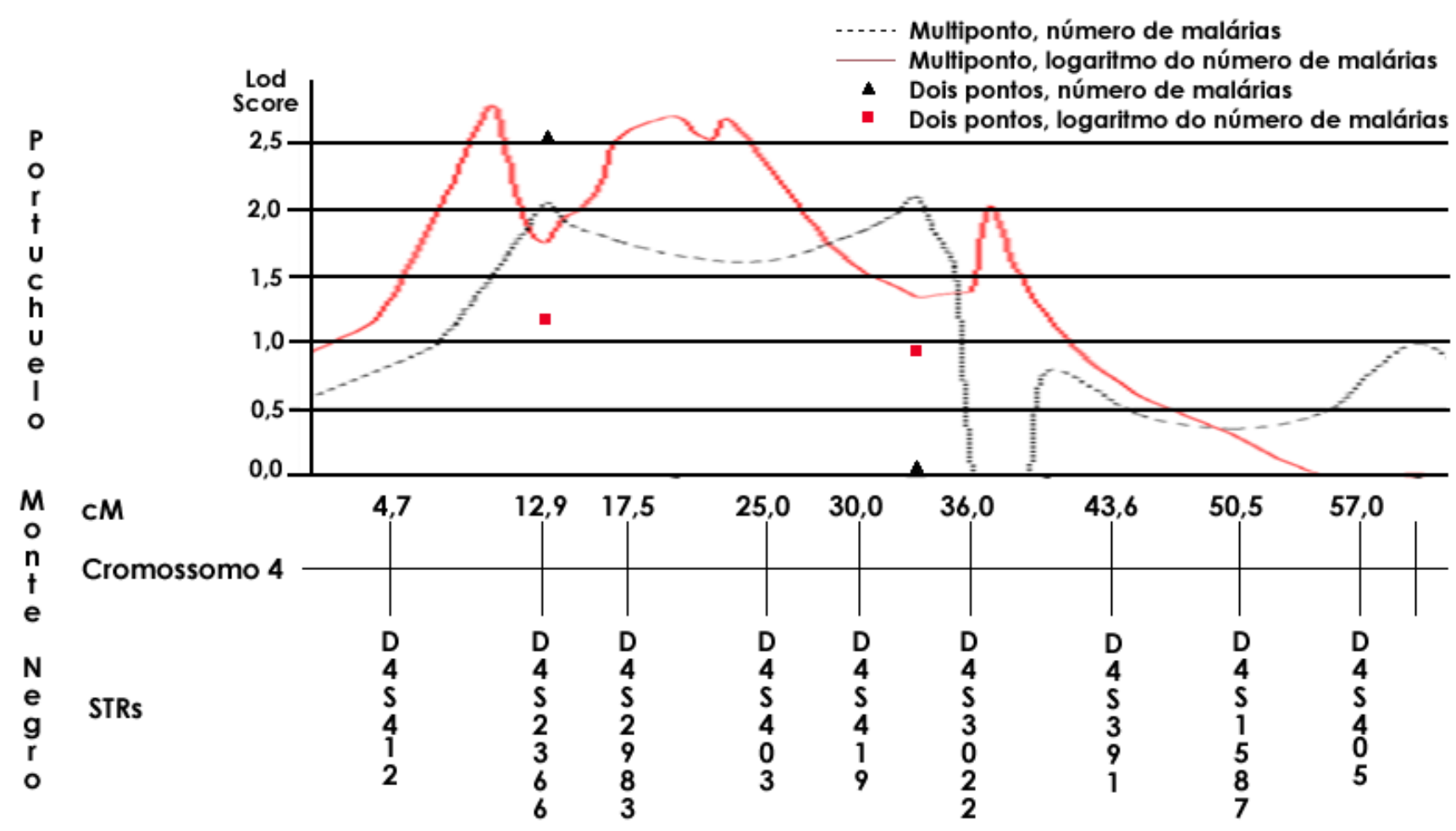

Figura 6. Representação gráfica dos resultados obtidos na análise de ligação em Portuchuelo (parte superior) e dos marcadores selecionados ao longo do braço curto do cromossomo 4, testados na população de Monte Negro (parte inferior). 


\section{DISCUSSÃO}

O número de episódios de malária relatado pelos indivíduos foi a base para o estudo realizado. Sem dúvida, esse fenótipo demonstrou ter um significativo valor epidemiológico, pois apresenta características interessantes aos estudos de epidemiologia genética. Entre essas características podemos citar: ser facilmente obtido em entrevista com os indivíduos da amostra e seus familiares; não exigir seguimento de casos e não ser invasivo. Outra propriedade desse fenótipo é que ele não é específico para um determinado tipo de malária. Pode-se argumentar que essa ausência de especificidade do fenótipo é indesejável ao estudo, entretanto, levando-se em conta essas vantagens e admitindo-se que os fatores ambientais que contribuem para a sua distribuição nas populações estudadas afetam a manifestação do fenótipo de forma aleatória, pode-se tecer hipóteses genéticas sobre os dados observados.

O número de episódios de malária apresentou distribuição leptocúrtica (Figura 4) e para que fosse propriamente analisado tornou-se necessário tomar o logaritmo de cada número de episódios relatados de malária acrescido de um. A transformação logarítmica, além de aproximar os dados à distribuição normal, deve minimizar as distorções decorrentes da dificuldade dos indivíduos, que vivem em áreas endêmicas de malária, em lembrar o número exato de episódios dessa doença. Devido à observação de que o número de episódios relatados de malária aumenta em função da idade e de que indivíduos do sexo masculino apresentam valor maior que os indivíduos do sexo feminino, os efeitos da idade e sexo foram removidos do logaritmo do número de malária, utilizando-se regressão múltipla escalonada. Quando possível foi utilizado também os postos do número de episódios. A utilização de postos e estatísticas não paramétricas permitem que os resultados sejam independentes da dimensão das diferenças entre os números relatados.

O caráter oligo-endêmico da transmissão de malária na Amazônia, e particularmente em Rondônia, é muito diferente do observado em áreas hiper endêmicas africanas e asiáticas freqüentemente estudadas do ponto de vista da epidemiologia genética. O estudo nas populações de Portuchuelo e Monte Negro, com padrão epidemiológico específico, relacionado em parte com a baixa densidade populacional na região, torna o trabalho original.

Para um maior entendimento sobre as populações estudas, bem como para verificar se havia heterogeneidade entre as estimativas de freqüência gênicas de marcadores genéticos foi realizado um estudo de mistura étnica. Foram estimadas as proporções étnicas destas duas populações e seus respectivos erros padrões (Tabela 3). Os erros padrões são relativamente 
altos, devido principalmente a contribuição da heterogeneidade entre os componentes dos sistemas. Essa heterogeneidade reflete, em grande parte, erros nas estimativas das freqüências gênicas ancestrais.

A maioria dos estudos utilizando-se microssatélites para inferir mistura racial baseiamse em marcadores do cromossomo $\mathrm{Y}$, com objetivo de caracterizar linhas paternas e são freqüentemente combinados com dados do genoma mitocondrial, caracterizando também a linhagem maternal. No Brasil, algumas populações indígenas foram estudadas utilizando microssatélites autossômicos (WANG et al., 2007) bem como populações mestiças (WANG et al., 2008). Não é de nosso conhecimento a existência de algum estudo comparando o uso de microssatélites com o uso de marcadores de tipos sanguíneos e proteínas.

Os valores de mistura obtidos utilizando-se microssatélites não apresentaram diferença estatística quando comparados àqueles baseados em marcadores clássicos (Tabela 4) em Portuchuelo. Os valores do erro padrão das estimativas de composição étnica, bem como alguns testes de ajuste ao modelo de mistura, são maiores nas análises baseadas em microssatélites do que nas análises utilizando marcadores clássicos. Devido às freqüências gênicas menos estudadas, alta taxa de mutação e heterogeneidade entre sistemas dos microssatélites, os marcadores clássicos aparentemente fornecem melhores estimativas de composição étnica em populações tri-híbridas.

Portuchuelo tem uma proporção étnica de ameríndios quase quatro vezes maior que a de Monte Negro provavelmente pelo fato desta ser composta por descendentes dos colonizadores (Sec. XIX/inicio Sec.XX) com uma grande mistura do grupo ameríndio Mura, (CAMARGO et al., 1994, 1996), enquanto Monte Negro é um município de origem muito mais recente e tem uma influência marcante dos migrantes do Sul do Brasil (CAMARGO et al., 2002). Uma interessante característica apresentada pelas duas populações é a contribuição africana ao componente gênico ser praticamente a mesma, indicando a persistência de uma relativamente pequena $(\sim 20 \%)$, mas significante proporção de mistura africana, provavelmente originada nas primeiras migrações de nordestinos, durante o ciclo da borracha e a construção a ferrovia Madeira-Mamoré (COURA et al., 2006).

Não existem relatos de estudos de mistura racial realizados em populações rurais na Amazônia. Estes se concentram normalmente em populações urbanas, tribos ribeirinhas e isolados descendentes de escravos (SANS, 2000). Trabalhos de análise sobre a composição étnica de muitas populações urbanas da Amazônia oriental e central, concluíram que existe um aumento na mistura ameríndia na medida em que se sobe o rio Amazonas chegando a 
40\% de mistura, em Manaus (AM). (SANTOS et al., 1999). Ambas as amostras aqui apresentadas diferem dos estudos já realizados pelo fato de pertencerem a populações predominantemente rurais, podendo, desta forma, refletir uma diferente composição genética. Os dados aqui apresentados mostram, no mínimo para tais populações rurais, que o perfil genético na Amazônia ocidental é diferente, sendo que a contribuição ameríndia é igual ou menor que a observada em Manaus, indicando um diferente padrão de colonização e migração.

Os polimorfismos que refletem efeito na resistência/susceptibilidade a malaria não mostraram discrepâncias significantes na mistura étnica, quando comparada com as médias estimadas, sugerindo que não há sinais de seleção.

Os resultados apresentados nas Tabelas 5 e 6 apóiam a hipótese da existência de um gene principal atuando na distribuição do número de malárias relatado pelos indivíduos amostrados das duas populações estudas. As evidências trazidas pela análise de segregação apóiam a busca de mecanismos genéticos atuando no acometimento pela malária.

A Tabela 7 traz o resultado da análise de associação entre marcadores clássicos e o número de episódios de malária corrigido por sexo e idade nas populações de Portuchuelo e Monte Negro e em ambas agrupadas. No ANEXO "The association of genetic markers and malaria infection in the Brazilian Western Amazonian region" dados similares são apresentados apenas para a população de Portuchuelo, com a diferença que nesse trabalho o fenótipo estudado não foi corrigido para sexo e idade. A análise de associação foi realizada utilizando apenas a geração parental de Monte Negro com resultados semelhantes (dados não apresentados).

$\mathrm{Na}$ Tabela 7 verificamos que foi encontrada associação entre o sistema sanguíneo ABO, que tem gene localizado no braço longo do cromossomo 9 (9q34.1-q34.2, 150cM) e o número de episódios de malaria na população de Monte Negro $(\mathrm{P}<0,001)$ e em ambas agrupadas $(\mathrm{P}=0,001)$ sem heterogeneidade significante $\left(\chi_{1}^{2}=3,464, P>0,05\right)$. Sabe-se que eritrócitos parasitados formam rosetas mais rapidamente quando os glóbulos vermelhos são dos tipos sanguíneos $\mathrm{A}, \mathrm{B}$ ou $\mathrm{AB}$ do que quando são do grupo $\mathrm{O}$ (UDOMSANGPETCH et al., 1989; CARLSON e WAHLGREN, 1992; BARRAGAN et al., 2000), e que, em Zimbábue, o grupo A foi associado com níveis baixos de hemoglobinas e malária grave, chegando ao coma (FISHER e BOONE, 1998). Alguns trabalhos porém, não encontraram associação entre o grupo sanguíneo ABO e malária (OSISANYIA, 1983; SINGH et al., 1986, 1995; BAYOUMI et al., 1986 e MONTOYA et al., 1994). No Brasil, Santos et al. (1983) 
detectaram a presença de associação entre o antígeno $\mathrm{B}$ e o número de episódios de malária. No presente estudo, indivíduos do tipo sanguíneo A apresentaram número de episódios relatados de malária maior que os indivíduos de outros grupos nas duas populações e em ambas agrupadas. Porém, em Portuchuelo, indivíduos do tipo $\mathrm{O}$ apresentaram o menor número de episódios relatados de malária (diferença não significativa), enquanto em Monte Negro os indivíduos do grupo B apresentaram o menor número. Essa heterogeneidade entre resultados de populações diferentes é conhecida, especialmente nos polimorfismos relacionados à citoaderência do plasmodium, como apresentado na introdução deste trabalho.

Entre os polimorfismos estudados, especial atenção foi dada ao sistema Duffy de grupos sanguíneos, que confere resistência à malária causada por $P$. vivax em indivíduos homozigotos $F y$-Fy-. A relação com o Duffy foi inclusive relatada em pacientes de Rondônia (CAVASINI, 2001). O fato de o fenótipo em estudo apresentar associação com indivíduos $F y$ Fy- em Portuchuelo $(P<0,05)$, Monte Negro $(P<0,01)$ e nas duas populações agrupadas $(P<0,001)$ sem heterogeneidade $(P>0,05)$ entre elas demonstra o potencial do número de episódios relatados de malária no estudo de mecanismos genéticos relacionados à malária.

Uma vez observada a associação com o sistema Duffy considerou-se que a indicação de gene principal apontada pela análise de segregação poderia ser causada por esse polimorfismo. Uma nova análise de segregação foi realizada, desta vez sem incluir os indivíduos $F y$-Fy-(Tabela 10). Apesar de algumas alterações nos resultados, a indicação de um gene principal atuando no fenótipo foi mantida, sugerindo então que, além do Duffy, outro gene atua na distribuição da variável.

As análises de ligação foram conduzidas utilizando tanto a variável número de episódios de malária sem tratamento estatístico (MAL) quanto o logaritmo desse fenótipo, corrigido para sexo e idade e ajustado à distribuição normal (MAL_LCA). Os resultados obtidos com a variável MAL devem ser avaliados com cautela, uma vez que o método de análise de ligação utilizado é sensível a desvios na distribuição normal (ALMASY e BLANGERO, 1998) e sem correção o número de episódios de malária apresentou distribuição leptocúrtica (Figura 4).

Diversos pontos da análise de ligação utilizando a variável MAL apresentaram lod score maior que 3. A posição desses pontos, delimitadas pela análise de dois pontos, e regiões delimitadas pela análise multiponto foram comparados com as posições em centimorgans do Quadro 1, em busca de regiões que pudessem ser coincidentes com posições de genes com conhecida associação com malária. 
Nas análises de ligação de dois pontos foram detectados, no cromossomo 1, lod score de 3,995 à 126 centimorgans (cM). O gene com associação à malária mais próximo é o Duffy, que fica a aproximadamente $167 \mathrm{cM}$ do início do cromossomo. Ainda no cromossomo 1 foi detectado um pico de lod score 3,856 à $275 \mathrm{cM}$. No cromossomo 5, foi detectado lod score de 4,003 à 98 cM.Essa região fica relativamente próxima a região do gene IL4 ( 136cM). No cromossomo 9 foi encontrado um pico de lod score 3,294 a 80cM sendo o gene que determina os grupos sanguíneos $\mathrm{ABO}$ o gene mais próximo $(\sim 150 \mathrm{cM})$ com relatos de associação a malária nesse cromossomo. No cromossomo 10 um lod score de 4,332 foi observado a 94cM. Na literatura, Timmann et al. (2007) sugeriu ligação a malária em uma população da zona rural de Gana no braço curto do cromossomo $10(\sim 12 \mathrm{cM})$, utilizando varredura genômica em 10.000 polimorfismos de nucleotídeos únicos (SNPs). No cromossomo 12 o lod score de 3,761 encontrado à $26 \mathrm{cM}$, o gene conhecido associado a malária mais próximo é o $I F N G$, à aproximadamente $77 \mathrm{cM}$ do início do cromossomo. No cromossomo 15 foi encontrado um pico de lod score 3,252 à $83 \mathrm{cM}$. Não há relatos de associação a malária no cromossomo 15. Por último, um lod score de 4,213 foi encontrado à $125 \mathrm{cM}$. Nesse cromossomo, o gene da talassemia, $H B A(1 \mathrm{cM})$, é conhecido por proteger os indivíduos de malária grave.

$\mathrm{Na}$ análise de ligação multiponto, além dos picos sobrepostos aos picos observados na analise de dois pontos, um lod score máximo de 3,84 $(56 \mathrm{cM})$ se estende de 50 à $60 \mathrm{cM}$ no braço curto do cromossomo 4, coincidindo com a posição do gene $N O S 2 A(\sim 50 \mathrm{cM})$. Entre os resultados obtidos utilizando o fenótipo MAL, apenas esse coincidiu com um gene que tem associação conhecido com malária.

Nas análises de ligação de dois pontos realizadas utilizando o logaritmo do número de episódios de malária corrigido (MAL_LCA) não foram encontrados lod scores sugestivos de ligação. Na análise multiponto do fenótipo MAL_LCA foi encontrado um pico de ligação no braço curto do cromossomo 4 , à cerca de $10 \mathrm{cM}$ do início do cromossomo. O lod score máximo observado foi de 2,777 , bem próximo do valor 3 , indicativo de ligação. Nessa região, delimitada por marcadores entre 0 e $40 \mathrm{cM}$ no cromossomo quatro, nenhum gene conhecido com associação a malária foi encontrado. Com base nesse resultado, e buscando encontrar um novo mecanismo genético de resistência a malária, 9 marcadores de microssatélites foram selecionados, aumentando assim a resolução da análise. Uma vez selecionados os microssatélites, um subconjunto de 480 indivíduos da população de Monte Negro foi selecionado. Esses indivíduos foram caracterizados e as análises de ligação foram conduzidas 
de forma semelhante as que foram feitas em Portuchuelo. Os resultados obtidos em Portuchuelo, porém, não foram confirmados nos dados da população de Monte Negro, uma vez que nenhum lod score sugestivo de ligação foi observado.

Em se tratando de mecanismos genéticos e doenças complexas diversas explicações podem ser dadas para a não reprodução dos resultados entre duas populações. Entre elas, os resultados falso-positivos, padrões epidemiológicos diferentes, diferenças entre os parasitas como ocorre especialmente nos polimorfismos relacionados à citoaderência e evasão do sistema imune e interação entre genes com alelos diferentes entre as populações entre outras. Um exemplo interessante e recente de interação entre genes atuando na variabilidade da resposta humana a malária mostra a epistase negativa entre a anemia falciforme e a $\alpha+$ talassemia (WILLIAMS et al., 2005).

A maioria dos genes relacionados a doenças infecciosas vieram de estudos de associação baseados em genes candidatos, porém novos resultados baseados em modelos animais e varredura genômica vêm sendo obtidos (HILL, 2006).

Atualmente, um dos maiores desafios nos estudos de varredura genômica, junto com os tamanhos amostrais, é o número de falso positivos e a conseqüente escolha do nível de significância a ser adotado em decorrência do grande número de testes utilizados (WANG et al., 2005). Estudos utilizando micro-arranjos de DNA, por exemplo, podem ter mais de um milhão de testes de associação. A abordagem utilizada neste trabalho, com coleta de dados similares entre duas populações diferentes e com padrões distintos permitiu que a evidência de ligação e associação obtidas em uma população pudesse ser testada e confirmada em outra, completamente independente da primeira. Os problemas relativos aos níveis significância, em testes múltiplos ficam assim resolvidos, sem o uso de correções altamente conservadoras, como por exemplo a correção de Bonferroni que muitas vezes leva a rejeição de resultados positivos verdadeiros (TODD, 2006).

A investigação de genes relacionados a doenças complexas é hoje um dos grandes desafios da genética (MORTON, 2008). As informações acerca dos genes humanos e suas funções (VENTER et al., 2001; LANDER et al., 2001), bem como sobre a variabilidade entre indivíduos e populações (THE INTERNATIONAL HAPMAP CONSORTIUM, 2007) estão crescendo em ritmo nunca antes visto. Novas tecnologias de seqüenciamento, que aumentam a velocidade de obtenção e a qualidade dos dados, bem como as tecnologias relacionadas ao estudo da variabilidade populacional com coberturas cada vez mais completas do genoma permitem hoje que, por exemplo, o genoma de um indivíduo seja completamente desvendado 
(LEVY et al., 2007) ou que milhões de polimorfismo de um indivíduo sejam estudados em dois ou três dias com custos inferiores a US\$500,00.

Apesar dos resultados obtidos em Portuchuelo não terem sido confirmados em Monte Negro, os mesmos não devem ser desprezados. O braço curto do cromossomo 4 fica sinalizado como possível região do genoma humano relacionado à resistência ou susceptibilidade a malária. Nesse contexto, fica aqui a sugestão de que as amostras aqui estudadas com cobertura de uma centena de microssatélites no caso da amostra de Portuchuelo e uma pequena porção do cromossomo 4 na amostra de Monte Negro sejam investigadas com novas técnicas de ampla cobertura do genoma. 


\section{CONCLUSÕES}

É importante enfatizar que o caráter oligo-endêmico da transmissão de malária na Amazônia, e particularmente em Rondônia, é muito diferente do observado em áreas hiper endêmicas africanas e asiáticas freqüentemente estudadas do ponto de vista da epidemiologia genética. O estudo das populações de Portuchuelo e Monte Negro, com padrão epidemiológico específico, relacionado em parte com a baixa densidade populacional na região, torna o trabalho diferente dos que vem sendo realizados por outros grupos que trabalham nessa área de pesquisa.

O estudo realizado demonstrou a utilidade do fenótipo número de episódios de malária na epidemiologia genética da doença.

A análise de segregação é uma ferramenta da epidemiologia genética que permite investigar o potencial de um fenótipo trazer informações acerca dos genes que determinam sua distribuição, evitando assim que esforço desnecessário seja desprendido em uma característica que não tenha evidências de ter sua distribuição determinada, ao menos parcialmente, por genes de efeito importante. As análises de segregação realizadas indicaram que a distribuição do número de episódios de malária relatado pelos indivíduos amostrados condiz com a distribuição esperada em características determinadas geneticamente.

A associação do fenótipo com o grupo sanguíneo ABO na população de Monte Negro e Duffy nas duas populações e em ambas agrupadas serviram como um tipo de controle positivo. Essas observações são, juntamente com os resultados da análise de segregação, fortes indícios do poder da característica estudada de trazer novas descobertas sobre os mecanismo genéticos relacionados ao acometimento de malária.

As vantagens do uso de um fenótipo retrospectivo como o utilizado aqui são várias e implicam diretamente na redução de custos do projeto e do tempo de obtenção da amostra, quando comparadas a estratégias baseadas em acompanhamento dos casos por longos períodos ou então realização de exames que eventualmente podem ser parte significante dos custos de uma pesquisa.

Os resultados obtidos em Portuchuelo, mesmo não sendo confirmados em Monte Negro, não devem ser desprezados. Fica aqui a sugestão do braço curto do cromossomo quatro ser uma nova região do genoma humano relacionada à resistência ou susceptibilidade a malária. 
O desafio de elucidar os mecanismos genéticos relacionados à malária segue. Considerando as novas tecnologias de genotipagem que chegam ao mercado em ritmo acelerado, novas estratégias de estudo podem ser traçadas. Nesse contexto, fica aqui a sugestão de que as amostras aqui estudadas com cobertura de uma centena de microssatélites no caso da amostra de Portuchuelo e uma pequena porção do cromossomo 4 na amostra de Monte Negro sejam investigadas com novas técnicas de ampla cobertura do genoma. 


\section{REFERÊNCIAS}

AKAIKE, H. A new look at statistical model identification. IEEE Trans. Automat. Contr., v. 19, p. 716-722, 1974.

ALBRECHT, L.; MERINO, E. F.; HOFFMANN, E. H.; FERREIRA, M. U.; FERREIRA, R. G. M.; OSAKABE, A. L.; DALLA MARTHA, R. C.; RAMHARTER, M.; DURHAM, A. M.; FERREIRA, J. E.; DEL PORTILLO, H. A.; WUNDERLICH, G. Extense variant gene family repertoire overlap in Western Amazon Plasmodium falciparum isolates. Mol Biochem Parasitol., v.150, p.157-165, 2006.

ALlEN, S. J.; O'DONNELl, A.; ALEXANDER, N. D.; MGONE, C. S.; PETO, T. E.; CLEGG, J. B.; ALPERS, M. P.; WEATHERALL, D. J. Prevention of cerebral malaria in children in Papua New Guinea by southeast Asian ovalocytosis band 3. Am. J. Trop. Med. Hyg., v. 60, p. 1056-1060, 1999.

ALLISON, A. C. Protection afforded by syckle-cell trait against subtertian malarial infection., Br. Med. J., p.153-163, 1954.

ALMASY, L.; BLANGERO, J. Multipoint quantitative trait linkage analysis in general pedigrees. Am. J. Hum. Genet., v. 62, p. 1198-1211, 1998.

ARPINI-SAMPAIO, Z.; COSTA, M. C.; MELO, A. A.; CARVALHO, M. F.; DEUS, M. S.; SIMÕES, A. L. Genetic polymorphisms and ethnic admixture in African-derived black communities of northeastern Brazil. Hum. Biol., v. 71, p. 69-85, 1999.

BEIGUELMAN, B.; ALVES, F. P.; MOURA, M. M.; ENGRACIA, V.; NUNES, A. C. S.; HECKMANN, M. I. O.; FERREIRA, R. G. M.; PEREIRA, DA SILVA, L. H.; CAMARGO, E. P.; KRIEGER, H. The association of genetic markers and malaria infection in the Brazilian Western Amazonian region. Mem. Inst. Oswaldo Cruz, v. 98, p. 455-460, 2003.

BARRAGAN, A.; KREMSNER, P.G.; WAHLGREN, M.; CARLSON, J. Blood group A antigen is a co-receptor in Plasmodium falciparum rosetting. Infect. Immun., v. 68, p. 2971$2975,2000$.

*ASSOCIAÇÃO BRASILEIRA DE NORMAS TÉCNICAS. NBR 6023: Informação e documentação: referências: elaboração. Rio de Janeiro, 2002. 
BAYOUMI, R.A.; BASHIR, A.H.; ABDULHADI, N.H. Resistance to falciparum malaria among adults in central Sudan. Am. J. Trop. Med. Hyg., v. 35, p. 45-55, 1986.

BELLAMY, R. J.; HILL, A. V. Host genetic susceptibility to human tuberculosis. Novartis Found. Symp., v. 217, p. 3-13, 1998.

BROWN, I. N.; GLYIN, A. A.; PLANT, J. Inbred mouse strain resistance to Mycobacterium leprae murium follows the Ity/Lsh pattern. Immunology, v. 47, p. 149-156, 1982.

CABELLO, P. H.; KRIEGER, H. Genioc: Sistema de Análise de Dados de Genética. Rio de Janeiro: Instituto Oswaldo Cruz, 1997. 139 p.

CAMARGO, L. M. A.; MOURA, M. M.; ENGRACIA, V.; PAGOTTO, R. C.; BASANO, S. A.; PEREIRA DA SILVA, L. H.; CAMARGO, E. P.; BEIGUELMAN, B. \& KRIEGER, H. A rural community in a Brazilian western Amazonia region: some demographic and epidemiological patterns. Mem. Instit. Oswaldo Cruz, v. 97, p. 193-195, 2002.

CAMARGO, L. M. A.; NORONHA, E.; SALCEDO, J. M. V.; DUTRA, A. P.; KRIEGER, H.; HILDEBRANDO PEREIRA DA SILVA. L.; PLESSMANN CAMARGO, E. The epidemiology of malaria in Rondonia (Western Amazon region, Brazil): Study of a riverine population. Acta trop., v. 72, p. 1-11, 1999.

CAMARGO, L. M.; DAL COLLETTO, G. M.; FERREIRA, M. U.; GURGEL, S. D. E. M.; ESCOBAR, A. L.; MARQUES, A.; KRIEGER, H.; CAMARGO, E. P.; DA SILVA, L. H. Hypoendemic malaria in Rondonia (Brazil, western Amazon region): seasonal variation and risk groups in an urban locality. Am. J. Trop. Med. Hyg., v. 55, p. 32-38, 1996.

CAMARGO, L. M.; FERREIRA, M. U.; KRIEGER, H.; DE CAMARGO, E. P.; DA SILVA, L. P. Unstable hypoendemic malaria in Rondonia (western Amazon region, Brazil): epidemic outbreaks and work-associated incidence in an agro-industrial rural settlement. Am. J. Trop. Med. Hyg., v. 51, p. 16-25, 1994.

CAMPINO, S.; KWIATKOWSKI, D.; DESSEIN, A.Mendelian and complex genetics of susceptibility and resistance to parasitic infections. Semin. Immunol., v. 18, p. 411-422, 2006.

CARLSON, J.; WAHLGREN, M. Plasmodium falciparum erythrocyte rosetting is mediated by promiscuous lectin-like interactions. J. Exp. Med., v. 176, p. 1311-1317, 1992. 
CARTER, R.; MENDIS, K. N. Evolutionary and Historical Aspects of the Burden of Malaria. Clin. Microbiol. Rev., v. 15, p. 564-594, 2002.

CATTANI, J. A.; GIBSON, F. D.; ALPERS, M. P.; CRANE, G. G. Hereditary ovalocytosis and reduced susceptibility to malaria in Papua New Guinea. Trans. R. Soc. Trop. Med. Hyg., v. 81, p. 705-709, 1987.

CAVASINI, C. E.; DE MATTOS, L. C.; COUTO, A. A.; COUTO, V. S.; GOLLINO, Y.; MORETTI, L. J.; BONINI-DOMINGOS, C. R.; ROSSIT, A. R.; CASTILHO, L.; MACHADO, R. L. Duffy blood group gene polymorphisms among malaria vivax patients in four areas of the Brazilian Amazon region. Malar. J., v. 6, p. 166-167, 2007a.

CAVASINI, C. E.; MATTOS, L. C.; COUTO, A. A.; BONINI-DOMINGOS, C. R.; VALENCIA, S. H.; NEIRAS, W. C.; ALVES, R. T.; ROSSIT, A. R.; CASTILHO, L.; MACHADO, R. L. Plasmodium vivax infection among Duffy antigen-negative individuals from the Brazilian Amazon region: an exception? Trans. R. Soc. Trop. Med. Hyg., v. 101, p. 1042-1044, 2007b.

CAVASINI, C. E.; DE MATTOS, L. C.; AlVES, R. T.; COUTO, A. A.; CALVOSA, V. S.; DOMINGOS, C. R.; CASTILHO, L.; ROSSIT, A. R.; MACHADO, R. L. Frequencies of ABO, MNSs, and Duffy phenotypes among blood donors and malaria patients from four Brazilian Amazon areas. Hum. Biol., v. 2, p. 215-219, 2006.

CAVASINI, C. E.; PEREIRA, F. J. T.; RIBEIRO, W. L.; WUNDERLICH, G.; FERREIRA, M. U. Duffy blood group genotypes among malaria patients in Rondônia, Western Brazilian Amazon. Rev. Soc. Bras. Med. Trop., v. 34, p. 591-595, 2001.

CHITNIS, C.; MILLER, L. H. Identification of the erythrocyte binding domains of Plasmodium vivax and Plasmodium knowlesi proteins involved in erythrocyte invasion. $\mathbf{J}$. Exp. Med., v. 180, p. 497-506, 1994.

CLARK, I. A.; AL-YAMAN, F. M.; COWDEN, W. B.; ROCKETT, K. A. Does malarial tolerance, through nitric oxide, explain the low incidence of autoimmune disease in tropical Africa? Lancet, v. 248, p-1492-1494, 1996.

COLAUTO, E. M.; BARRAVIERA, B.; MEIRA, D. A.; MATSUBARA, L. S.; PELLEGRINO, J. J.; MACHADO, P. E.; SOGAYAR, R.; BARBOZA, A. F.; SILVA, E. A.; COLAUTO, R.; PIROLLA, J. A.; MENDES, R. P. Malaria in the municipality of Humaitá, State of Amazonas. XII - Incidence of erythrocyte resistance factors in the general population and in patients: hemoglobin S and Duffy blood system. Rev. Inst. Med. Trop., v. 23, p. 7278, 1981. 
COURA, J. R.; SUÁREZ-MUTIS, M.; LADEIA-ANDRADE, S. A new challenge for malaria control in Brazil: asymptomatic Plasmodium infection--a review. Mem. Inst. Oswaldo Cruz, v. 101, p. 229-237, 2006.

COX-SINGH, J.; DAVIS, T. M.; LEE, K. S.; SHAMSUL, S. S.; MATUSOP, A.; RATNAM, S.; RAHMAN, H. A.; CONWAY, D. J.; SINGH, B. Plasmodium knowlesi malaria in humans is widely distributed and potentially life threatening. Clin. Infect. Dis., v. 46, p. 165-171, 2008.

CROCKER, P. R.; BLACKWELL, J. M.; BRADLEY, D. J. Expression of the natural resistance gene Lsh in resident liver macrophages. Infect. Immun. v. 43, p. 1033-1040, 1984.

CUNHA, A. X.; MORAIS, M .H. X. Os grupos sanguineos dos portugueses. Grupos KellCellano, Duffy e MNSs. Contr. Antropol. Port., v. 8, p. 5-15, 1966.

DALlA MARTHA, R. C.; TADA, M. S.; FERREIRA, R. G.; DA SILVA, L. H.; WUNDERLICH, G. Microsatellite characterization of Plasmodium falciparum from symptomatic and non-symptomatic infections from the Western Amazon reveals the existence of non-symptomatic infection-associated genotypes. Mem. Inst. Oswaldo Cruz, v. 102, p. 293-298, 2007.

ELAGIB, A. A.; KIDER, A. O.; AKERSTRÖM, B.; ELBASHIR, M. I. Association of the haptoglobin phenotype (1-1) with falciparum malaria in Sudan. Trans. R. Soc. Trop. Med. Hyg., v. 92, p. 309-311, 1998.

ELSTON, R. C.; STWEART, J. A general model for the genetic analysis of pedigree data. Hum. Hered., v. 21, p. 523-542, 1971.

FISCHER, P.R. e BOONE, P. Severe malaria associated with blood group. Am. J. Trop. Med. Hyg., v. 58, p. 122-123, 1998.

FOO, L. C.; REKHRAJ, V.; CHIANG, G. L.; MAK, J. W. Ovalocytosis protects against severe malaria parasitemia in the Malayan aborigines. Am. J. Trop. Med. Hyg., v. 47, p. 271-275, 1992.

FRANCO, M. H. L. P.; WEIMER, T. A.; SALZANO, F. M. Blood polymorphisms and racial admixture in two Brazilian populations. Am. J. Phys. Anthropol., v. 58 p. 127-132, 1982. 
GENTON, B.; AL-YAMAN, F.; MGONE, C. S.; ALEXANDER, N.; PANIU, M. M.; ALPERS, M. P.; MOKELA, D. Ovalocytosis and cerebral malaria. Nature, v. 378, p. 564$565,1995$.

GILLES, H. M.; FLETCHER, K. A.; HENDRICKSE, R. G.; LINDNER, R.; REDDY, S.; ALLAN, N. Glucose-6-phosphate-dehydrogenase deficiency, sickling, and malaria in African children in South Western Nigeria. Lancet, v. 1, p. 138-140, 1967.

GROS, P.; SKAMENE, E.; FORGET, A. Genetic control of natural resistance to Mycobacterium bovis (BCG) in mice. J. Immunol., v. 6, p. 2417-2421, 1981.

HADLEY, T. J.; KLOTZ, F. W.; PASVOL, G.; HAYNES, J. D.; MCGINNISS, M. H.; OKUBO, Y.; MILLER, L. H. Falciparum malaria parasites invade erythrocytes that lack glycophorin $\mathrm{A}$ and $\mathrm{B}(\mathrm{MkMk})$. Strain differences indicate receptor heterogeneity and two pathways for invasion. J. Clin. Invest., v. 80, p. 1190-1193, 1987.

HALDANE, J. B. S. Disease and evolution. Roma: Ric. Sci. Suppl., 1949, A. 19, p. 68-76.

HIGUCHI, R. Simple and rapid preparation of samples for PCR. PCR technology principles and applications for DNA amplification, New York: Stockton, 1989, p. 36.

HILL, A. V. S. Aspects of genetic suscetibility to human infectious diseases. Annu. Rev. Genet., v. 40, p. 469-486, 2006.

HILL, A. V. S. Genetics and Genomics of infectious disease susceptibility. Br. Med. Bull., v. 55, p. 401-413, 1999.

HILL, A. V. S. The immunogenetics of human infectious diseases. Annu. Rev. Immunol., v. 16, p. 593-617, 1998.

IMRIE, H.; FERGUSON, D. J.; CARTER, M.; DRAIN, J.; SCHIFLETT, A.; HAJDUK, S. L.; DAY, K. P. Light and electron microscopical observations of the effects of high-density lipoprotein on growth of Plasmodium falciparum in vitro. Parasitology, v. 128, p. 577-584, 2004.

KRIEGER, H. K.; MORTON, N. E.; M, M. P.; AZEVEDO, E.; FREIRE-MAIA, A. AND YASUDA, N. Racial Admixture in North-Eastern Brazil. Ann. Hum. Genet., v. 29 p. 113$125,1965$. 
KRIEGER, H.; FEITOSA, M. F. Genetic epidemiology of infectious disease. J. Braz. Assoc. Adv. Sci., v. 51, p.191-198, 1999.

KÜHNL, P.; SCHWABENLAND, R.; SPIELMANN, W. Investigations on the polymorphism of glyoxalase I (EC 4.4.1.5) in the population of Hessen, Germany. Hum. Genet., v. 38, p. 99-106, 1977.

KWIATKOWSKI D. P. How malaria has affected the human genome and what human genetics can teach us about malaria. Am. J. Hum. Genet., v. 77, p. 171-192, 2005.

LALOUEL, J. M.; RAO, D. C.; MORTON, N. E.; ELSTON, R. C. A unified model for complex segregation analysis. Am. J. Hum. Genet., v. 35, p. 816-826, 1983.

LANDER, E. S.; et al. International Human Genome Sequencing Consortium. Initial sequencing and analysis of the human genome. Nature, v. 409, p. 860-921, 2001.

LESSA, A. A individualidade biologica do sangue. Portugal: Livraria Luso-Espanhola, 1970.

LEVY, G.; et al. The Diploid Genome Sequence of an Individual Human. PLoS Biol., v. 5, p. e254, 2007.

MARSHFIELD CLINIC RESEARCH FOUNDATION. Mammalian Genotyping Service. Disponível em: $<\mathrm{http}: / /$ :research.marshfieldclinic.org/genetics/GeneticResearch/ screeningsets .asp?page $=$ screeningsets $>$. Acesso em: 21 mar. 2007.

MILLER, L. H.; BARUCH, D. I.; MARSH, K.; DOUMBO, O. K. The pathogenic basis of malaria. Nature, v.415(6872), p. 673-679, 2002.

MILLER, L. H.; MASON, S. J.; CLYDE ,D. F.; MCGINNISS, M. H. The resistance factor to Plasmodium vivax in blacks. The Duffy-blood-group genotype, FyFy. N. Engl. J. Med., v. 295, p. 302-304, 1976.

MONTOYA, F.; RESTREPO, M.; MONTOYA, A.E.; ROJAS, W. Blood groups and malaria. Rev. Inst. Med. Trop. Sao Paulo, v. 36, p. 33-38, 1994.

MORTON, N.E. Into the post-HapMap era. Adv. Genet., v.60, p.727-742, 2008. 
MORTON, N. E.; MACLEAN, C. J. Analysis of family resemblance. III Complex segregation analysis of quantitative traits. Am. J. Hum. Genet., v. 26, p. 489-503, 1974.

MOURANT, A.; KOPEC, A.; DOMANIEWSKA-SOBCZAK, K. The Distribution of the Human Blood Groups and Other Polymorphisms. London: Oxford Press, 1976.

NEVES, D. P.; MELO, A. L.; LINARDI, P. M. Parasitologia Humana. 10. ed. São Paulo: Atheneu, 2000.

OSISANYIA, J.O. ABO blood groups and infections with human malarial parasites in vivo and in vitro. East. Afr. Med. J., v. 60, p. 616-621, 1983.

PARASOL, N.; REID, M.; RIOS, M.; CASTILHO, L.; HARARI, I.; KOSOWER, N. S. A novel mutation in the coding sequence of the $\mathrm{FY}^{*} \mathrm{~B}$ allele of the Duffy chemokine receptor gene is associated with an altered erythrocyte phenotype. Blood, v. 92, p. 2237-2243, 1998.

PASVOL, G.; WEATHERALL, D. J.; WILSON, R. J. Cellular mechanism for the protective effect of haemoglobin S against P.falciparum malaria. Nature, v. 274, p. 5672-5701, 1978.

PATTANAPANYASAT, K.; YONGVANITCHIT, K.; TONGTAWE, P.; TACHAVANICH, K.; WANACHIWANAWIN, W.; FUCHAROEN, S.; WALSH, D. S. Impairment of Plasmodium falciparum growth in thalassemic red blood cells: further evidence by using biotin labeling and flow cytometry. Blood, v. 93, p. 3116-3119, 1999.

PAULING, L. The structure of antibodies and the nature of serological reaction. Chimia (Aarau), v. 3, p. 63-66, 1949.

QUAYE, I. K.; EKUBAN, F. A.; GOKA, B. Q.; ADABA YERI, V.; KURTZHALS, J. A.; GYAN, B.; ANKRAH, N. A.; HVIID, L.; AKANMORI, B. D. Haptoglobin 1-1 is associated with susceptibility to severe Plasmodium falciparum malaria. Trans. R. Soc. Trop. Méd. Hyg., v. 94, p. 216-219, 2000.

REY, L. Parasitologia. 3. ed. Rio de Janeiro: Guanabara Koogan, 2001.

SAlZANO, F. M.; WEIMER, T. A.; FRANCO, M. H. L. P. et al. Protein genetic studies among the TupiMonde Indians of the Brazilian Amazonia. Am. J. Hum. Biol., v. 10, p. 711 $722,1998$. 
SANS, M. Admixture studies in Latin America: from the 20th to the 21st century. Hum. Biol., v. 72, p. 155-177, 2000.

SANTOS, R. V.; COIMBRA, C. E. JR. Hardships of contact: enamel hypoplasias in TupíMondé Amerindians from the Brazilian Amazonia. Am. J. Phys. Anthropol., v. 109, p. 111$127,1999$.

SANTOS, S. E. B.; SALZANO, F. M.; FRANCO, M. H. L. P.; FREITAS, M. J. M. Mobility, genetic markers, susceptibility to malaria and race mixture in Manaus, Brazil. J. Hum. Evol., v. 12, p. 373-381, 1983.

SHEAR, H. L.; ROTH, E. F. JR.; FABRY, M. E.; COSTANTINI, F. D.; PACHNIS, A, HOOD, A.; NAGEL, R. L. Transgenic mice expressing human sickle hemoglobin are partially resistant to rodent malaria. Blood, v. 81, p. 222-226, 1993.

SILVA, L. H. P. Hypoendemic malaria in Rondonia (Brazil, Western Amazon Region): Seazonal variation and risk groups in a urban locality. Am. J. Trop. Med. Hyg., v. 55, p. 3238, 1996.

SINGH, N.; SHUKLA, M.M.; UNIYAL, V.P.; SHARMA, V.P. ABO blood groups among malaria cases from district Mandla, Madhya Pradesh. Indian J. Malariol., v. 32, p. 59-63, 1995.

SINGH, I.P.; WALTER, H.; BHASIN, M.K.; BHARDWAJ, V.; SUDHAKAR, K. Genetic markers and malaria. Observations in Gujarat, India. Hum. Hered., v. 36, p. 31-36, 1986.

SMITH, J. D.; CHITNIS, C. E.; CRAIG, A. G.; ROBERTS, D. J.; HUDSON-TAYLOR, D. E.; PETERSON, D. S.;PINCHES, R.; NEWBOLD, C. I.; MILLER, L. H. Switches in expression of Plasmodium falciparum var genes correlate with changes in antigenic and cytoadherent phenotypes of infected erythrocytes. Cell, v.82, p.101-110, 1995.

SMITH, I. Chromatographic and electrophoretic techniques. London: William Heinemann, 1968.

SOBEL, E.; LANGE, K. Descent graphs in pedigree analysis: applications to haplotyping, location scores, and marker sharing statistics. Am. J. Hum. Genet., v. 58, p.1323-1337, 1996.

SOBEL, E.; PAPP, J. C.; LANGE, K. Detection and integration of genotyping errors in statistical genetics. Am. J. Hum. Genet., v. 70, p. 496-508, 2002. 
SOBEL, E.; SENGUL, H.; WEEKS, D. E. Multipoint estimation of identity-by-descent probabilities at arbitrary positions among marker loci on general pedigrees. Hum. Hered., v. 52, p. 121-131, 2001.

SOUSA, T.N.; CERÁVOLO, I.P.; FERNANDES FONTES, C.J; COUTO, A.; CARVALHO, L.H.; BRITO, C.F. The pattern of major polymorphisms in the Duffy binding protein ligand domain among Plasmodium vivax isolates from the Brazilian Amazon area. Mol. Biochem. Parasitol., v. 146, p. 251-254, 2006.

THE INTERNATIONAL HAPMAP CONSORTIUM. A second generation human haplotype map of over 3.1 million SNPs. Nature, v.449, p. 851-861, 2007.

TIMMANN, C.; EVANS, J.A.; KÖNIG, I.R.; KLEENSANG, A.; RÜSCHENDORF, F.; LENZEN, J.; SIEVERTSEN, J.; BECKER, C.; ENUAMEH, Y.; KWAKYE, K.O.; OPOKU, E.; BROWNE, E.N.; ZIEGLER, A.; NÜRNBERG, P.; HORSTMANN, R.D. Genome-wide linkage analysis of malaria infection intensity and mild disease. PLoS Genet., v. 3, p. e48, 2007.

TODD, J.A. Statistical false positive or true disease pathway? Nat. Genet., v. 38, p. 731-733, 2006.

UDOMSANGPETCH, R.; CARLSSON, J.; WÅHLIN, B.; HOLMQUIST, G.; OZAKI, L. S.; SCHERF, A.; MATTEI, D.; MERCEREAU-PUIJALON, O.; UNI, S.; AIKAWA, M. Reactivity of the human monoclonal antibody $33 \mathrm{G} 2$ with repeated sequences of three distinct Plasmodium falciparum antigens. J. Immunol., v. 142, p. 3620-3626, 1989.

USSUI, C. A.; DUTRA, A. P. Malária. Superintendência de Controle de Endemias do Estado de São Paulo, 2001. Disponível em: <http://www.sucen.sp.gov.br/doenças/ malaria/texto_malaria_pro.htm>. Acesso em: $11 \mathrm{dez} 2007$.

VENTER, J. C. et al. The sequence of the human genome. Science, v.291, p.1304-1351, 2001 .

WANG, S.; RAY, N.; ROJAS, W.; PARRA, M. V.; BEDOYA, G.; GALLO, C.; POLETTI, G.; MAZZOTTI, G. HILL, K.; HURTADO,A. M.; CAMRENA, B.; NICOLINI, H.; KLITZ, W.; BARRANTES, R.; MOLINA, J. A.; FREIMER, N. B.; BORTOLINI, M. C.; SALZANO, F. M.; PETZL-ERLER, M. L.; TSUNETO, L. T.; DIPIERRI, J. E.; ALFARO, E. M.; BAILLIET, G.; BIANCHI, N. O.; LLOP, E.; ROTHHAMMER, F.; EXCOFFIER, L.; RUIZLINARES, A. Geographic Patterns of Genome Admixture in Latin American Mestizos. PLoS Genet., v. 4, e1000037, 2008. 
WANG, S.; LEWIS, C. M.; JAKOBSSON, M. JR.; RAMACHANDRAN, S.; RAY, N.; BEDOYA, G.; ROJAS, W.; PARRA, M. V.; MOLINA, J. A.; GALLO, C.; MAZZOTTI, G.; POLETTI, G.; HILL, K.; HURTADO, A. M.; LABUDA, D.; KLITZ, W.; BARRANTES, R.; BORTOLINI, M. C.; SALZANO, F. M.; PETZL-ERLER, M. L.; TSUNETO, L. T.; LLOP, E.; ROTHHAMMER, F.; EXCOFFIER, L.; FELDMAN, M. W.; ROSENBERG, N. A.; RUIZ-LINARES, A. Genetic Variation and Population Structure in Native Americans. PLoS Genet., v.3, p:e185, 2007.

WANG, W.Y.; BARRATT, B.J.; CLAYTON, D.G.; TODD, J.A. Genome-wide association studies: theoretical and practical concerns. Nat. Rev. Genet., v. 6, p. 109-118, 2005.

WANG, L.; CROUCH, L.; RICHIE, T. L.; NHAN, D. H.; COPPEL, R. L. Naturally acquired antibody responses to the components of the Plasmodium falciparum merozoite surface protein 1 complex. Parasite Immunol., v. 25, p. 403-412, 2003.

WILLIAMS, T. N.; MWANGI, T. W.; WAMBUA, S.; PETO, T. E.; WEATHERALL, D. J.; GUPTA, S.; RECKER, M.; PENMAN, B. S.; UYOGA, S.; MACHARIA, A.; MWACHARO, J. K.; SNOW, R. W.; MARSH, K. Negative epistasis between the malaria-protective effects of alpha+-thalassemia and the sickle cell trait. Nat. Genet., v. 37, p. 1253-1257, 2005.

WILLIAMS, T. N.; WEATHERALL, D. J.; NEWBOLD, C. I. The membrane characteristics of Plasmodium falciparum-infected and -uninfected heterozygous alpha(0)thalassaemic erythrocytes. Br. J. Haematol., v. 118, p. 663-670, 2002.

WORLD HEALTH ORGANIZATION e THE UNITED NATIONS CHILDREN'S FUND. World Malaria Report 2005. Disponível em: $<$ http://www.rbm.who.int/ wmr2005/pdf/adv_e.pdf>. Acesso em: 11 dez. 2006. 


\section{ANEXO}

Trabalhos publicados

BEIGUELMAN, B.; ALVES, F. P.; MOURA, M. M.; ENGRACIA, V; NUNES, A. C.; HECKMANN, M. I.;, FERREIRA, R. G. M.; SILVA, L.H.; CAMARGO, E.P.; KRIEGER, $\mathrm{H}$. The association of genetic markers and malaria infection in the Brazilian Western Amazonian region. Mem. Inst. Oswaldo Cruz, v. 98, p. 455-460, 2003.

FERREIRA, R. G. M.; MOURA, M. M.; ENGRACIA, V.; PAGOTTO, R. C.; ALVES, F. P.; CAMARGO, L.M.; SILVA, L.H.; CAMARGO, E.P.; BEIGUELMAN, B.; KRIEGER, H. Ethnic admixture composition of two western Amazonian populations. Hum. Biol., v. 74, p. 607-614, 2002.

PROSDOCIMI, F.; CERQUEIRA, G. C.; BINNECK, E.; SILVA, A. F.; REIS, A. N.; JUNQUEIRA, A. C. M.; SANTOS, A. C. F.; NHANI JÚNIOR, A.; WUST, C. I.; CAMARGO FILHO, F.; KESSEDJIAN, J. L.; PETRETSKI, J. H.; CAMARGO, L. P.; FERREIRA, R. G. M.; LIMA, R. P.; PEREIRA, R. M.; JARDIM, S.; SAMPAIO, V. S.; FOLGUERAS-FLATSCHART, Á. V. Bioinformática: Manual do Usuário. Um guia básico e amplo sobre os diversos aspectos dessa nova ciência. Biotecnologia, v. 5, p. 12-25, 2002.

FERREIRA, R. G. M.; KAWAMATA, C. E. M.; KRIEGER, H. Diagnóstico e Tratamento.

Capítulo: 4. Genes em indivíduos e famílias, v. 3, p. 217-225. Ed. Manole. 


\title{
The Association of Genetic Markers and Malaria Infection in the Brazilian Western Amazonian Region
}

\author{
B Beiguelman, FP Alves, MM Moura*/**, V Engracia****, ACS Nunes*, MIO Heckmann*, \\ RGM Ferreira, LH Pereira da Silva*, EP Camargo, H Krieger ${ }^{+}$
}

Departamento de Parasitologia, Instituto de Ciências Biomédicas, Universidade de São Paulo, Av. Lineu Prestes 1374, 05508-900 São Paulo, SP, Brasil *Centro de Pesquisas em Doenças Tropicais, Porto Velho, RO, Brasil **Universidade Federal de Rondônia, Porto Velho, RO, Brasil

\begin{abstract}
Almost all individuals (182) belonging to an Amazonian riverine population (Portuchuelo, RO, Brazil) were investigated for ascertaining data on epidemiological aspects of malaria. Thirteen genetic blood polymorphisms were investigated (ABO, MNSs, Rh, Kell, and Duffy systems, haptoglobins, hemoglobins, and the enzymes glucose-6phosphate dehydrogenase, glyoxalase, phosphoglucomutase, carbonic anhydrase, red cell acid phosphatase, and esterase D). The results indicated that the Duffy system is associated with susceptibility to malaria, as observed in other endemic areas. Moreover, suggestions also arose indicating that the EsD and Rh loci may be significantly associated with resistance to malaria. If statistical type II errors and sample stratification could be ruled out, hypotheses on the existence of a causal mechanism or an unknown closely linked locus involved in susceptibility to malaria infection may explain the present findings.
\end{abstract}

Key words: malaria - genetic markers - association studies - Western Amazonia - Rondônia - Brazil

Malaria, an infectious disease caused by an intra-cellular erythrocyte parasite (Plasmodium sp.), has significant associations with several red blood cell polymorphisms (hemoglobin, glucose-6-phosphate dehydrogenase, ABO and Duffy systems) detected in populations who are or were living under hyper-endemic conditions in the Old World (Allison 1954a,b, Vandepitte \& Delaisse 1957, Motulsky 1960, 1964, Siniscalco et al. 1961, Miller et al. 1976, Santos et al. 1983, Udomsangpetch et al. 1989, 1993, Carlson \& Wahlgren 1992, Barragan et al. 2000). The Amazon region, characterized by an hypo-endemic pattern of infection, due mainly to its low demographic index, provides an excellent field to test hypotheses on the generalization of these associations, as well as to investigate the existence of other associations due to either different mechanisms or to linkage disequilibria between genetic markers and genes involved with susceptibility/resistance to Plasmodium infection.

The present study is part of a large scientific project aimed to investigate the biological characteristics of some infectious diseases in the Western Amazon region of Brazil (Camargo et al. 1994, 1996, 1999) in which the association of some blood polymorphisms with two traits involved with the malaria infection is tested. Exception made to

Supported by Fundação de Amparo à Pesquisa do Estado de São Paulo (Fapesp), Conselho Nacional de Desenvolvimento Científico e Tecnológico (CNPq), Financiadora de Estudos e Projetos (Finep), Programa de Apoio aos Núcleos de Excelência (Pronex) and Fundação Nacional de Saúde.

${ }^{+}$Corresponding author. Fax: +55-11-3091.7417. E-mail: hkrieger@icb.usp.br

Received 4 December 2002

Accepted 14 March 2003 haptoglobin, which has an important role as hemoglobin carrier, the investigated genetic markers are red blood cell polymorphisms, since erythrocytes are the ultimate target cells of the malarial parasite.

\section{MATERIALS AND METHODS}

A blood sample was collected from each of 182 individuals, practically the whole population living in Portuchuelo, a riverine settlement in the state of Rondônia, Brazil (Figure), right bank of the Madeira river ( $8^{\circ} 37^{\prime} \mathrm{S}$, $63^{\circ} 49^{\prime} \mathrm{W}$ ) that can be reached by boat throughout the year, and also by road during the dry season (from May to September). All individuals were clinically examined, malaria being diagnosed by light microscopy and by nested polymerase chain reaction (PCR) assay. The clinical examination included a detailed anamnesis with emphasis on past exposure to malaria. The same information was given by the parents of children unable to answer satisfactorily. This research was approved by the "Medical Board of the State of Rondônia, Brazil", and an informed consent was obtained from all adults, as well as from the parents or legal guardians of minors who participated in the present study.

The community of Portuchuelo is composed by descendants of the 19th and beginning of the 20th century European settlers, with a heavy admixture with the Amerindians who lived in this part of the Madeira region. During the "rubber boom" and the construction of the Madeira-Mamoré railroad, an African contribution to the gene pool of Portuchuelo's population was brought by both the Northeastern Brazilian and Caribbean workers, particularly from Granada and Barbados, who migrated to this area. Now, this tri-hybrid population seems to be stable, and the contribution of each of its components is estimated as Amerindians $=0.44 \pm 0.64$; Caucasoids $=$ $0.35 \pm 0.069$; Africans $=0.21 \pm 0.046$ (Ferreira et al. 2002) . 


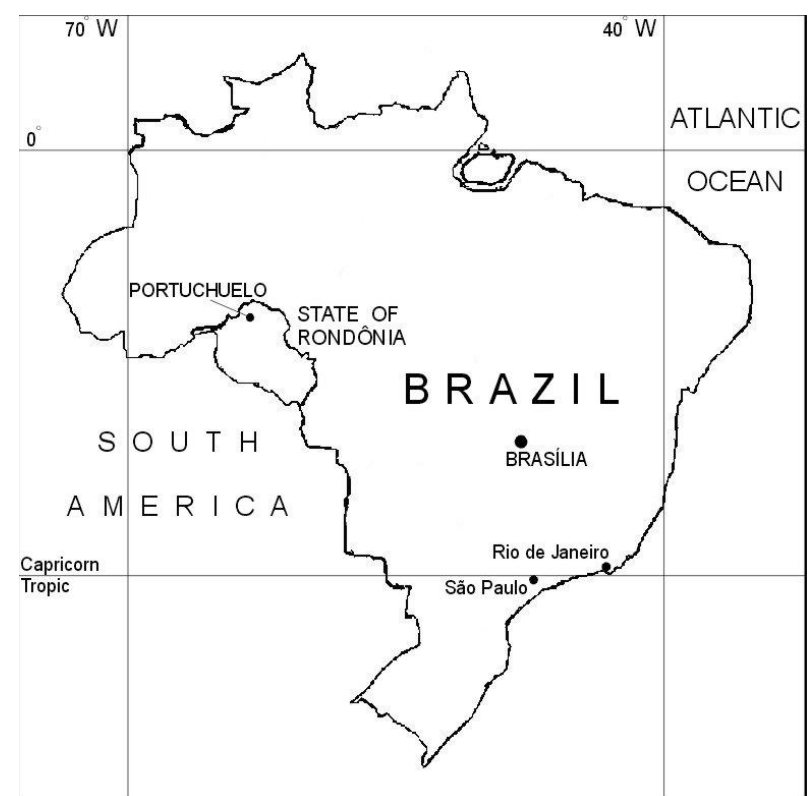

Map displaying the State of Rondônia within Brazil, and the settlement of Portuchuelo within the State of Rondônia.

The mean age of this community was 24.9 years. Since this population was represented by nuclear families the very large standard deviation observed (19.75 years) is understandable. As expected, when parents and offspring were analyzed separately, the standard deviations narrowed, notwithstanding continuing broad. Thus, the mean age of the parental generation was $47.6 \pm 16.0$ for males and $41.5 \pm 15.0$ for females, whereas for the offspring generation it was $15.5 \pm 13.6$ for males and $13.4 \pm 12.0$ for females. The sex ratio of the population was 1.04, a value that is usually found in other Brazilian populations (Beiguelman et al. 1995).

The main occupation of the great majority of fathers is concerned with both fishing and subsistence agriculture, while the mothers are dedicated to both domestic and agricultural activities.

Two main phenotypes involved with Plasmodium infection were studied: a) the presence of symptomless infection, i.e., presence of Plasmodium vivax or Plasmodium falciparum in blood, diagnosed by the traditional thick smear and/or by PCR amplification of Plasmodium ribosomal DNA, but without malaria symptoms during a 60 days follow-up after diagnosis, regardless of the onset of the infection; b) the reported number of previous malaria episodes for life.

During the first year of this study 45 patients presented symptomatic infection. All of them were treated according to the National Health Foundation standard protocols. The annual parasite index (API) in this settlement was 385 per 1,000 inhabitants in 1999, a much higher value than the API estimated for the whole state of Rondônia in the same year (49.6 per 1,000 inhabitants). Detailed information on the malarial epidemiological data, that included prevalence of $P$. falciparum and $P$. vivax infections in the cross-sectional surveys, is presented elsewhere (Camargo et al. 1999, Alves et al. 2002).
The ABO, Rh (C, c, D, E, e antigens), MNSs (M, N, S, $\mathrm{s}$ antigens), Kell (K antigen) and Duffy (Fy and $\mathrm{Fy}^{\mathrm{b}}$ antigens) blood group systems were investigated by means of a micro-typing kit (DiaMed-ID Micro Typing System), Coombs test being used for the last two systems. Haptoglobin (Hp) typing was conducted in starch gel electrophoresis according to the classical Smithies' (1955) method. Glyoxalase (GLO1), esterase D (EsD), carbonic anhydrase (CAII), phosphoglucomutase (PGM1), glucose6-phosphate dehydrogenase (G-6-PD) and hemoglobin $(\mathrm{Hb})$ were typed by starch-agarose gel electrophoresis according to the method of Wraxall and Stolorow (1978) and stained following procedures described in Harris and Hopkinson (1976). Red cell acid phosphatase (ACP1) was typed by high field strength iso-electric focusing on cellulose acetate membrane according to the method of Kane et al. (1990).

Non-parametric independence tests $(2 \times \mathrm{n}$ contingency chi-square tests for symptomless infection phenotypes and Kruskal-Wallis tests for the number of malaria episodes) were applied to the data. Since the number of malarial episodes has no normal distribution, it was taken the logarithm of each value to enable a stepwise multiple regression analysis, in which the number of malarial episodes was the dependent variable.

\section{RESULTS}

Table I shows the results of the independence chisquare $\left(\chi^{2}\right)$ tests between the ABO, MNSs, Rh, Kell, Duffy, $\mathrm{Hb}, \mathrm{Hp}, \mathrm{G}-6-\mathrm{PD}$, GLO, PGM1, ACP1, and EsD systems and the symptomless infection with $P$. vivax, $P$. falciparum, and the pooled infection, as well as results of the Kruskal-Wallis independence test $(\mathrm{H})$ for investigating the association between the same genetic systems and the number of malarial episodes.

In this Table it seems clear that when the independence tests were applied to the distribution of the ABO blood groups no significant associations could be detected. In contrast, a significant association between individuals with $\mathrm{A}$ or/and $\mathrm{B}$ antigens and the number of malaria episodes was observed.

In the population of Portuchuelo eight Rh phenotypes have been recognized with five $\mathrm{Rh}$ anti-sera (CCDee, CCDEe, CcDee, CcDEe, ccDee, ccDEe, ccDEE, and ccddee). No significant associations could be observed either when all these phenotypes were taken into account or when the reactions with anti-D or with anti-C and antic sera were analyzed separately. However, when the EE, $\mathrm{Ee}$, and ee phenotypes were considered, a tendency for association with the number of malarial episodes was observed. This prompted us to retest this association by analyzing only two phenotypic classes ( $\mathrm{E}_{-}$and ee phenotypes). This time a significant association could be observed $(\mathrm{H}=4.499 ; 1$ d.f.; $\mathrm{P}=0.034)$, ee phenotype individuals exhibiting a higher number of malaria episodes than phenotype E_ persons.

Similarly, no significant association was observed when the phenotypes Fy(a+b-), Fy $(a+b+), F y(a-b+)$, and Fy(ab-) of the Duffy system were tested. However, when these phenotypes except Fy(a-b-) were pooled together for the independence tests, a significant association with the 
number of malarial episodes emerged. In Table I it is also seen that the number of malarial episodes was significantly associated with the esterase D system, this association being due to a lesser number of these episodes manifested by the heterozygous phenotype (1-2) for EsD. Concerning the independence tests between the different genetic polymorphisms and the symptomless infections, only G-6PD system among females has shown a significant association with symptomless $P$. vivax infection.

As expected, age was significantly associated with the number of malarial episodes (Table II), the lower age groups exhibiting lower mean ranks of the number of malarial episodes than the higher age groups $(\mathrm{H}=31.418$; D.F. $=9 ; \mathrm{P}<0.001)$. Since the observed associations with the number of malarial episodes could be an effect of age, the mean rank of ages of the sample grouped as: either $\mathrm{O}$ or with $\mathrm{A}$ or/and $\mathrm{B}$ antigens; $\mathrm{E}$ and ee phenotypes; Fy(ab-) and non-Fy(a-b-) groups; as well as EsD phenotypes (1-1, 1-2, 2-2) were compared by applying a Kruskal-Wallis test to all cases. The results obtained enabled to reject the hypothesis that age could have influenced the observed association between the number of malarial episodes with $\mathrm{E}$ and ee phenotypes $(\mathrm{H}=0.299 ; 1$ D.F.; $\mathrm{P}=$ $0.585)$, the Duffy system $(\mathrm{H}=3.362$; D.F.; $\mathrm{P}=0.067)$ or with $\operatorname{EsD}(\mathrm{H}=0.926$; D.F. $=2 ; \mathrm{P}=0.629)$. The same was not true for the $\mathrm{ABO}$ system, since the mean rank of age of the group $\mathrm{O}$ subjects was significantly lower than that of individuals with $\mathrm{A}$ and/or $\mathrm{B}$ antigens $(\mathrm{H}=8.001$; D.F. $=1$;
$\mathrm{P}=0.005)$. Curiously, this phenomenon was confirmed in the offspring generation $(\mathrm{H}=5.657$; D.F. $=1 ; \mathrm{P}=0.017)$ but not among the parents $(\mathrm{H}=0.446$; D.F. $=1 ; \mathrm{P}=0.504)$.

Taking into account these results, the influence of several independent variables [age, squared age, sex (coded as zero for females and 1 for males), age $\times$ sex, squared age $\times$ sex, and $\mathrm{ABO}$ system grouped as $\mathrm{O}$ (coded as zero) and with A or/and B antigens (coded as 1)] on the

\section{TABLE II}

Distribution of the mean number of malarial episodes according to age groups, and Kruskal-Wallis test to investigate the association of age groups with the number of malarial episodes (mean ranks)

\begin{tabular}{lccc}
\hline $\begin{array}{l}\text { Age groups } \\
\text { (years) }\end{array}$ & $\mathrm{Nr}$ & $\begin{array}{c}\text { Mean number } \\
\text { of malarial } \\
\text { episodes }\end{array}$ & Mean rank \\
\hline$<5$ & 24 & $1.25 \pm 1.85$ & 44.69 \\
$5-10$ & 28 & $3.04 \pm 2.43$ & 83.38 \\
$10-15$ & 28 & $3.68 \pm 4.20$ & 84.69 \\
$15-20$ & 19 & $5.21 \pm 3.68$ & 108.08 \\
$20-25$ & 15 & $5.27 \pm 5.32$ & 97.97 \\
$25-30$ & 9 & $10.22 \pm 15.59$ & 112.33 \\
$30-35$ & 6 & $9.00 \pm 9.70$ & 109.75 \\
$35-40$ & 7 & $5.00 \pm 7.44$ & 78.21 \\
$40-45$ & 6 & $8.00 \pm 15.71$ & 80.33 \\
$\geq 45$ & 37 & $10.03 \pm 16.82$ & 110.86 \\
\hline
\end{tabular}

H: 31.418; D.F.: 9; $\mathrm{P}<0.001$

TABLE I

Results of the independence tests between different genetic systems and symptomless infection and number of malarial episodes

\begin{tabular}{|c|c|c|c|c|c|}
\hline \multirow{3}{*}{ Phenotypes } & \multirow{3}{*}{$\begin{array}{l}\text { Degrees } \\
\text { of } \\
\text { freedom }\end{array}$} & \multicolumn{3}{|c|}{ Symptomless infection } & \multirow{2}{*}{$\begin{array}{c}\mathrm{Nr} \text { of } \\
\text { malarial } \\
\text { episodes }\end{array}$} \\
\hline & & Plasmodium vivax & $P$ falciparum & Total & \\
\hline & & $\chi^{2} ; \mathrm{P}$ & $\chi^{2} ; \quad \mathrm{P}$ & $\chi^{2} ; \mathrm{P}$ & $\mathrm{H} ; \mathrm{P}$ \\
\hline $\mathrm{ABO}$ & 3 & $0.352 ; 0.996$ & $0.400 ; 0.940$ & $0.523 ; 0.914$ & $4.589 ; 0.204$ \\
\hline $\mathrm{A}+\mathrm{B}+\mathrm{AB}$ & 1 & $0.003 ; 0.953$ & $0.003 ; 0.953$ & $0.044 ; 0.833$ & $4.054 ; 0.044$ \\
\hline $\mathrm{B}+\mathrm{AB}$ & 1 & $0.001 ; 0.980$ & $0.261 ; 0.609$ & $0.065 ; 0.800$ & $2.933 ; 0.087$ \\
\hline MNSs & 8 & $8.583 ; 0.379$ & $5.813 ; 0.668$ & $5.048 ; 0.752$ & $5.684 ; 0.683$ \\
\hline $\mathrm{MM}, \mathrm{MN}, \mathrm{NN}$ & 2 & $0.655 ; 0.721$ & $0.012 ; 0.994$ & $0.348 ; 0.840$ & $1.036 ; 0.596$ \\
\hline $\mathrm{SS}, \mathrm{Ss}, \mathrm{sS}$ & 2 & $1.248 ; 0.536$ & $4.233 ; 0.120$ & $1.187 ; 0.552$ & $2.836 ; 0.242$ \\
\hline $\mathrm{Rh}$ & 7 & $5.616 ; 0.585$ & $8.943 ; 0.257$ & $3.151 ; 0.871$ & $7.273 ; 0.401$ \\
\hline $\mathrm{CC}, \mathrm{Cc}, \mathrm{cc}$ & 2 & $0.719 ; 0.698$ & $1.050 ; 0.592$ & $0.216 ; 0.898$ & $1.843 ; 0.398$ \\
\hline D_, dd & 1 & $1.341 ; 0.247$ & $0.355 ; 0.551$ & $0.310 ; 0.578$ & $0.472 ; 0.492$ \\
\hline $\mathrm{E} \overline{\mathrm{E}}, \mathrm{Ee}, \mathrm{ee}$ & 2 & $1.625 ; 0.444$ & $0.988 ; 0.610$ & $1.953 ; 0.377$ & $5.713 ; 0.057$ \\
\hline E, ee & 1 & $0.621 ; 0.431$ & $0.174 ; 0.676$ & $0.060 ; 0.807$ & $4.499 ; 0.034$ \\
\hline Këll & 1 & $1.518 ; 0.218$ & $0.219 ; 0.640$ & $0.488 ; 0.485$ & $0.886 ; 0.347$ \\
\hline Duffy & 3 & $1.255 ; 0.740$ & $0.800 ; 0.849$ & $1.719 ; 0.633$ & $5.043 ; 0.169$ \\
\hline Fy(a-b-) & 1 & $0.001 ; 0.970$ & $0.551 ; 0.456$ & $0.315 ; 0.575$ & $4.632 ; 0.031$ \\
\hline $\mathrm{Hp}$ & 3 & $2.120 ; 0.548$ & $2.141 ; 0.544$ & $0.365 ; 0.947$ & $1.104 ; 0.776$ \\
\hline Hp1-1 & 1 & $0.726 ; 0.394$ & $1.526 ; 0.217$ & $0.090 ; 0.764$ & $0.499 ; 0.480$ \\
\hline $\mathrm{Hb}$ & 1 & $0.040 ; 0.841$ & $0.483 ; 0.487$ & $0.052 ; 0.820$ & $0.202 ; 0.653$ \\
\hline G-6-PD, Males & 2 & $4.195 ; 0.123$ & $1.029 ; 0.598$ & $1.240 ; 0.538$ & $1.182 ; 0.554$ \\
\hline G-6-PD, Females & 1 & $4.353 ; 0.037$ & $0.064 ; 0.801$ & $2.721 ; 0.099$ & $0.323 ; 0.570$ \\
\hline GLO & 2 & $4.263 ; 0.119$ & $2.018 ; 0.365$ & $3.530 ; 0.171$ & $0.825 ; 0.662$ \\
\hline PGM1 & 2 & $3.944 ; 0.139$ & $0.029 ; 0.985$ & $4.002 ; 0.135$ & $0.473 ; 0.790$ \\
\hline ACP1 & 4 & $4.849 ; 0.303$ & $7.123 ; 0.129$ & $8.617 ; 0.071$ & $4.342 ; 0.362$ \\
\hline EsD & 2 & $0.660 ; 0.719$ & $4.240 ; 0.120$ & $0.784 ; 0.676$ & $6.840 ; 0.033$ \\
\hline
\end{tabular}

$\chi^{2}$ : results of the independence chi-square test; H: results of the independence Kruskal-Wallis test; P: probability 
logarithm of the number of malarial episodes (dependent variable) were analyzed by stepwise multiple regression. This analysis enabled to see that, exception made to the product of squared age $\times$ sex, all other variables have not influenced significantly the number of malarial episodes. Since the females were coded as zero and the partial regression coefficient of squared age $\times$ sex on the dependent variable was positive (3.702 with a standard error of $0.834 ; \mathrm{t}=4.437 ; \mathrm{P}<0.001)$, this result also indicates that the influence of age is restricted to the males.

\section{DISCUSSION}

It is known that parasitized erythrocytes form rosettes more readily with red blood cells of either A, B or AB groups than with those belonging to blood group $\mathrm{O}$ (Udomsangpetch et al. 1989,1993, Carlson \& Wahlgren 1992, Barragan et al. 2000), and that, in Zimbawe, blood group A was associated with both lower hemoglobin levels and severe central nervous system malaria with coma (Fisher \& Boone 1998). In spite of the fact that these phenomena might provoke an association of ABO blood groups and the number of malarial episodes, the results presented above do not enable to reject the null hypothesis that this polymorphic system is not associated with the number of malarial episodes. The absence of association between $\mathrm{ABO}$ system and malaria infection was also observed in other populations (Osisanyia 1983, Singh et al. 1986, 1995, Bayoumi et al. 1986, Montoya et al. 1994) but Santos et al. (1983) detected in Brazil a significant association between the presence of $\mathrm{B}$ antigen and the number of malarial episodes. Although our results pointed to the same direction, we were not able to confirm this observation by combining the frequency of $\mathrm{B}$ and $\mathrm{AB}$ individuals. However, it should be mentioned that, agreeing with Santos' et al. (1983) data, performing a preliminary analysis on another sample (Camargo et al., in preparation) we were able to detect an association between the number of malarial episodes and the presence of B antigen among 873 individuals living in Monte Negro, a rural area of the same State of Rondônia $\left(10^{\circ} 15^{\prime} \mathrm{S}, 63^{\circ} 18^{\prime} \mathrm{W}\right)$, the Kruskal-Wallis test resulting in $\mathrm{H}=4.114 ; 1$ d.f.; $\mathrm{P}=$ 0.043 .

The genetic polymorphism of glycophorin plays an important role in the resistance to the invasion of erythrocytes by P. falciparum (Pasvol et al. 1982, Hadley et al. 1986). Since long it is known that sialic acid is an essential part of the $\mathrm{M}, \mathrm{N}$ receptors and that the receptive capacity of glycophorin depends on sialic acid, which is an essential part of the $\mathrm{M}, \mathrm{N}$ receptors, one might suppose that MNSs system could be associated in some way with malaria infection (Mäkelä \& Cantell 1958). However, as it is seen in Table I, no significant associations could be observed either when the nine phenotypes observed were taken into account (MMSS, MMSs, MMss, MNSS, MNSs, MNss, NNSS, NNSs, and NNss) or when the reactions with anti-M, anti-N and anti-S, anti-s were analyzed separately. This result is in disagreement with that of Montoya et al. (1994), who observed in Colombia that the MNSs system confers resistance to both species of Plasmodium. Nevertheless, it should be stressed that the proportion of individuals who were negative to both anti-M and anti-N among the Negroids studied by Montoya et al. (1994) was conspicuously high (7.8\%).

Concerning the $\mathrm{Rh}$ system, it is curious that in another population of the state of Rondônia, living in Monte Negro (Camargo et al., in preparation), it was observed that the E_ phenotype individuals exhibited a higher number of malarial episodes than ee phenotype persons, the Kruskal-Wallis test resulting in a highly significant value $(\mathrm{H}=12.324 ; 1$ d.f.; $\mathrm{P} \cong 0)$. Since this result is completely opposite to that observed in the present population, the association of the number of malarial episodes with $\mathrm{E}$ or ee phenotypes might be taken as fortuitous, although $\overline{\text { it }}$ is attractive to speculate whether the Rh locus might be closely linked to a gene involved in susceptibility to malaria infection, being the observed significant deviations due to different phases of linkage disequilibrium.

Kell system did not exhibit association with the phenotypes involved in Plasmodium infection, a result that was also observed in other populations (Singh et al. 1986, Bayoumi et al. 1986, Montoya et al. 1994).

The lesser mean number of malarial episodes in Fy(ab-) individuals as compared to other positive Duffy phenotypes may obviously be considered as a consequence of the well-known resistance to $P$. vivax infection manifested by individuals whose red blood cells do not react with both anti-Fy and anti-Fy ${ }^{\mathrm{b}}$ antisera (Miller et al. 1976, Wertheimer \& Barnwell 1989). Concerning the individuals with symptomless $P$. vivax infection who exhibit Duffy negative phenotype it may be said that their number is too small to allow any statistically valid interpretation.

Harrison et al. (1976), in spite of not finding an association between haptoglobin and the presence of malaria parasites in blood, claimed to have strong evidence that, in New Guinea, homozygotes for $H p$, gene are more likely to show signs of hepatomegaly and splenomegaly than $\mathrm{Hp}_{1} \mathrm{Hp}_{2}$ heterozygotes. Santos et al. (1983) and Singh et al. (1986) found a significant excess of individuals with the Hp1-1 phenotype among malaria patients in Brazil and in India, respectively. In our data haptoglobin did not show significant association with the phenotypes involved in Plasmodium infection neither when all detected phenotypes (Hp1-1, Hp1-2, Hp 2-2, Hp1-2M) were considered nor when all of them except Hp1-1 were pooled together. Supporting the present results, no association between haptoglobin phenotypes and $P$. falciparum infection was also observed by Bayoumi et al. (1986) in Sudan.

Since long it is known that sickle cell trait affords protection against $P$. falciparum infection (Allison 1954a,b Vandepitte \& Delaisse 1957). In our data no significant association between AS genotype and the phenotypes involved in Plasmodium infection could be detected due to both a relatively low proportion of $P$. falciparum infection $(30 \%)$ among the malarial cases and a small frequency of AS individuals in Portuchuelo (3\%).

The relative protection of G-6-PD deficiency against P. falciparum postulated by Motulsky (1960) is manifested by the heterozygous females but not by the males who are hemizygous for the deficient gene (Bienzle et al. 1972, Usanga \& Luzzato 1985). Therefore, the absence of association between G-6-PD among males and the phenotypes 
involved in Plasmodium infection seen in Table I, as well as the significant association of the females symptomless for $P$. vivax with homozygosis for the gene $G d^{B}$ has no practical meaning.

The distribution of GLO phenotypes (1-1, 1-2, and 2-2) was independent from the phenotypes involved with Plasmodium infection, a result that agrees with that observed by Bayoumi et al. (1986) in Sudan. Regarding PGM1 system, these authors found a significant excess of the 1-1 phenotype among malaria patients, but such association could not be demonstrated in Portuchuelo. No statistical tests were performed concerning CA2, since all individuals except one (phenotype 1-2) exhibited phenotype 1-1.

Bottini et al. (1972) have suggested a possible disadvantage of the allele $\mathrm{ACP} 1 * \mathrm{C}$ in areas characterized in the past by high malaria endemicity (Mediterranean area), while other authors indicated that the ACP $1 * \mathrm{R}$ allele could have this disadvantage in Africa (Spedini et al. 1980). In Portuchuelo, as in African populations where malaria is endemic (Destro-Bisol et al. 1992), the ACP $1 *$ R allele was not found while the five ACP1 observed phenotypes (A, $\mathrm{AB}, \mathrm{AC}, \mathrm{B}$, and $\mathrm{BC}$ ) showed no association with the phenotypes involved with Plasmodium infection.

A result that should be confirmed in other populations, since it is here referred for the first time, is the observed significant association between the number of malarial episodes and EsD. The caution to associate a particular genetic system with a disease stems from the fact that statistic type II error, sample non-randomness, and stratification are common factors that mimic genetic associations. Also it should be stressed that the authors could not find an easy explanation for the correlation of the number of malarial episodes with age being restricted to males.

Finally, it should be emphasized that the authors are aware on the difficulty that people living in an endemic area have to remind the exact number of malarial episodes. However, it should be reminded that this difficulty has been somewhat circumvented when both the logarithm of the number of malarial episodes and the rank of the number rather than the number itself were used, since these transformations minimize small distortions of the informed values.

\section{REFERENCES}

Allison AC 1954a. Protection afforded by sickle-cell trait against subtertian malarial infection. Brit Med J 1: 290-294.

Allison AC 1954b. The distribution of sickle-cell trait in East Africa and elsewhere and its apparent relationship to the incidence of subtertian malaria. Trans $R$ Soc Trop Med Hyg 48: 312-318.

Alves FP, Durlacher RR, Menezes MJ, Krieger H, Pereira da Silva LH, Camargo EP 2002. High prevalence of asymptomatic Plasmodium vivax and Plasmodium falciparum infections in native Amazonian populations. Am J Trop Med Hyg 66: 641-648.

Barragan A, Kremsner PG, Wahlgren M, Carlson J 2000. Blood group A antigen is a coreceptor in Plasmodium falciparum rosetting. Infect Immun 68: 2971-2975.

Bayoumi RA, Bashir AH, Abdulhadi NH 1986. Resistance to falciparum malaria among adults in central Sudan. Am J Trop Med Hyg 35: 45-55.
Beiguelman B, Franchi-Pinto C, Dal Colletto GMD, Krieger H 1995. Annual variation of sex ratio in twin births and in singletons in Brazil. Acta Genet Med Gemell 44: 159-164.

Bienzle U, Ayeni O, Lucas AO, Luzzato L 1972. Glucose-6phosphate dehydrogenase and malaria. Greater resistance of females heterozygous for enzyme deficiency and of males with non deficient variant. Lancet 1: 107-110.

Bottini E, Lucarelli P, Bastianon V, Gloria F 1972. Erythrocyte acid phosphatase and hemolysis. J Med Genet 9: 434-435.

Camargo LMA, Dal Colleto GMD, Ferreira MU, Gurgel SM, Escobar AL, Marques A, Krieger H, Camargo EP, Pereira da Silva LH 1996. Hypoendemic malaria in Rondônia (Brazil, Western Amazon region): seasonal variation and risk groups in an urban locality. Am J Trop Med Hyg 55: 32-38.

Camargo LMA, Ferreira MU, Krieger H, Camargo EP, Pereira da Silva LH 1994. Unstable hypoendemic malaria in Rondônia (Western Amazon region, Brazil): epidemic outbreaks and work-associated incidence in agro-industrial rural settlement. Am J Trop Med Hyg 51: 16-25.

Camargo LMA, Noronha E, Salcedo JMV, Dutra AP, Krieger H, Pereira da Silva LH, Camargo EP 1999. The epidemiology of malaria in Rondônia (Western Amazon region, Brazil): study of a riverine population. Acta Trop 72: 1-11.

Carlson J, Wahlgren M 1992. Plasmodium falciparum erythrocyte rosetting is mediated by promiscuous lectin-like interactions. J Exp Med 176: 1311-1317.

Destro-Bisol G, Battaggia C, Macchiarelli R, Bailly C, Scozzani MR, Spedini G 1992. A bio-anthropological study on the Bakakas of Cameroon. Ann Hum Biol 19: 185-195.

Ferreira RGM, Moura MM, Engracia V, Pagotto RC, Alves FP, Camargo LM, Pereira da Silva LH, Camargo EP, Beiguelman B, Krieger H 2002. Ethnic admixture composition of two western Amazonian populations. Hum Biol 74: 607-613.

Fisher PR, Boone P 1998. Severe malaria associated with blood group. Am J Trop Med Hyg 58: 122-123.

Hadley TJ, Erkmen Z, Kaufman BM, Futrovsky S, McGinnis MH, Graves P, Sadoff JC, Miller LH 1986. Factors influencing invasion of erythrocytes by Plasmodium falciparum parasites: the effects of an N-acetyl glucosamine neoglycoprotein and an anti-glycophorin A antibody. Am J Trop Med Hyg 35: 898-905.

Harris H, Hopkinson DA 1976. Handbook of Enzyme Electrophoresis in Human Genetics, North Holland Publ. Co., Amsterdam, 374 pp.

Harrison GA, Boyce AJ, Hornabrook RW, Craig WJ 1976. Associations between polymorphic variety and disease susceptibility in two New Guinea populations. Ann Hum Biol 4: 253-267.

Kane M, Yamamoto Y, Yamada M, Fukunaga T, Tatsuno Y 1990. Phenotyping of erythrocyte acid phosphatase and esterase D by high field strength isoelectric focusing on cellulose acetate membrane. Electrophoresis 2:318-321.

Mäkelä O, Cantell K 1958. Destruction of M and N blood group receptors of human red cells by some influenza viruses. Ann Med Exp Fenn 36: 366-374.

Miller LH, Mason SJ, Clyde DF, McGinniss MH 1976. The resistance factor to Plasmodium vivax in Blacks. The Duffy blood-group genotype FyFy. N Engl J Med 295: 302-304.

Montoya F, Restrepo M, Montoya AE, Rojas W 1994. Blood groups and malaria. Rev Inst Med Trop São Paulo 36: 3338 .

Motulsky AG 1960. Metabolic polymorphisms and the role of infectious diseases in human evolution. Hum Biol l32: 2862.

Motulsky AG 1964. Hereditary red cell traits and malaria. Am J Trop Med Hyg 13: 147-158. 
Osisanyia JO 1983. ABO blood groups and infections with human malarial parasites in vivo and in vitro. East Afr Med J 60: 616-621.

Pasvol G, Wainscoat JS, Weatherall DJ 1982. Erythrocytes deficiency in glycophorin resist invasion by the malarial parasite Plasmodium falciparum. Nature 297: 64-66.

Santos SEB, Salzano FM, Franco MHLP, Freitas MJM 1983. Mobility, genetic markers, susceptibility to malaria and race mixture in Manaus, Brazil. J Hum Evol 12: 373-381.

Singh IP, Walter H, Bhasin MK, Veena B, Sudhakar K 1986. Genetic markers and malaria. Observations in Gujarat, India. Hum Hered 36: 31-36.

Singh N, Shukla MM, Uniyal VP, Sharma VP 1995. ABO blood groups among malaria cases from District Mandla, Madhya Pradesh. Indian J Malariol 32: 59-63.

Siniscalco M, Bernini L, Latte B, Motulsky AG 1961. Favism and thalassemia in Sardinia and their relationship to malaria. Nature 190: 1170-1180.

Smithies O 1955. Zone electrophoresis in starch gels: group variation in serum proteins of normal human adults. Bioch $J$ 61: 629-631.

Spedini G, Capucci E, Fuciarelli M, Rickards O 1980. The AcP polymorphisms frequencies in the Mbugu and Sango of
Central Africa (correlations between the $\mathrm{P} * \mathrm{r}$ allele and some climatic factors in Africa). Ann Hum Biol 7: 125-128.

Udomsangpetch R, Todd J, Carlson J, Greenwood BM 1993. The effects of hemoglobin genotype and $\mathrm{ABO}$ blood group on the formation of rosettes by Plasmodium falciparuminfected red blood cells. Am J Trop Med Hyg 48: 149-153.

Udomsangpetch R, Wählin B, Carlson J, Berzins K, Torii M, Aikawa M, Perlmann P, Wahlgren M 1989. Plasmodium falciparum-infected erythrocytes form spontaneous erythrocyte rosettes. J Exp Med 169: 1835-1840.

Usanga EA, Luzzato L 1985. Adaptation of Plasmodium falciparum to glucose-6-phosphate dehydrogenase-deficient host red cells by production of parasite-encoded enzyme. Nature 313: 793-795.

Vandepitte J, Delaisse J 1957. Sicklemie et paludisme. Ann Soc Belge Med Trop 3: 703-735.

Wertheimer SP, Barnwell JW 1989. Plasmodium vivax interaction with the human Duffy blood group glycoprotein: identification of a parasite receptor-like protein. Exp Parasitol 69: 340-350.

Wraxall BG, Stollorow MD 1978. The simultaneous separation of the enzymes glyoxalase I, esterase D, phosphoglucomutase. Forensic Sci 31: 1439-1441. 


\title{
Ethnic Admixture Composition of Two Western Amazonian Populations
}

\author{
R.G.M. FERREIRA, ${ }^{1}$ M.M. MOURA,${ }^{2,3}$ V. ENGRACIA,${ }^{2,3}$ R.C. PAGOTTO, ${ }^{1}$ F.P. ALVES, ${ }^{1}$ \\ L.M.A. CAMARGO,${ }^{1}$ L.H. PEREIRA DA SILVA, ${ }^{3}$ E.P. CAMARGO,${ }^{1}$ B. BEIGUELMAN,${ }^{1}$ AND \\ H. KRIEGER ${ }^{1}$
}

\begin{abstract}
A small riverine community, Portuchuelo ( $\left.8^{\circ} 37^{\prime} \mathrm{S}, 6^{\circ} 49^{\prime} \mathrm{W}\right)$, and a rural county, Monte Negro $\left(10^{\circ} 15^{\prime} \mathrm{S}, 63^{\circ} 18^{\prime} \mathrm{W}\right)$, both in the state of Rondônia, Brazil, were studied for the purposes of ascertaining health conditions and the causes of the variability of some infectious diseases. The sample included 181 inhabitants of Portuchuelo and 924 of Monte Negro. Data on 11 blood polymorphisms (ABO, Rh, MNSs, Kell, Fy, haptoglobin, hemoglobin, ACP1, PGM1, GLO1, and CA2) were used to determine the ethnic composition of the inhabitants of Portuchuelo and Monte Negro. The contributions of Africans, Amerindians, and Europeans to the ethnic composition of the studied populations were, respectively, $0.21 \pm 0.046,0.44 \pm 0.064$, and $0.35 \pm 0.069$ in Portuchuelo; and $0.25 \pm 0.032,0.12 \pm 0.046$, and $0.63 \pm 0.054$ in Monte Negro.
\end{abstract}

Despite the obvious implications of demographic, ecological, and temporal influences on the epidemiological profile of infectious diseases in a population, studies on the ethnic origin of that population may give a new insight on disease causes and explain the possible heterogeneity of epidemiological patterns existing among populations. In fact, ethnic differences may reflect the assortment of favorable genetic mechanisms involved in the resistance/susceptibility to specific infectious/ecological diseases. The known contribution of European, African, and Amerindian genes to the present Amazonian populations is diverse (Schüller et al. 1982) and depends upon the type of population under study. Here, we present data on the ethnic admixture of two different western Amazonian populations, based on several blood genetic markers.

${ }^{1}$ Departmento de Parasitologia, Instituto de Ciências Biomédicas, Universidade de São Paulo, Brazil.

${ }^{2}$ Universidade Federal de Rondônia, Rondônia, Brazil.

${ }^{3}$ Centro de Pesquisa em Doenças Tropicais, Rondônia, Brazil.

Human Biology, August 2002, v. 74, no. 4, pp. 607-613.

Copyright $\odot 2002$ Wayne State University Press, Detroit, Michigan 48201-1309

KEY WORDS: WESTERN AMAZONIA, ETHNIC ADMIXTURE, MONTE NEGRO, PORTUCHUELO, TRIHYBRID POPULATIONS 


\section{Subjects and Methods}

As part of a large research project on pure and applied research on infectious diseases in the state of Rondônia, Brazil (Camargo et al. 1994, 1996, 1999), data on two populations from the western Amazonian region were analyzed in order to estimate ethnic admixture proportions. These two populations were from Portuchuelo $\left(8^{\circ} 37^{\prime} \mathrm{S}, 63^{\circ} 49^{\prime} \mathrm{W}\right)$, a riverine community, and Monte Negro $\left(10^{\circ} 15^{\prime} \mathrm{S}, 63^{\circ} 18^{\prime} \mathrm{W}\right)$, a somewhat more recent, mostly rural settlement. The populations differ in several aspects, including population size, demographic density, and health care. More details on sampling as well as other characteristics of the population structure and dynamics are given elsewhere (Camargo et al. 1999, 2001).

A blood sample was collected from each studied individual (181 in Portuchuelo and 924 in Monte Negro) and tested within 24 hours for 14 antigens of five blood group systems using the classical immuno-hematological techniques. Blood groups ABO, Rh (CcDEe antigens), MNSs, Kell, and Duffy (Fya and Fyb antigens) were typed using a microtyping kit (DiaMed-ID Micro Typing System). The Coombs test was used in the last two systems. A horizontal starch gel electrophoresis was employed to type the haptoglobin (Hp) system (Smithies 1955). ACP1 (red cell acid phosphatase) was typed by isoelectric focusing (IEF), according to Kane et al. (1990). Typing of PGM1 (phosphoglucomutase 1), GLO1 (glyoxalase 1), CA2 (carbonic anhydrase 2), and hemoglobin ( $\mathrm{Hb}$ ) was conducted in the same starch-agarose gel electrophoresis, following the Wraxall and Stollorow (1978) method and the stain procedures described in Harris and Hopkinson (1976). Due to technical problems, the blood samples collected in Monte Negro were not typed for ACP1.

The maximum likelihood method of Krieger et al. (1965), using the program Mistura (Cabello and Krieger 1997), was employed to ascertain the ethnic proportions of these trihybrid populations.

Since the Africans brought to Brazil included many Bantu as well as various Sudanese groups (Freire-Maia 1963), it seemed reasonable to use weighted means based on several sources for estimating the ancestral contribution of Africans. Thus, the frequencies of various African populations summarized by Mourant et al. (1976) in Tables 2.11.2, 6.1, and 8.3.1 of their book were taken into account in calculating the gene frequencies of MNSs (Ghana and Nigeria, Tanzania and Uganda), Kell (Cabo Verde, Dahomey, Gambia, Ghana, Guinea, Ivory Coast, Liberia, and Nigeria), and Duffy (Ethiopia, Ghana and Nigeria, Moçambique, Rodesia, Tanzania, Uganda, and Zambia) systems, respectively. For the other analyzed systems the weighted means published by Franco et al. (1982) (ABO, Rh, haptoglobin, and hemoglobin) and Arpini-Sampaio et al. (1999) (ACP1, PGM1, GLO1, and CA2) were preferred. The gene frequencies of all these systems among Amerindians were drawn from Franco et al. (1982), Salzano et al. (1998), and Arpini-Sampaio et al. (1999), who have published weighted means of gene frequencies that were observed, sometimes in a very large number, 
in South American Indian tribes (Salzano et al. 1998). Finally, the gene frequencies of the analyzed traits among Portuguese and/or Spaniards (Cunha and Morais 1966; Lessa 1970; Franco et al. 1982; Arpini-Sampaio et al. 1999) were used as European ancestral gene frequencies, since it is well known that the European contribution to the gene pool of Brazilian populations was predominantly of Iberian origin.

\section{Results and Discussion}

Estimates of gene frequencies for the ancestral populations are given in Table 1. The same table also shows the gene frequencies calculated for both samples according to the admixture model.

Table 2 gives the estimates of the admixture proportions and their respective standard errors for the two populations. As can be seen, the standard errors are relatively high, due largely to the heterogeneity between systems, which most likely reflects errors in estimation of ancestral gene frequencies.

The results show that the riverine population of Portuchuelo has an Amerindian ethnic proportion almost four times that of Monte Negro. This proportion reflects the fact that the Portuchuelo community is descended from settlers arriving in the 19th to the beginning of the 20th century, heavily admixed with the Mura Amerindian group, who lived in this part of the Madeira river region. In contrast, the Monte Negro population has a much more recent history and a conspicuous influence of southern Brazilian migrants. An interesting feature arising from the analyses is that the African contribution to the gene pool of these two populations is practically the same, indicating the persistence of a relatively small (around 20\%) but significant proportion of African admixture, probably originating from the early migration of northeastern Brazilians during the "rubber boom" and the construction of the Madeira-Mamoré railroad.

Most of the data on the ethnic composition of the Amazonian populations refer to either urban populations or to small Amerindian tribes and former African slave isolates (cf. Sans 2000). There are virtually no reports on rural populations. The samples studied here differ from those of earlier studies in that they belong to predominantly rural populations and therefore may reflect a different genetic background.

Santos et al. (1999), analyzing the ethnic composition of several eastern and central Amazonian urban populations, concluded that there is an increased Amerindian admixture as one travels up the Amazon river, reaching around 40\% in Manaus, state of Amazonas. The present data have shown, at least for rural populations, that the picture in western Amazonia is different in the sense that the Amerindian contribution is either equal to or smaller than that observed in Manaus, indicating a different pattern of colonization and migration.

The polymorphisms with reported effects on malaria resistance/susceptibility did not show significant discrepancies of ethnic admixture, as compared with the overall estimates, suggesting that either there are no noteworthy signs of se- 
Table 1. Ancestral and Estimated Blood Group Gene Frequencies Used to Estimate the Ethnic Admixture of Two Western Amazonian Populations $(\mathrm{AF}=$ African, $\mathrm{AM}=$ Amerindian, $\mathrm{E}=$ European $)$

\begin{tabular}{|c|c|c|c|c|c|c|c|c|c|c|}
\hline \multirow{2}{*}{ System } & \multirow[t]{2}{*}{ Ethnic Group } & \multicolumn{8}{|c|}{ Allele Frequencies } & \multirow[t]{2}{*}{ Reference } \\
\hline & & $*_{A}$ & $*_{B}$ & $* O$ & & & & & & \\
\hline \multirow[t]{6}{*}{$\mathrm{ABO}$} & $\mathrm{AF}$ & 0.151 & 0.128 & 0.721 & & & & & & Franco et al. 1982 \\
\hline & $\mathrm{AM}$ & - & - & 1 & & & & & & Franco et al. 1982 \\
\hline & $\mathrm{E}$ & 0.298 & 0.057 & 0.645 & & & & & & Lessa 1970 \\
\hline & Portuchuelo & 0.135 & 0.047 & 0.819 & & & & & & Present study \\
\hline & Monte Negro & 0.226 & 0.068 & 0.706 & & & & & & Arpini-Sampaio et al. 1999 \\
\hline & & $c D e$ & $C D e$ & $c D E$ & $C D E$ & cde & Cde & $c d E$ & $C d E$ & \\
\hline \multirow[t]{6}{*}{$\mathrm{Rh}$} & $\mathrm{AF}$ & 0.555 & 0.096 & 0.070 & 0.001 & 0.270 & 0.005 & 0.003 & - & Franco et al. 1982 \\
\hline & $\mathrm{AM}$ & 0.052 & 0.542 & 0.341 & 0.056 & 0.006 & - & 0.001 & 0.002 & Salzano et al.1998 \\
\hline & E & 0.030 & 0.428 & 0.139 & 0.005 & 0.384 & 0.010 & 0.004 & - & Franco et al. 1982 \\
\hline & Portuchuelo & 0.150 & 0.409 & 0.214 & 0.027 & 0.192 & 0.005 & 0.002 & 0.001 & Present study \\
\hline & Monte Negro & 0.166 & 0.358 & 0.145 & 0.010 & 0.311 & 0.007 & 0.003 & 0.000 & Present study \\
\hline & & $M S$ & Ms & $M S u$ & $N S$ & Ns & $N S u$ & & & \\
\hline \multirow[t]{6}{*}{ MNSs } & $\mathrm{AF}$ & 0.159 & 0.328 & 0.066 & 0.088 & 0.265 & 0.093 & & & Mourant et al.1976 \\
\hline & $\mathrm{AM}$ & 0.244 & 0.510 & - & 0.073 & 0.173 & - & & & Salzano et al. 1998 \\
\hline & E & 0.214 & 0.300 & - & 0.071 & 0.374 & - & & & Cunha and Morais 1966 \\
\hline & Portuchuelo & 0.219 & 0.405 & 0.014 & 0.077 & 0.266 & 0.020 & & & Present study \\
\hline & Monte Negro & 0.209 & 0.341 & 0.017 & 0.078 & 0.331 & 0.024 & & & Present study \\
\hline & & $K$ & $L K$ & & & & & & & \\
\hline \multirow[t]{5}{*}{ Kell } & $\mathrm{AF}$ & 0.013 & 0.987 & & & & & & & Mourant et al.1976 \\
\hline & $\mathrm{AM}$ & 0.001 & 0.999 & & & & & & & Salzano et al. 1998 \\
\hline & $\mathrm{E}$ & 0.038 & 0.962 & & & & & & & Cunha and Morais1966 \\
\hline & Portuchuelo & 0.016 & 0.984 & & & & & & & Present study \\
\hline & Monte Negro & 0.027 & 0.973 & & & & & & & Present study \\
\hline
\end{tabular}




\begin{tabular}{|c|c|c|c|c|}
\hline \multirow{6}{*}{ Duffy } & & $F Y * A$ & $F Y * B$ & $F Y$ \\
\hline & $\mathrm{AF}$ & 0.020 & 0.020 & 0.960 \\
\hline & $\mathrm{AM}$ & 0.669 & 0.331 & - \\
\hline & E & 0.369 & 0.631 & - \\
\hline & Portuchuelo & 0.429 & 0.370 & 0.201 \\
\hline & Monte Negro & 0.315 & 0.440 & 0.245 \\
\hline \multirow{6}{*}{ Haptoglobin } & & $H P * 1$ & $H P * 2$ & $H P * 2 M$ \\
\hline & $\mathrm{AF}$ & 0.633 & 0.335 & 0.032 \\
\hline & $\mathrm{AM}$ & 0.660 & 0.340 & - \\
\hline & $\mathrm{E}$ & 0.403 & 0.597 & - \\
\hline & Portuchuelo & 0.554 & 0.428 & 0.007 \\
\hline & Monte Negro & 0.481 & 0.511 & 0.008 \\
\hline \multirow{6}{*}{ Hemoglobin } & & $H B B * A$ & $H B B^{*} C$ & $H B B * S$ \\
\hline & $\mathrm{AF}$ & 0.900 & 0.016 & 0.084 \\
\hline & $\mathrm{AM}$ & 1 & - & - \\
\hline & $\mathrm{E}$ & 1 & - & - \\
\hline & Portuchuelo & 0.979 & 0.003 & 0.018 \\
\hline & Monte Negro & 0.975 & 0.004 & 0.021 \\
\hline \multirow{5}{*}{ ACP1 } & & $A C P 1 * A$ & $A C P 1 * B$ & $A C P 1 * C$ \\
\hline & $\mathrm{AF}$ & 0.171 & 0.829 & - \\
\hline & $\mathrm{AM}$ & 0.152 & 0.848 & - \\
\hline & E & 0.358 & 0.522 & 0.121 \\
\hline & Portuchuelo & 0.227 & 0.731 & 0.042 \\
\hline \multirow{6}{*}{ PGM1 } & & $P G M 1 * 1$ & $P G M 1 * 2$ & \\
\hline & $\mathrm{AF}$ & 0.837 & 0.163 & \\
\hline & AM & 0.785 & 0.215 & \\
\hline & E & 0.735 & 0.265 & \\
\hline & Portuchuelo & 0.779 & 0.221 & \\
\hline & Monte Negro & 0.767 & 0.233 & \\
\hline
\end{tabular}

Mourant et al. 1976

Salzano et al. 1998

Cunha and Morais 1966

Present study

Present study

Franco et al. 1982

Franco et al. 1982

Franco et al. 1982

Present study

Present study

Franco et al. 1982

Franco et al. 1982

Franco et al. 1982

Present study

Present study

Arpini-Sampaio et al. 1999

Arpini-Sampaio et al. 1999

Arpini-Sampaio et al. 1999

Present study

Arpini-Sampaio et al. 1999

Arpini-Sampaio et al. 1999 Arpini-Sampaio et al. 1999

Present study

Present study 
Table 1. (Continued)

\begin{tabular}{|c|c|c|c|c|}
\hline System & Ethnic Group & & Allele Frequencies & Reference \\
\hline & & $G L O 1 * 1$ & GLOI*2 & \\
\hline GLO1 & $\mathrm{AF}$ & 0.306 & 0.694 & Arpini-Sampaio et al. 1999 \\
\hline & $\mathrm{AM}$ & 0.273 & 0.727 & Arpini-Sampaio et al. 1999 \\
\hline & E & 0.426 & 0.574 & Arpini-Sampaio et al. 1999 \\
\hline & Portuchuelo & 0.333 & 0.667 & Present study \\
\hline & Monte Negro & 0.378 & 0.622 & Present study \\
\hline & & $C A 2 * 1$ & $C A 2 * 2$ & \\
\hline CA2 & $\mathrm{AF}$ & 0.924 & 0.076 & Arpini-Sampaio et al. 1999 \\
\hline & $\mathrm{AM}$ & 1 & - & Arpini-Sampaio et al. 1999 \\
\hline & E & 1 & - & Arpini-Sampaio et al. 1999 \\
\hline & Portuchuelo & 0.984 & 0.016 & Present study \\
\hline & Monte Negro & 0.981 & 0.019 & Present study \\
\hline
\end{tabular}


Table 2. Ethnic Composition of Two Trihybrid Populations from Western Amazonia (State of Rondônia, Brazil)

\begin{tabular}{lccc} 
Sample & African & Amerindian & Caucasoid \\
\hline Portuchuelo & $0.21 \pm 0.046$ & $0.44 \pm 0.064$ & $0.35 \pm 0.069$ \\
Monte Negro & $0.25 \pm 0.032$ & $0.12 \pm 0.046$ & $0.63 \pm 0.054$ \\
\hline
\end{tabular}

lection (either by differential survival rate or migration), or the method is not sensitive enough to detect single polymorphism effects.

Acknowledgments This work was supported by São Paolo State Research Foundation (FAPESP), National Research Council (CNPq), Projects and Research Financing National Office (FINEP), Pronex, and Fundação Nacional de Saúde.

Received 12 April 2002; revision received 18 April 2002.

\section{Literature Cited}

Arpini-Sampaio, Z., M. C. Costa, A. A. Melo et al. 1999. Genetic polymorphisms and ethnic admixture in African-derived black communities of northeastern Brazil. Hum. Biol. 71:69-85.

Cabello, P.H., and H. Krieger. 1997. GENIOC: Sistema para análises de dados de genética. Rio de Janeiro, Brazil: FIOCRUZ.

Camargo, L. M.A., M.M. Moura, V. Engracia et al. 2001. A rural community in Brazilian western Amazon region: Some demographic and epidemiological patterns. To be published in Mem. Inst. Oswaldo Cruz.

Camargo, L.M.A., G.M.D. Dal Colletto, M.U. Ferreira et al. 1996. Hypoendemic malaria in Rondônia (Brazil, Western Amazon Region): Seasonal variation and risk groups in a urban locality. Amer. J. Trop. Med. Hyg. 55:32-38.

Camargo, LM.A., M.U. Ferreira, H. Krieger et al. 1994. Unstable hypo-endemic malaria in Rondônia (western amazon region, Brazil): Epidemic outbreaks and work-associated incidence in agroindustrial rural settlement. Amer J. Trop. Med. Hyg. 51:16-25.

Camargo, L.M.A., E. Noronha, J.M.V. Salcedo et al. 1999. The epidemiology of malaria in Rondônia (Western Amazon region, Brazil): Study of a riverine population. Acta tropica 72:1-11.

Cunha, A. X. da, and M.H.X. da Morais. 1966. Os grupos sangüíneos dos portugueses. Grupos KellCellano, Duffy e MNSs. Contr. Antrop. Port. 8: 5-15. Apud Mourant et al. 1976 op. cit.

Franco, M.H.L.P., T.A. Weimer, and F.M. Salzano. 1982. Blood polymorphisms and racial admixture in two Brazilian populations. Am. J. Phys. Anthrop. 58: 127-132.

Freire-Maia, N. 1963. The load of lethal mutations in White and Negro Brazilian populations. II. Second survey. Acta Genet., Basel 13:199-225.

Harris, H., and D.A. Hopkinson. 1976. Handbook of enzyme electrophoresis in Human Genetics. Amsterdam, Netherlands: North Holland Co.

Kane, M., Y. Yamamoto, M. Yamada et al. 1990. Phenotyping of erythrocyte acid phosphatase and esterase D by high field strength isoelectric focusing on cellulose acetate membrane. Electrophoresis 2:318-321. 


\section{4 / FERREIRA ET AL.}

Krieger, H., N.E. Morton, M.P. Mi et al. 1965. Racial admixture in north-eastern Brazil. Ann. Hum. Genet. 29:113-125.

Lessa, A. 1970. A individualidade biológica do sangue. Lisboa, Portugal: Livraria Luso-Espanhola.

Mourant, A.E., A.C. Kopec, and K. Domaniewska-Sobczak. 1976. The Distributions of the Human Blood Groups and Other Polymorphisms. London, UK: Oxford University Press.

Salzano, F.M., T.A. Weimer, M.H.L.P. Franco et al. 1998. Protein genetic studies among the TupiMondé Indians of the Brazilian Amazonia. Am. J. Hum. Biol. 10:711-722.

Sans, M. 2000. Admixture studies in Latin America: From the 20th to the 21st century. Hum. Biol. 72:155-177.

Santos, S.E.B., J.D. Rodrigues, A.K.C. Ribeiro-dos-Santos et al. 1999. Differential contribution of indigenous men and women to the formation of an urban population in the Amazon Region as revealed by mtDNA and Y-DNA. Amer. J. Phys. Anthrop. 109:175-180.

Schüller, L., F.M. Salzano, M.H.L.P. Franco et al. 1982. Demographic and blood genetic characteristics in an Amazonian population. J. Hum. Evol. 11:549-558.

Smithies, O. 1955. Zone electrophoresis in starch gels: Group variation in serum proteins of normal human adults. Bioch. J. 61:629-631.

Wraxall, B.G., and M.D. Stollorow. 1978. The simultaneous separation of the enzymes glyoxalase I, esterase D, phosphoglucomutase. Forensic Sci. 31:1439-1441.

Workman, P.L., B.S. Blumberg, and A. J. Cooper. 1963. Selection, gene migration and polymorphic stability in U.S. White and Negro population. Amer. J. Hum. Genet. 15:429-437. 


\section{* Bioinformática: \\ Pesquisa \\ Manual do Usuário}

Ilustrações cedidas pelos autores

Um guia básico e amplo sobre os diversos aspectos dessa nova ciência

Francisco Prosdocimi

Mestrando em Genética e Especialista

em Bioinformática

Universidade Federal de Minas Gerais

franc@icb.ufmg.br

\section{Gustavo Coutinbo}

\section{Cerqueira}

Bacharel em Ciência da Computação e

Especialista em Bioinformática

Universidade Federal de Minas Gerais cerca@csr.ufmg.br

\section{Eliseu Binneck}

Doutor em Ciência e Tecnologia de

Sementes e Especialista em

Bioinformática

Embrapa Soja

binneck@cnpso.embrapa.br

\section{Acácia Fernandes Silva}

Mestre em Agronomia e Especialista

em Bioinformática

Empresa Pernambucana de Pesquisa

Agropecuária

acacia@ipa.br

\section{Adriana Neves dos Reis}

Bacharel em Informática e Especialista

em Bioinformática

Universidade do Vale do Rio dos Sinos

adriana@exatas.unisinos.br

\section{Ana Carolina Martins \\ Junqueira \\ Mestre em Genética e Biologia \\ Moleculare Especialista em \\ Bioinformática \\ Universidade de Campinas \\ anacmj@unicamp.br}

Ana Cecília Feio dos Santos

Mestranda em Genética e Biologia

Moleculare Especialista em

Bioinformática

Universidade Federal do Pará

cecifeio@ufpa.br

Antônio Nbani Júnior

Doutor em Bioquímica e Especialista

em Bioinformática

Universidade Estadual Paulista

nhani@fcav.unesp.br

\section{Charles I. Wust}

Mestrando em Ciências da Computação e Especialista em Bioinformática Universidade Federal de Santo

Catarina

wust@inf.ufsc.br
Fernando Camargo Filbo

Mestrando em Biotecnologia Vegetal e

Especialista em Bioinformática

Universidade de Ribeirão preto

camargo@odin.unaerp.br

\section{Jayme Lourenço Kessedjian}

Analista de sistemas e Especialista em

Bioinformática

Embrapa Agrobiologia

jayme@cnpab.embrapabr

\section{Jorge H. Petretski}

Prof. Associado e Especialista em

Bioinformática

Universidade Estadual do Norte

jhpetretski@uenf.br

\section{Luiz Paulo Camargo}

Analista de Sistemas e Especialista em

Bioinformática

Universidade de Ribeirão Preto

huizpcam@uol.com.br

\section{Ricardo de Godoi Mattos}

\section{Ferreira}

Bacharel em Ciências Biológicas e Especialista em Bioinformática

Universidade de São Paulo

ricgmf@lineu.icb.usp.br

\section{Roceli P. Lima}

Mestrando em Informática e Especialista em Bioinformática

Universidade do Amazonas

rossi@horizon.com.br

\section{Rodrigo Matbeus Pereira}

Mestrando em Microbiologia e Especialista em Bioinformática

Universidade Estadual Paulista

rodrigus@fcav.unesp.br

\section{Sílvia Jardim}

Mestre em Farmacologia e Especialista em Bioinformática

Embrapa Milbo e Sorgo

silviajardim@yahoo.com.br

Vanderson de Souza Sampaio

Mestrando em Genética e Biologia

Moleculare Especialista em

Bioinformática

Universidade Federal do Pará

vander@ufpa.br

Áurea V. Folgueras-Flatschart Doutora em Microbiologia e Especialista em Bioinformática

Universidade Federal de Minas Gerais folguera@bol.com.br

\section{INTRODUÇÃO}

Do início até meados do século passado os geneticistas e químicos se questionaram sobre a natureza química do material genético. Das pesquisas desenvolvidas, surgiu a conclusão de que o DNA era a molécula que armazenava a informação genética e, em 1953, sua estrutura química foi desvendada no clássico trabalho de Watson e Crick. Com a posterior descoberta do código genético e do fluxo da informação biológica, dos ácidos nucléicos para as proteínas, tais polímeros passaram a constituir os principais objetos de estudo de uma nova ciência, a Biologia Molecular. Logo surgiram métodos de seqüenciamento desses polímeros, principalmente do DNA, que permitiam a investigação de suas seqüências monoméricas constituintes. Desde então, mais de 18 bilhões dessas seqüências já foram produzidas e estão disponíveis nos bancos de dados públicos.

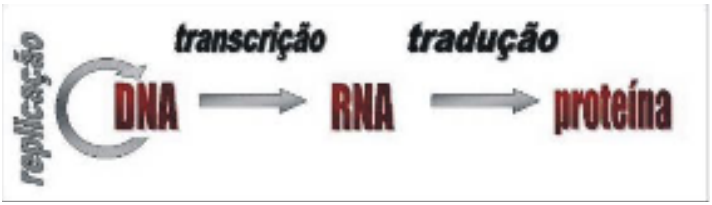

Figura 1: O Dogma Central da

Biologia Molecular

Na segunda metade da década de 90, com o surgimento dos seqüenciadores automáticos de DNA, houve uma explosão na quantidade de seqüências a serem armazenadas, exigindo recursos computacionais cada vez mais eficientes. Além do armazenamento ocorria, paralelamente, a necessidade de análise desses dados, o que tornava indispensável a utilização de plataformas computacionais eficientes para a interpretação dos resultados obtidos.

Assim nascia a bioinformática. Essa nova ciência envolveria a união de diversas linhas de conhecimento - a engenharia de softwares, a matemática, a estatística, a ciência da computação e a biologia molecular. Os primeiros projetos na área eram compostos por profissionais de diferentes 
áreas da biologia e informática e percebia-se uma certa dificuldade de comunicação: enquanto o biólogo procurava uma solução que levasse em consideração as incertezas e erros que ocorrem na prática, o cientista da computação procurava uma solução eficiente para um problema bem definido. Assim, surgiu a necessidade de um novo profissional, que entendesse bem ambas as áreas e fizesse a ponte entre elas: o Bioinformata. Esse profissional deveria ter o conhecimento suficiente para saber quais eram os problemas biológicos reais e quais seriam as opções viáveis de desenvolvimento e abordagem computacional dos problemas em questão.

Dado o sucesso e a importância que alcançaram os projetos Genoma e seus desmembramentos, o bioinformata tem sido um profissional requisitado e raro. No exterior, podem ser encontrados pelo menos 122 cursos de formação em bioinformática, em sua grande maioria centrados na América do Norte e Europa (http://linkage. rockefeller. edu/wli/ bioinfocourse/). No Brasil, entretanto, até o início deste ano, não existiam cursos que formassem tais profissionais especializados. Políticas científicas governamentais têm procurado incentivar a formação de grupos de pesquisa e de pessoal nessa área, financiando projetos e criando cursos de pós-graduação. Em 2002, foi implantado o primeiro Curso de Especialização (pós-graduação lato sensu) do LNCC (http://www. lncc.br/ biologia) - do qual formamos a segunda turma. Ainda neste ano foi autorizada pela CAPES a criação de dois cursos de doutorado em Bioinformática, um na USP e outro na UFMG (http://www. capes.gov.br/).

Parece-nos que cada vez mais a bioinformática vai ser necessária para a análise de dados em biologia molecular e, nesse sentido, o presente artigo foi escrito com o intuito de conter as informações mais relevantes para quem deseja começar a trabalhar na área. Assim, tentamos apresentar os principais conceitos relacionados à biologia e à computação, os softwares mais utilizados, os sites mais freqüentados e as principais áreas de interesse.

\section{Sistemas operacionais}

O sistema operacional ( $\mathrm{SO}$ ) é o principal programa de um computador. Ele é responsável pelo gerenciamento da memória, pelo acesso aos discos e também intermedeia todo acesso aos componentes físicos da máquina (hardware).

Os SOs mais conhecidos e utilizados são aqueles baseados no Windows, Unix e MacOS. Muitas das aplicações utilizadas em bioinformática são compiladas e distribuídas para a execução em plataformas derivadas do Unix, portanto o conhecimento desse sistema operacional é de grande importância para aqueles que desejam aprofundar-se na área. A preferência por sistemas baseados em Unix deve-se ao fato de que tais sistemas são normalmente mais confiáveis, gerenciam melhor o trabalho com grandes quantidades de dados e que algumas de suas variantes, como o Linux, possuem código aberto e distribuições gratuitas.

\section{Linguagens de programação}

Um profissional embioinformática, além de saber utilizar os programas produzidos por outros programadores, deve também ser capaz de desenvolver programas aplicativos para lidar com os mais diversos problemas encontrados durante a análise de dados em biologia molecular. Para desenvolver, portanto, tais programas, o bioinformata deve ter conhecimento sobre algum tipo de linguagem de programação.

As Linguagens de programação foram criadas para facilitar a especificação de tarefas a um computador. Existem milhares de linguagens de programação e cada uma delas possui um conjunto de comandos específicos que criam esta interface homem-máquina. Das linguagens de programação mais utilizadas, podemos citar: basic, pascal, C, C++, java, cobol e fortran. Entretanto, a linguagem mais utilizada pelos bioinformatas é, sem sombra de dúvida, o PERL.

O PERL (Practical Extract and Report Language) é uma linguagem de programação, simples e muito rica, além de disponível gratuitamente. Foi criada por Larry Wall, originalmente para produzir relatórios de informações de erros, que a disponibilizou na Internet no espírito freeware, pensando que alguém pudesse achá-la útil. Ao longo dos anos esta linguagem conquistou milhares de adeptos e, através de várias colaborações recebidas para seu aprimoramento, o PERL é hoje conceituado como uma linguagem sofisticada, que possui como ponto forte a manipulação de texto, mas que, além disso, possui todas as características de uma linguagem de alto-nível genérica. É essa grande facilidade para a manipulação de texto que fez do PERL a linguagem mais utilizada no tratamento de dados de seqüências de DNA e proteínas.

O PERL pode ter suas funcionalidades acrescidas através de módulos, que são distribuídos gratuitamente. Existem módulos para uma gama de aplicações, desde métodos estatísticos clássicos, aplicações gráficas em 3D, até acesso a internet via programação PERL. O site CPAN (Comprehensive Perl Archive Network - http://www. cpan.org) é o principal ponto de distribuição de módulos e de suas respectivas documentações. Alguns destes módulos são especialmente dirigidos para aplicações em Bioinformática, destacando-se os módulos bioperl e biographics, que apresentam ferramentas bastante úteis para as mais diversas aplicações nesta área.

Uma boa interconectividade com bancos de dados é outra característica desejada em uma linguagem de programação. A linguagem PERL atende muito bem a esta demanda através da biblioteca PERL-DBI, um conjunto de módulos que fornece uma interface consistente para soluções de integração com bancos de dados.

\section{Bancos de dados}

Em conseqüência da grande quantidade de informações de seqüências de nucleotídeos e de aminoácidos que são produzidas atualmente, principalmente em projetos Genoma, Transcriptoma e Proteoma, o uso dos bancos de dados vem as- 
sumindo uma importância crescente nabioinformática.

Um banco de dados pode ser considerado uma coleção de dados inter-relacionados, projetado para suprir as necessidades de um grupo específico de aplicações e usuários. Um banco de dados organiza e estrutura as informações de modo a facilitar consultas, atualizações e deleções de dados.

A grande maioria dos bancos de dados é atrelado a um sistema denominado SGBD (Sistema de Gerenciamento de Banco de Dados). Este sistema é responsável por intermediar os processos de construção, manipulação e administração do banco de dados solicitados pelos usuários ou por outras aplicações.

Existem vários sistemas de gerenciamento de banco de dados, sendo que cada sistema possui seus prós e contras. O mysqlé um sistema muito utilizado pela comunidade acadêmica e em projetos genoma por ser gratuito, possuir código aberto e acesso veloz aos dados, mas apresenta certas limitações em suas ferramentas. O postgreSQL também é um SGBD gratuito, com ferramentas muito poderosas, entretanto não é muito utilizado pela dificuldade no seu gerenciamento. Os SGBD's Oraclee SQL Serversão robustos e sofisticados, mas devido ao alto custo de suas licenças possuem seu uso limitado às grandes empresas.

\section{Bancos de dados públicos em bioinformática}

O investimento contínuo na construção de bancos de dados públicos é um dos grandes motivos do sucesso dos projetos genoma e, em especial, do Projeto genoma Humano. Devidoà magnitude do conjunto de dados produzidos torna-se fundamental a organização desses dados em bancos que permitam acesso on-line.

Os bancos de dados envolvendo seqüências de nucleotídeos, de aminoácidos ou estruturas de proteínas podem ser classificados em bancos de seqüências primários e secundários. Os primeiros são formados pela deposição direta de seqüências de nucleotídeos, aminoácidos ou estruturas protéicas, sem qualquer processamento
BOX1 - Exemplo de programa PERL para obter a fita reversacomplementar a partir de uma seqüência de DNA desejada.

$\# !$ usr/bin/perl

\# Seqüência que se deseja utilizar

\$meuDNA = 'TTCCGAGCCAATTGTATCAGTTGCCAATAG';

\# Inverte a ordem da seqüência de DNA

$\$$ RevCom = reverse $\$$ meuDNA;

\# Troca as bases produzindo a fita complementar

\$RevCom $=\sim$ tr/ACGT/TGCA/;

print "Minha seqüência invertida é: \n \$RevCom";

A primeira linha é obrigatória e diz ao programa o caminho onde se encontra o interpretador PERL para que o programa possa achá-lo na hora de sua execução. As linhas seguintes que se iniciam com o sinal de "\#" representam linhas de comentário. As variáveis em PERL são sempre seguidas do sinal de "\$” e não precisam ser declaradas, cabe ao programador saber como e em que contexto devem ser utilizadas. Os comandos terminam sempre com ponto-e-vírgula e o sinal de "= " está relacionado à utilização de uma expressão regular.

\section{BOX2 - Principais Sistemas de Gerenciamento de Bancos de dados}

MySQL http://www.mysql.org

Acesso livre para download do gerenciador MySQL, como também a várias ferramentas de conexão como: DBI, Java, ODBC e etc. Apresenta documentação completa.

PostgreSQL http://www.pgsql.com/

Acesso livre para download do gerenciador PostgreSQL, como também algumas ferramentas. Apresenta documentação completa.

ORACLE http://www.oracle.com

Informações comerciais sobre o banco de dados.

Microsoft SQLServer http://www.microsoft.com/sql/

Informações comerciais sobre o banco de dados.

\section{BOX3 - Bancos de Dados mais utilizados em bioinformática}

Genbank http://www.ncbi.nlm.nih.gov/

Banco de dados americano de seqüências de DNA e proteínas.

EBI http://www.ebi.ac.uk/

Banco de dados europeu de seqüências de DNA.

DDBJ http://www.ddbj.nig.ac.jp/

Banco de dados japonês de seqüências de DNA.

PDB http://www.rcsb.org/pdb

Armazena estruturas tridimensionais resolvidas de proteínas.

GDB http://gdbwww.gdb.org/

Banco de dados oficial do projeto genoma humano.

TIGR Databases http://www.tigr.org/tdb/

Banco com informações de genomas de vários organismos diferentes.

PIR http://www-nbrf.georgetown.edu/

Banco de proteínas anotadas.

SWISS-PROT http://www.expasy.ch/spro/

Armazena seqüências de proteínas e suas respectivas características moleculares, anotado manualmente por uma equipe de especialistas.

INTERPRO http://www.ebi.ac.uk/interpro/

Banco de dados de famílias, domínios e assinaturas de proteínas.

KEGG http://www.genome.ad.jp/kegg/

Banco com dados de seqüências de genomas de vários organismos diferentes e informações relacionadas às suas vias metabólicas. 
ou análise. Os principais bancos de dados primários são o GenBank, oEBI (European Bioinformatics Institute), o DDBJ (DNA Data Bank of Japan) e o PDB (Protein Data Bank). Os três primeiros bancos são membros do INSDC (International Nucleotide Sequence Database Colaboration) e cada um desses centros possibilita a submissão individual de seqüências de DNA. Eles trocam informações entre si diariamente, de modo que todos os três possuem informações atualizadas de todas as seqüências de DNA depositadas em todo o mundo. Apesar disso, cada centro apresenta seus dados de forma particular, apesar de bastante semelhante. Atualmente a maioria das revistas exige que as seqüências identificadas pelos laboratórios sejam submetidas a um destes bancos antes mesmo da publicação do artigo.

Os bancos de dados secundários, como o PIR (Protein Information Resource) ou o SWISS-PROT, são aqueles que derivam dos primários, ou seja, foram formados usando as informações depositadas nos bancos primários. Por exemplo, o SWISS-PROT é um banco de dados onde as informações sobre seqüências de proteínas foram anotadas e associadas à informações sobre função, domínios funcionais, proteínas homólogas e outros.

Os bancos de seqüências também podem ser classificados como bancos estruturais ou funcionais. Os bancos estruturais mantêm dados relativos à estrutura de proteínas. Embora a seqüência de nucleotídeos, a seqüência de aminoácidos e a estrutura de proteína sejam formas diferentes de representar o produto de um dado gene, esses aspectos apresentam informações diferentes e são tratados por projetos diferentes, que resultam em bancos específicos.

Dos bancos funcionais, o KEGG (Kyoto Encyclopedia of Genes and Genomes) é um dos mais utilizados. Disponibiliza links para mapas metabólicos de organismos com genoma completamente ou parcialmente seqüenciados a partir de seqüências e de busca através palavras-chave.

Com o crescente número de dados biológicos que vem sendo gerados, vários bancos de dados têm surgido e anualmente a revista Nucleic Acids
Research (http://www3.oup.co.uk/nar/ database/) publica uma lista atualizada com a classificação de todos os bancos de dados biológicos disponíveis.

\section{Alinhamento de seqüências}

O alinhamento de seqüências possui uma diversidade de aplicações na bioinformática, sendo considerada uma das operações mais importantes desta área. Este método de comparação procura determinar o grau de similaridade entre duas ou mais seqüências, ou a similaridade entre fragmentos destas seqüências. No caso de mais de duas seqüências o processo é denominado alinhamento múltiplo.

É bom lembrar que similaridade e homologia são conceitos diferentes. O alinhamento indica o grau de similaridade entre seqüências, já a homologia é uma hipótese de cunho evolutivo, e não possui gradação: duas seqüências são homólogas caso derivem de um ancestral comum ou, caso esta hipótese não se comprove, simplesmente não são homólogas.

Existem vários programas de computador que realizam esta tarefa e a grande maioria deles pode ser utilizado on-line, sem a necessidade de instalação. Como exemplo temos os programas: ClustalW, Multialin, FASTA, BLAST 2 sequences, etc.

\section{A C D $E$ F \\ $\begin{array}{llllll}\text { A } & 4 & 0 & -2 & -1 & -2\end{array}$ \\ $\begin{array}{llllll}\text { C } & 0 & 9 & -3 & -4 & -2\end{array}$ \\ D $\begin{array}{lllll}-2 & -3 & 6 & 2 & -3\end{array}$ \\ E $\begin{array}{lllll}-1 & -4 & 2 & 5 & -3\end{array}$ \\ $\begin{array}{llllll}F & -2 & -2 & -3 & -3 & 6\end{array}$ \\ Figura 3. Parte de uma matriz de substituição BLOSUM62, utilizada em alinhamentos de seqüências de proteinas. As letras representam os aminoácidos e os números indicam os pontos a serem contabilizados na ocorrência de match (diagonal principal) ou mismatch}

tas matrizes indicam os diferentes valores a serem contabilizados para cada par de unidades.

As matrizes de substituição são normalmente utilizadas no alinhamento de seqüências protéicas. Assim o valor de cada uma de suas células indica a chance da ocorrência da substituição correspondente ao par de aminoácidos deste mismatch.

\section{\begin{tabular}{|rc|}
\hline seq1 & KKAK-TTHHGA--VHN-G \\
seq2 & KKADDTTH-GAIKVGNTG \\
& \\
$\square$ match & $\square$ mismatch $\quad \square$ gap \\
\hline
\end{tabular}}

Figura 2-Alinhamento de duas seqüências de proteinas

O processo consiste em introduzir espaços (gaps) entre os monômeros de uma ou mais seqüências a fim de obter o melhor alinhamento possível. A qualidade de um alinhamento é determinada pela soma dos pontos obtidos por cada unidade pareada (match) menos as penalidades pela introdução de gaps e posições não pareadas (mismatch)

\section{Matrizes de substituição}

Matrizes de substituição são uma alternativa aos valores fixos de pontuação para matches e mismatches. Es-
As matrizes de substituição mais utilizadas são aquelas pertencentes às famílias de matrizes PAM (Point Accepted Mutation) e BLOSUM. A matriz PAM1 foi construída através da análise de mutações entre proteínas homólogas com 1\% de divergência (1\% dos aminoácidos diferentes). As outras matrizes, PAM50, PAM100, PAM250 são extrapolações da matriz PAM1. As matrizes BLOSUM foram construídas tendo como base os alinhamentos do banco de motivos BLOCKS. Uma matriz BLOSUM62 é definida através da análise das substituições nas seqüências de BLOCKS que possuem menos 
que $62 \%$ de similaridade. As seqüências que ultrapassam este limite são mescladas, e participam da definição da matriz como se fossem uma única seqüência.

\section{Alinbamento global e local}

Quantoà região analisada, o alinhamento de seqüências pode ser grosseiramente classificado em dois tipos, o alinhamento global e o alinhamento local. No alinhamento global, as seqüências envolvidas devem ser alinhadas de um extremo ao outro, dando origem a apenas um resultado. Já no alinhamento local, procura-se alinhar apenas as regiões mais conservadas, independente da localização relativa de cada região em sua seqüência. Consequentemente, este alinhamento tem como resultado uma ou mais regiões conservadas entre as seqüências.

O alinhamento globalé freqüentemente utilizado para determinar regiões mais conservadas de seqüências homólogas. Exemplo de programas que utilizam este alinhamento são ClustalW e Multialin. O alinhamento localé geralmente utilizado na procura por seqüências homólogas ou análogas (funcionalmente semelhantes) em banco de dados. O algoritmo utilizado pelo programa BLAST (Basic Local Alignment Search Tool) realiza este tipo de alinhamento.

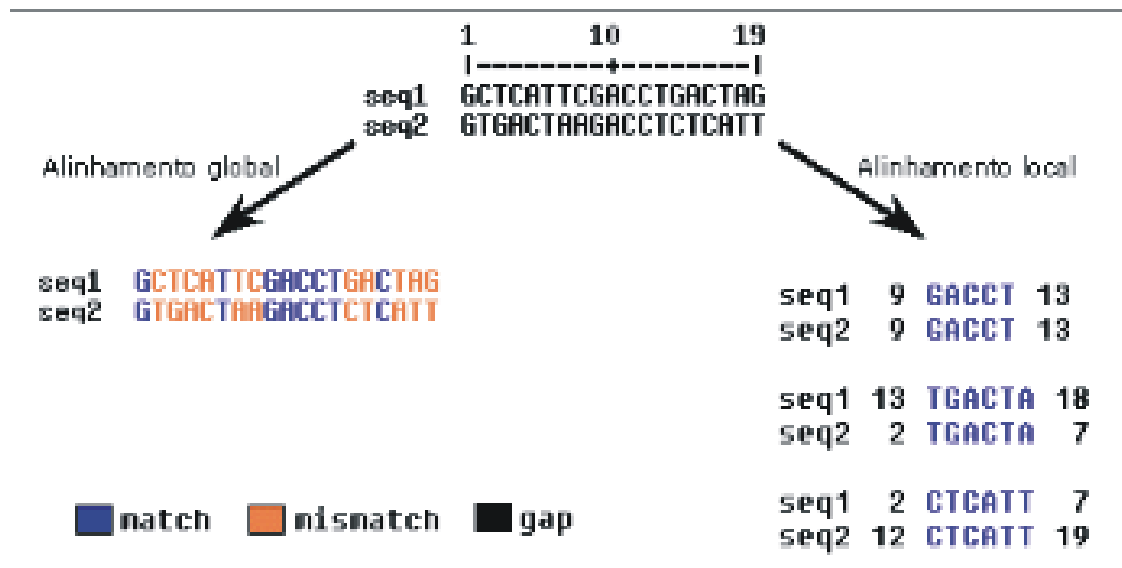

Figura 4: Exemplos de alinhamento global e local. No alinhamento global as seqüências são alinhadas do início ao fim, já no alinhamento local alinha-se as subseqüências conservadas

\section{Projetos genoma e transcriptoma}

Grande parte dos bioinformatas modernos trabalha com dados de projetos genoma ou transcriptoma. Em projetos genoma adota-se a abordagem de fragmentar todo o genoma de um organismo em pequenos pedaços e de seqüenciar tais pedaços, utilizando programas computacionais para montá-los e reconstituir a informação genômica inicial. Essa estratégia é adotada principalmente devido à restrição do tamanho da seqüência que pode ser lida nos seqüenciadores. Mesmo os mais modernos conseguem ler apenas cerca de 1000 pares de base em cada

\section{BOX4 - Softwares mais utilizados para o alinhamento de seqüências}

ClustalWhttp://www.ebi.ac.uk/clustalw/index.html

Versão web de um dos programas de alinhamento múltiplo mais utilizados (Clustal). Fornece ao usuário uma grande quantidade de parâmetros e de saídas diferentes. Possui interface gráfica onde os alinhamentos podem ser visualizados de forma agradável e alterados.

Multialin http://prodes.toulouse.inra.fr/multalin/multalin.html Programa de alinhamento múltiplo bastante conhecido. Fácil e rápido. Fastahttp://www.ebi.ac.uk/fasta33/

Precursor dos programas de alinhamento.

Promove serviço de busca em banco de dados de ácidos nucléicos e proteínas.

BLAST, BLAST2sequences http://www.ncbi.nlm.nih.gov/BLAST/

BLAST é o programa de alinhamento mais utilizado no mundo. Realiza a busca por seqüências homólogas em banco de dados de ácidos nucléicos e proteínas. O programa BLAST 2 sequences consiste no algoritmo BLAST para alinhamento de duas seqüências. corrida.

Em projetos genomas de procariotos, normalmente realiza-se a quebra do DNA inteiro do organismo desejado em fragmentos pequenos (através da técnica de shotgun) que são clonados em vetores plasmidiais que serão seqüenciados em suas extremidades. Após uma primeira etapa de montagem desse genoma, fragmentos maiores são clonados em cosmídeos e seqüenciados. Essa segunda etapa é importante para a montagem do genoma completo do organismo, já que a primeira normalmente produz uma seqüência incompleta, apresentando alguns buracos de seqüência ( $g a p s$ ).

Já em projetos genomas de organismos eucariotos, que possuem freqüentemente uma enorme quantidade de DNA, normalmente prefere-se adotar uma técnica conhecida como shotgun hierárquico. Nessa técnica, o DNA inteiro do organismo é primeiramente inserido em grandes vetores de clonagem, como cromossomos artificiais de bactérias (BACs) ou de leveduras (YACs). Depois então é realizado um shotgun desses grandes fragmentos dos vetores, gerando fragmentos menores que são agora clonados em vetores plasmidiais para o sequenciamento. Portanto, tais projetos consistem de duas etapas, a montagem de cada um dos grandes fragmentos clonados nos BACs e YACs e a montagem final que reunirá as seqüências completas dos BACs e YACs montados para a reconstituição da informação genômica inicial. 


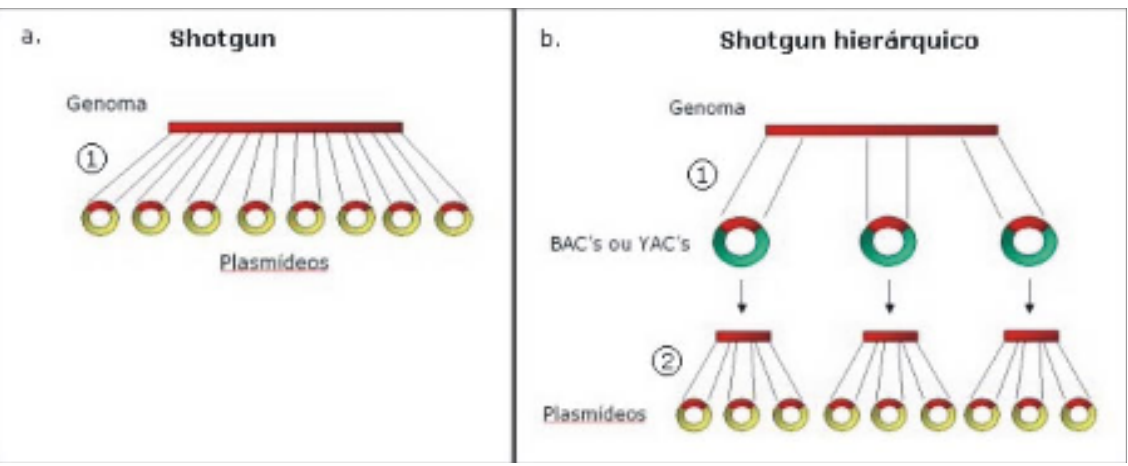

Figura 5. a) Na estratégia de shotgun, todo o DNA genômico de um organismo é fragmentado em pequenos pedaços (1), que são clonados em vetores de pequeno porte, como plasmídeos, para o posterior seqüenciamento. b) Na estratégia de shotgun bierárquico, normalmente utilizada para grandes genomas, realizam-se dois passos. (1) Primeiramente fragmenta-se o genoma em grandes pedaços, que são clonados em vetores de grande porte, como BACs ou YACs. (2) Posteriormente realiza-se uma segunda etapa de shotgun, onde as seqüências contidas nesses vetores são fragmentadas em pequenos pedaços e clonadas em vetores de pequeno porte, que serão sequenciados

Muitas vezes, ao invés de ser realizado o seqüenciamento genômico de um organismo eucarioto, prefere-se realizar o seqüenciamento só das regiões gênicas, utilizando informações oriundas de RNA mensageiro (mRNA). Dessa forma é realizada uma biblioteca de cDNA, representando o conjunto de mRNAs de uma célula, que são clonados em vetores plasmidiais. Os insertos de cDNA presentes em tais vetores são então seqüenciados a partir de suas extremidades 5' ou 3', produzindo pequenas seqüências que irão representar pedaços dos genes expressos no momento da extração do mRNA da célula em questão. Esses pedaços seqüenciados representam etiquetas de genes expressos, ou ESTs (Expressed Sequence Tags) e uma análise dos genes expressos é uma abordagem bastante utilizada na tentativa de entender o funcionamento do metabolismo dos mais diversos organismos. Como exemplo, no Brasil abordagens transcriptômicas já foram utilizadas em larga escala no projeto da canade-açúcar e vêm sendo utilizados em organismos parasitas, como é o caso dos projetos de seqüenciamento de ESTs de Schistosoma mansoniem São Paulo e em Minas Gerais.

Como já foi mencionado anteriormente, normalmente adota-se a estratégia de seqüenciamento genômico em organismos cujo genoma é pequeno e que contém baixa quantidade de seqüências repetitivas. Entretanto, a estratégia de seqüenciamento do transcriptoma, ou a produção de ESTs, não é utilizada apenas quando o genoma do organismoé muito grande. Essa estratégia é importante também para estudaro desenvolvimento dos organismos, produzindo bibliotecas de diferentes fases de desenvolvimento e observando quais genes são expressos em cada momento. Tal abordagem também é importante para estudarmos como ocorre a expressão diferencial de genes em diferentes órgãos de um mesmo organismo, para que possamos entender a função desses órgãos ou como eles realizam funções conhecidas. Portanto podemos dizer que as estratégias de seqüenciamento de genomas e transcriptomas são complementares e ambas devem ser realizadas, quando possível, para que possamos obter informações relevantes sobre os organismos que estamos estudando.

\section{Base calling}

Os dados brutos provenientes do seqüenciador de DNA são normalmente submetidos diretamente a algum programa de base calling. O base calling consiste no processo de leitura dos dados do seqüenciador e identificação da seqüência de DNA gerada, atribuindo ainda um valor de qualidade para cada posição nucleotídica identificada. Normalmente cada seqüenciador apresenta um programa de base calling associado. Entretanto, o programa mais utilizado nessa etapa é o PHRED.

O PHRED reconhece dados de seqüências a partir de arquivos $S C F$ (Standard Chomatogram Format), arquivos de cromatograma dos analisadores automáticos de DNA $A B I$ e arquivos MegaBA$C E$ ESD. Este software reconhece a seqüência de nucleotídeos a partir do arquivo de dados brutos do seqüenciador, atribui valores de qualidade às bases constituintes da seqüência nucleotídica e gera arquivos de saída contendo informações sobre o base calle os valores de qualidade. O valor de qualidade das seqüências analisadas pode ser encontrado nos arquivos FASTA e PHD.

De acordo com Ewing et al (1998) as atribuições seguras de valores às seqüências nucleotídicas são proporcionadas pela implantação de um algoritmo que tem como base os métodos de Análise de Fourier. O algoritmo analisa as quatro bases e prediz a provável região central dos picos e as distâncias relativas entre os picos da seqüência de DNA. O valor de qualidade atribuído a cada base é obtido pela fórmula a seguir, que calcula a probabilidade de erro no base call, onde o Peé a probabilidade de uma base estar errada.

$$
\text { PHRED Quality = }-10 \log (P e)
$$

As pontuações inseridas nos arquivos de saída do PHRED representam a probabilidade logarítmica negativa em escala de erro de um base call; portanto, quanto maior o valor de qualidade do PHRED, menor a probabilidade de ter ocorrido um erro. Só como exemplo, um valor de PHRED 20 para uma determinada posição nucleotídica significa que ela apresenta uma chance em 100 de estar errada. Já um valor de PHRED 30 significa que determinada base apresenta uma chance em 1000 de ter havido um erro no base calling. Esses valores são importantes para determinar se uma região precisa ser resseqüenciada.

\section{Mascaramento de vetores}

A estratégia freqüentemente adotada após a realização do base calling é a 
procura por regiões de contaminantes na seqüência produzida. Regiões contaminantes são partes da seqüência obtida que não representam o DNA ou o cDNA que se deseja analisar. Tais regiões representam, normalmente, partes dos vetores de clonagem onde as seqüências de interesse foram inseridas ou pedaços de DNA adaptadores utilizados durante a construção das bibliotecas. Como essas regiões não representam as seqüências que se deseja analisar, elas devem ser retiradas ou mascaradas por um programa. E aqui, o programa mais utilizado é o Cross_match. Esse é, na verdade, um programa para a comparação de duas seqüências e é preciso utilizar como entrada um arquivo apresentando a seqüência dos vetores que se deseja mascarar. O que o Cross_match faz é comparar a seqüência desejada com o arquivo de seqüências de vetores e, onde o programa encontrar similaridade entre as seqüências, ele irá mascarar (acrescentando letras $\mathrm{X}$ ) a seqüência de entrada. Assim, os nucleotídeos das seqüências de entrada similares a regiões de vetores de clonagem serão alterados para X e não atrapalharão os processos posteriores de análise computacional.

\section{Agrupamento de seqüências}

Após a geração de arquivos sem contaminantes, contendo a identificação das bases e a qualidade, todas essas informações são repassadas a um software de montagem como o PHRAP, O CAP3 ou o TIGR Assembler. O softwaremais utilizado nessa etapa, o PHRAP (Phragment Assembly Program) é o programa responsável pela leitura das informações do base calle montagem dos pequenos fragmentos de DNA seqüenciados em seqüências maiores, os contíguos (contigs). Este programa possui diversos pontos chaves para a obtenção de resultado final satisfatório, como: construção de seqüência do contíguo através de um mosaico de partes das seqüências com alta qualidade; utilização de informações da qualidade dos dados computados internamente e de implementações feitas pelos usuários para aumentar a qualidade da montagem; apresenta extensivas informações sobre a monta- gem realizada (incluindo valores de qualidades para a seqüência dos contíguos). Em projetos genoma espera-se obter, na saída do PHRAP, a seqüência montada do contíguo genômico. Já em projetos trancriptoma esperamos obter as seqüências de cada dos genes expressos após a execução deste software de montagem.

A visualização e edição das seqüências geradas após a montagem são realizadas normalmente através do programa Phrapview ou Consed.

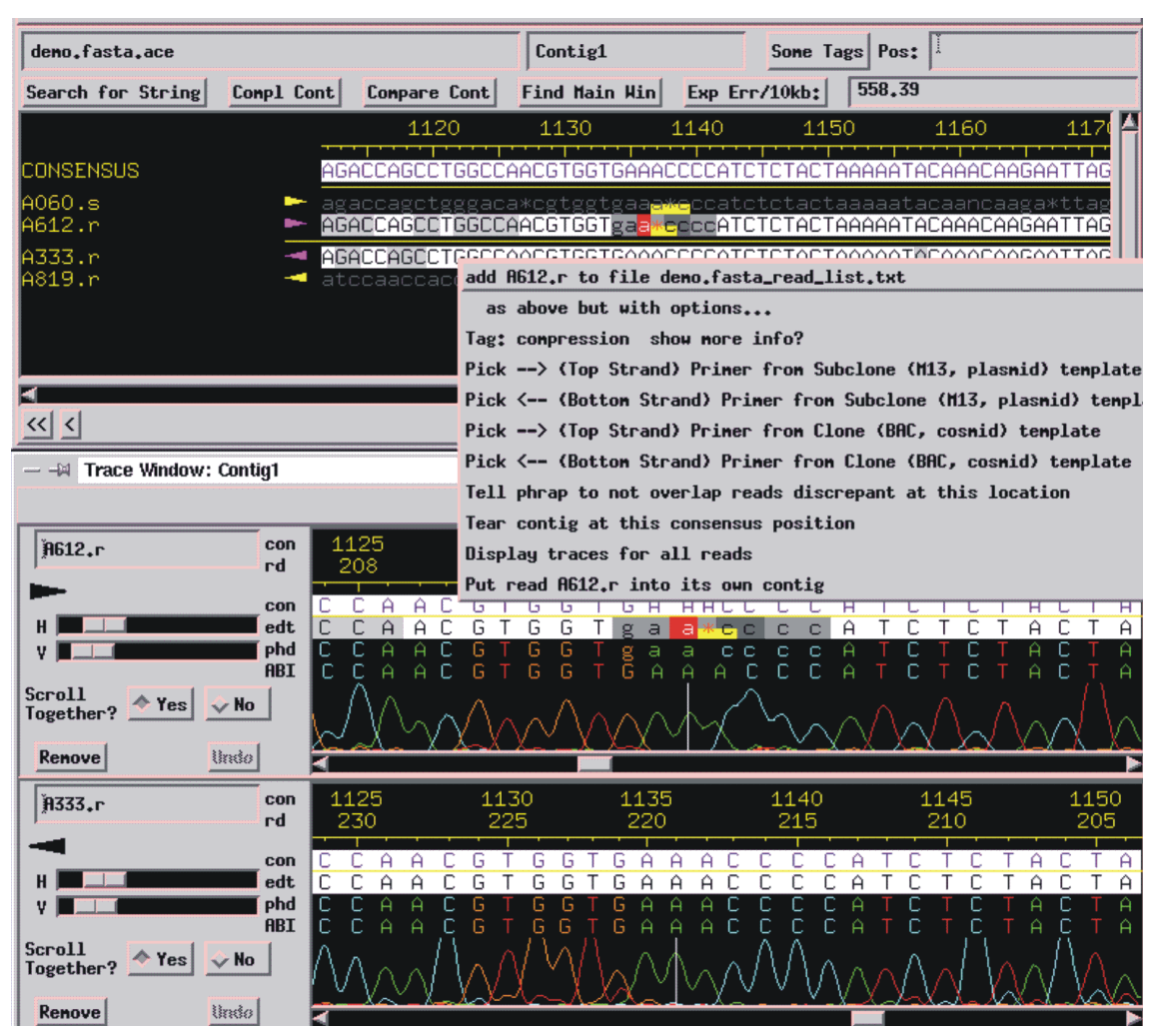

Figura 6: Interface do programa Consed

\section{BOX5 - Programas mais utilizados em projetos genoma e transcriptoma}

\section{PHRED http://www.phrap.org}

Software para a realização do base calling e a produção do cromatograma processado.

CROSS-MATCH http://www.phrap.org

Software para a comparação entre duas seqüências de DNA. Normalmente utilizado para o mascaramento de regiões representando vetores em seqüências genômicas ou de cDNA. Distribuído juntamente com o PHRAP.

PHRAP http://www.phrap.org

Software mais utilizado para a realização do agrupamento de seqüências (clustering analysis) e montagem de contíguos genômicos.

CAP3 http://genome.cs.mtu.edu/cap/cap3.html

Software utilizado para o agrupamento de seqüências e montagem de contíguos genômicos. Utiliza um algoritmo diferente do PHRAP.

CONSED http://www.phrap.org

Software mais utilizado para a visualização dos resultados obtidos por softwares de agrupamento de seqüências. Permite a edição das bases seqüenciadas, além de diversos outros recursos. 


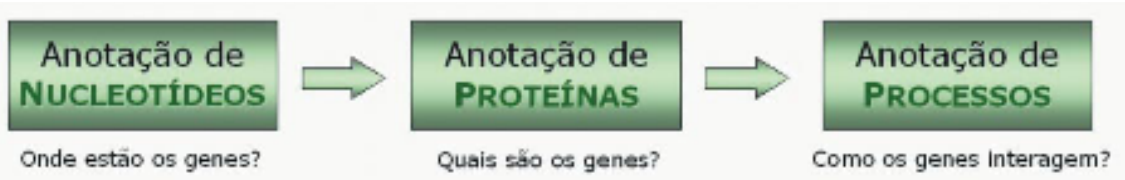

Figura 7: Etapas da anotação em projetos genoma e as perguntas que se deseja responder em cada uma delas

A partir da anotação de seqüências nucleotídicas procura-se, primeiramente, identificar a natureza de uma determinada seqüência. Devemos descobrir se tal seqüência está inserida em uma região gênica, se representa uma molécula de RNA transportador ou RNA ribossômico, se pertence a algum tipo de região repetitiva já descrita ou se apresenta algum marcador genético conhecido em seu interior. O principal objetivo dessa etapa é construir um mapa do genoma do organismo, posicionando cada um dos possíveis genes e caracterizando as regiões não-gênicas. Nesta fase, alguns programas de predição gênica são usados para a localização de possíveis genes nas seqüências de DNA. A procura por elementos como o códon de iniciação de proteínas (a trinca de nucleotídeos ATG) e códons de terminação na mesma fase de leitura são utilizados por alguns desses programas. O tamanho delimitado por esta janela de leitura é freqüentemente utilizado para definir uma determinada região como sendo gênica ou não. Alguns outros programas são capazes de identificar, dependendo do genoma analisado, regiões gênicas codificadoras (éxons) e não codificadoras (íntrons). Alguns exemplos são o GenomeScan e o GenScan. Em projetos de trancriptômica, onde se utiliza a abordagem de seqüenciamento de ESTs, essa etapa não é realizada, uma vez que todas as seqüências produzidas se restringem a regiões gênicas.

Mapeados os genes, a etapa seguinte consiste em identificar quais proteínas são codificadas, e nisso consiste o processo de anotação das seqüências protéicas. Nessa etapa, procura-se montar um catálogo dos genes presentes no organismo estudado, dando-lhes nomes e associando-os a prováveis funções. No caso de projetos genoma, deseja-se identificar o número total de genes presentes no organis- mo seqüenciado, já que há informação da seqüencia de DNA de todo o genoma. Já em projetos transcriptoma, a tarefa consiste em identificar os genes expressos no organismo em uma determinada condição. Apesar de não ser capaz de identificar todos os genes de um determinado organismo, os projetos de transcriptômica podem permitir a identificação de genes expressos em diferentes tecidos e fases de desenvolvimento, além de permitir a observação daqueles que apresentam variantes de splicing. Portanto, nessa etapa da anotação, o principal objetivo é identificar e caracterizar cada uma das proteínas codificadas pelos mRNAs presentes no organismo estudado em determinada condição.

A parte mais interessante e desafiadora dos processos de anotação gênica é relacionar, finalmente, a genômica com os processos biológicos, e essa é a etapa de anotação dos processos bioló- gicos. Essa etapa é comum a projetos genoma e transcriptoma. Identificados os genes, devemos agora tentar relacioná-los de modo a obtermos um mapa funcional do organismo estudado. Nesse ponto deve-se identificar quais vias bioquímicas estão completas ou incompletas no organismo e quais vias alternativas ele possui. Aqui é fundamental a participação de biólogos especialistas em diversas áreas para que se possa descobrir como o metabolismo do organismo pode influenciar seu modo de vida e seu comportamento. Esse é o momento onde é possível levantar várias hipóteses que relacionem o funcionamento dos organismos com seus dados genômicos. Tais hipóteses devem ser testadas experimentalmente, por pesquisadores que trabalhem com o organismo estudado.

\section{Como é realizada a anotação}

Até aqui foi mostrado o que é normalmente feito em um processo de anotação gênica. Vejamos agora como tal processo é realizado. Lincoln Stein definiu muito bem como acontece a sociologia dos projetos de anotação gênica. Ele dividiu o processo de anotação de genomas em três etapas: a fábrica, o museu e a festa.

\section{BOX6 - Principais softwares utilizados durante a anotação gênica}

Repeat Masker http://repeatmasker.genome.washington.edu/

Utilizado para a identificação e o mascaramento de regiões repetitivas freqüentemente encontradas em genomas.

Genscan http://genes.mit.edu/GENSCAN.html

Utilizado para a predição de genes em genomas eucarióticos. Seu método de predição é baseado em cadeias escondidas de Markov.

tRNAscan-SE http://www.genetics.wustl.edu/eddy/tRNAscan-SE/

Utilizado para encontrar genes de tRNA em uma seqüência genômica.

BLAST http://www.ncbi.nlm.nih.gov/BLAST

Utilizado para encontrar similaridades entre seqüências de nucleotídeos e proteínas contra bancos de dados com grande número de seqüências dos mais diversos organismos. É um dos principais programas utilizados na identificação dos genes.

Interpro http://www.ebi.ac.uk/interpro

Utilizado para realizar buscas contra diferentes bancos de dados de domínios e famílias de proteínas. Integra os serviços do Pfam, PRINTS, ProDom, PROSITE, SMART, TIGRFAMS E SWISS-PROT.

GeneOntology http://www.geneontology.org

Consórcio destinado a produzir um vocabulário comum a ser aplicado para a classificação dos genes presentes em organismos eucarióticos. Cada gene é classificado em três níveis: função molecular, processos celulares e localização celular. 
Na primeira etapa trabalham apenas as ferramentas de bioinformática, funcionando em larga escala, como uma fábrica. Assim, as seqüências obtidas passam por uma grande diversidade de programas, que devem ajudar os anotadores a identificá-las e agrupá-las para a próxima fase.

A segunda etapa necessita de especialistas que observem os dados obtidos na primeira etapa pelas ferramentas automáticas e que, como curadores de um museu, identifiquem as seqüências de acordo com critérios pré-definidos.

Após a identificação dos genes, é feita a anotação dos processos. Nesse momento deve-se promover a interação entre vários anotadores, bioinformatas e biólogos especialistas em diferentes áreas e no organismo estudado. Nessa festa deve-se discutir como as informações obtidas nas etapas anteriores podem estar relacionadas com a biologia do organismo em questão.

\section{A era pós-genômica}

Uma das características mais fascinantes da explosão, ocorrida nos últimos 10 anos, de projetos e consórcios destinados a compor o genoma completo dos mais diversos organismos, foi o estabelecimento de abordagens e tecnologias que permitiram um estilo "linha-de-montagem" na obtenção, em tempos cada vez mais curtos, de quantidades "industriais" de seqüências de ácidos nucleicos (DNA e RNA). Agora começamos a enfrentar o problema de interpretar e adicionar significado a essas seqüências. Temos agora que, a partir dos bancos de dados existentes, processar e correlacionar os dados brutos transformando-os em informação e a partir desta informação gerar conhecimento, que é a informação testada experimentalmente. No final, esta nova etapa promete ser uma jornada, provavelmente sem fim, através das proteínas, suas estruturas e funções, vias metabólicas e interações celulares. Esta mudança do foco de atenção, dos ácidos nucleicos para as proteínas, tem sido utilizada para batizar esta nova etapa da pesquisa biológica em larga escala como "Era Pós-Genômica". Contudo, trata-se apenas de mais uma etapa e, certamente, não a última para que os frutos dos programas de seqüenciamento de genomas possam ser colhidos. Etapas estas que foram previstas pelo Projeto do Genoma Humano. Das cinco metas a serem atingidas, o estudo da expressão de proteínas e a obtenção de mapas de interação proteína-proteína ocupam o segundo e terceiro estágios, dos quais se espera o maior impacto econômico, levando à descoberta de novas drogas e reduzindo o seu tempo de entrada no mercado.

Resumidamente, na Era Pós-Genômica procura-se estudar a expressão dos genes codificados pelo genoma dos organismos, tecidos, células ou compartimentos celulares em determinadas condições fisiológicas (por exemplo, uma doença, uma situação de estresse ou ainda a administração de uma droga). Tentando entender a resposta a essas condições, são alvos de estudos: a ativação ou repressão de determinados genes, a indução de mudanças no estado pós-traducional das proteínas e qualquer processo que resulte na modificação do número e/ ou da composição das proteínas existentes.

\section{Análise da Expressão Gênica}

Lembrando do dogma central da biologia (DNA $\rightarrow$ mRNA $\rightarrow$ Proteína), é facil perceber que podemos avaliar a expressão gênica através da análise de transcritos (mRNA).

Em organismos eucariotos, a facilidade de isolamento dos mRNAs (usando oligonucleotídeos poli-T para capturar os mRNAs pela cauda poli-A), a possibilidade da transcrição reversa do mRNA para cDNA (usando a técnica de RT-PCR) e o domínio das técnicas de seqüenciamento em massa de cDNAs tornaram possível a análise qualitativa e quantitativa, em larga escala, dos genes transcritos em organismos, tecidos e células. Desta forma, nos projetos Transcriptoma, como já comentado, é feito o seqüenciamento parcial de cDNAs representativos da população de mRNA de maneira a permitir a identificação de diferentes transcritos (pela comparação das seqüências do cDNA) e sua abundância na população (pelo número de vezes em que cada transcrito é seqüencia- do). As técnicas mais usadas são as de ESTs e SAGE (Serial Analysis of Gene Expression). Nesta última técnica, mais recente, são gerados e seqüenciados concatâmeros de fragmentos de cDNAs com apenas 10 ou 17 nucleotídeos de cada mensageiro, respectivamente denominados $S A G E$ tagse $S A G E$ long tags.

\section{DNA chips e Microarrays}

Uma outra forma de análise de transcritos, que permite a busca de transcritos de genes específicos na população dos mRNAs expressos, usa o já conhecido princípio da hibridação de DNA a sondas moleculares. As mais novas versões da técnica são os $D N A$ chipse os microarrays, que permitem a análise simultânea da expressão de milhares de genes. Nestas duas técnicas, respectivamente, oligonucleotídeos ou fragmentos de cDNA conhecidos são ligados a uma lâmina de vidro e, em cada experimento de hibridação, os mRNAs de dois tipos celulares diferentes ou de células em duas condições patológicas ou tratamentos são analisados. As duas populações de mRNAs são amplificadas e marcadas com diferentes corantes fluorescentes (cianinas ou Cys), um verde e outro vermelho. Ao hibridarem com cada gene (oligo ou cDNA) aplicado sobre a lâmina de vidro, a cor verde ou vermelha de cada ponto (ou spot) indicará que esse gene está sendo mais transcrito em um tipo ou condição celular do que no outro. A cor amarela indicará que o gene é transcrito igualmente em ambos os tipos ou condições celulares. Além disso, a maior ou menor intensidade de cada cor indicará maior ou menor nível de expressão do gene.

A enorme quantidade de dados gerada nos experimentos de DNA chips e microarrays são analisados por softwares específicos que envolvem métodos de inferência estatística. Uma etapa bastante importante na fase de análise dos resultados é a que chamamos de normalização. Usando como referência os spots de genes controles (sabidamente expressos ou reprimidos nos tecidos ou células estudados), o que se busca é, basicamente, retirar dos valores de cada spota influência de 
manchas espúrias (background) e de variações do processo de hibridação. Desta forma, após a normalização, torna-se possível a comparação de spots de uma mesma lâmina ou de experimentos diferentes. Em uma etapa posterior, programas de clustering procuram identificar e agrupar os spots super-expressos, reprimidos ou que não tem expressão alterada nos tecidos ou células analisadas. Apesar dos métodos de análise empregados, a falta de reprodutibilidade dos resultados ainda é uma queixa bastante comum. O uso de maior número de réplicas de cada spot e/ou a busca de métodos de inferência estatística mais adequados parecem ser úteis para a validação destes resultados.

Mais recentemente, com novas técnicas para isolamento de mRNA de procariotos, projetos de ESTs e de microarray também têm sido desenvolvidos para estes organismos. Vários grupos de pesquisa em todo o Brasil estão iniciando projetos nesta área. Apenas como exemplo, entre os vários projetos brasileiros nesta área temos o projeto Cooperation for Analysis of Gene Expression (CAGE) (http:// bioinfo.iq.usp.br/ehttp://www.vision. ime.usp.br/ cage/) e o Projeto Genoma Raízes da Embrapa Soja (http:// www.cnpab.embrapa.br/pesquisas/ gp.html)

\section{Projetos Proteoma}

Um problema que surge com a abordagem descrita acima, de avaliação da expressão gênica a partir da análise dos mRNAs transcritos, é que nem sempre a quantidade de um mRNA reflete a quantidade da proteína correspondente expressa na célula e, assim, não podemos relacionar diretamente essa proteína a uma função nas células. Por isto, uma outra abordagem, embora muito mais trabalhosa, tem sido usada para avaliar a expressão gênica: a análise das proteínas expressas. Esta "contrapartida protéica" do genoma é conhecida como proteoma. Por permitir relacionar diretamente a uma proteína determinada função, esta abordagem constitui um instrumento particularmente poderoso para elucidar os mecanismos celulares relaciona-

\section{BOX7 - Exemplos de Projetos Transcriptoma:}

Procuram avaliar quais são os genes expressos, e quanto deles é expresso, a partir do seqüenciamento parcial dos mRNAs transcritos.

Dados obtidos pela técnica de SAGE podem ser consultados na página http:/ /www.ncbi.nlm.nih.gov/SAGE/.Já no banco dbEST estão depositadas ESTs de diversos Projetos Transcriptoma desenvolvidos em todo o mundo (http:/ /www.ncbi.nlm.nih.gov/dbEST/).

\section{Mais informações sobre DNA Chips e Microarrays}

Nestas técnicas, a verificação da expressão de genes específicos é feita em experimentos de hibridação em lâminas de vidro contendo milhares de fragmentos de DNA.

Na página http://cmgm.stanford.edu/pbrown/, do pioneiro da técnica de microarray, Dr. Patrick Brown, há mais explicações, um forum de discussão e bancos de dados de microarrays. Na página http://ihome.cuhk.edu.hk/ b400559/array.html há informações sobre os equipamentes necessários, uma tabela de comparação dos programas de análise mais usados, noções de estatística aplicadas a microarrays, sugestões de bibliografia, etc.

\section{Programa gratuíto para análise de microarrays}

ScanAlyse: escrito por Michael Eisen, o programa pode ser obtido gratuitamente na página http://rana.lbl.gov/EisenSoftware.htm. Assinando um termo de compromisso, o autor permite, inclusive, o acesso ao código-fonte.

dos ao desenvolvimento de doenças, ao mecanismo de funcionamento de compostos químicos (por exemplo, fármacos) e identificar novos alvos terapeuticos.

As bases experimentais da proteômica não são novas e pertencem ao arsenal "clássico" da bioquímica, mas houve, nos últimos anos, um salto qualitativo e quantitativo sem precedentes Esse salto foi resultado de grandes investimentos privados na busca de abordagens mais agressivas e rápidas no isolamento, identificação e caracterização de proteínas, no mesmo estilo "industrial" que caracterizou a era genômica. O isolamento de proteínas em grande número, inicialmente repousava nas técnicas eletroforéticas, como a eletroforese mono e bi-dimensional em géis de poliacrilamida. Embora tais técnicas certamente sempre venham a ter um papel importante em qualquer laboratório de proteômica, nota-se hoje uma tendência cada vez maior no uso da cromatografia líquida de alta eficiência, com o uso de colunas capilares, no desempenho desta tarefa. A identificação e caracterização das proteínas depende de um conjunto de tecnologias (com certeza as que mais sofreram incremento no desempenho) envolvendo a espectrometria de massa, a ressonância magnética nuclear, além de recursos computacionais para a armazenagem, análise e compartilhamento dos diversos tipos de dados gerados por estas tecnologias (imagens de géis bidimensionais, sequências protéicas, estruturas protéicas, espectros de massa, etc.).

Nos últimos anos a espectrometria de massa, em conjunto com a cromatografia líquida de alta performance, vem se tornando a abordagem preferida para identificar e caracterizar proteínas, devido essencialmente a três motivos. O primeiro é o desenvolvimento de novos métodos para ionização de proteínas e peptídeos, especialmente o MALDI e o ESI (Matrix-Assisted Laser Dessorption-Ionizatione ElectroSpray Ionization). O segundo é o desenvolvimento de recursos da bioinformática, permitindo a análise de dados obtidos por espectrometria de massas em bancos genômicos e de sequências protéicas. E o terceiro é que a espectrometria de massas fornece informação detalhada de modificações pós-traducionais, em particular as fosforilações e glicosilações. 


\section{BOX8 - MALDI e ESI}

\section{MALDI - Matrix-Assisted Laser Desorption-Ionization}

Uma amostra de proteína ou peptídeo é misturada com um largo excesso de uma matriz, formada por uma substância que absorve no ultra-violeta, e posta para secar. Um lasercom um comprimento de onda que seja absorvido pela matriz, em um compartimento sob vácuo, incide sobre a amostra seca e fragmentos ionizados da amostra são carreados pela vaporização da matriz e capturados por um campo elétrico do analisador de massas.

\section{ESI - ElectroSpray Ionization}

Um voltagem aplicada em uma fina agulha contendo uma solução protéica, gera uma névoa de pequenas gotículas da solução, contendo pequeno número de moléculas protéicas. A redução das gotículas por evaporação acaba colocando em fase gasosa as proteínas ionizadas. Elas são então capturadas pelo analisador de massas. A grande vantagem desta técnica é permitir o acoplamento direto de um sistema cromatográfico de alta eficiência ao espectrômetro de massas, possibilitando a análise em fluxo contínuo de misturas protéicas complexas.

No Brasil, apenas agora começamos a montar grupos de pesquisa nesta área. Merecem destaque as redes de proteômica em São Paulo, sediada no Laboratório Nacional de Luz Síncrotron (http://www.lnls.br/), e no Rio de Janeiro (http://www.faperj.br/ interna.phtml?obj_id=219). mero de proteínas codificadas pelo genoma da espécie humana (o que ainda hoje é discutido), é previsível que em alguns anos possamos conhecer de 4000 a 10000 proteínasalvo, sobre as quais medicamentos poderão agir. Para termos uma idéia da grandeza destes números, todo o

\section{BOX9 - Links interessantes}

Eletroforese bi-dimensional em géis de poliacrilamida (PAGE-2D)

http://us.expasy.org/ch2d/protocols/

http://www.aber.ac.uk/parasitology/Proteome/Tut_2D.html

Cromatografia líquida de alta eficiência, com o uso de colunas capilares (HPLC)

http://www.ionsource.com/tutorial/chromatography/rphplc.htm

http://www.ionsource.com/tutorial/capillary/introduction.htm

\section{Espectrometria de Massas (MS)}

http://ms.mc.vanderbilt.edu/tutorials/ms/ms.htm

\section{Software gratuíto para análise de PAGE-2D - Melanie}

Desenvolvido no Swiss Prot, está disponível diretamente na página do Swiss Prot, http://www.expasy.org/ ou num link na página http:// www.science.gmu.edu/ ntongvic/Bioinformatics/software.html, que dá acesso a muitos outros programas de bioinformática.

As técnicas experimentais expostas acima, além de oferecerem respostas à curiosidade humana, constituem formas inovadoras na pesquisa para o combate de problemas globais como diabetes, câncer, hemofilia, etc... Na prática, independentemente do nú- arsenal terapêutico que conhecemos hoje atua sobre apenas 500 delas. O número de drogas disponíveis hoje nos EUA, derivadas destas novas tecnologias, chegou a 103 no ano passado (21 delas foram aprovadas em 2000).

\section{Modelagem molecular}

Ainda neste sentido, procurando associar proteínas a suas funções, a bioinformática pode e deverá trazer, nas próximas décadas, suas maiores contribuições à biologia. O conhecimento da estrutura terciária de uma proteína constitui uma informação valiosa para determinação de sua função, pois pode permitir a identificação de domínios conhecidos, como sítios catalíticos, sítios de modificação alostérica e outros.

Além disso, tendo as estruturas tridimensionais das proteínas determinadas, podemos então realizar pesquisas mais direcionadas no sentido de encontrar inibidores, ativadores enzimáticos e outros ligantes que permitam a produção de fármacos mais eficientes e específicos: o almejado Desenvolvimento Racional de Fármacos (Rational Drug Design).

Atualmente a abordagem mais eficaz na determinarção da estrutura terciária de proteínas é aquela que se utiliza de técnicas experimentais como NMR (Ressonância Magnética Nuclear) e cristalografia por difração de raios-X. Dezenas de milhares de protéinas tiveram suas estruturas terciárias conhecidas através destes métodos e têm fornecido dados para o desenvolvimento de programas de modelagem e para a modelagem por homologia. Entretanto os métodos experimentais são, frequentemente, procedimentos dispendiosos e de difícil execução. Além disso, existem limitações técnicas que dificultam a determinação de várias proteínas. A obtenção de cada proteína pura é um desses fatores limitantes. Outro fator é a dificuldade de cristalização das proteínas, etapa necessária para a determinação de estrutura por difração de raios-X. Este é um problema comum em proteínas de membrana ou glicosiladas. Mesmo usando robôs para acelerar o processo experimental, estas e outras dificuldades fazem com que a determinação de novas estruturas protéicas não consiga acompanhar a velocidade de obtenção de dados dos projetos genoma. 


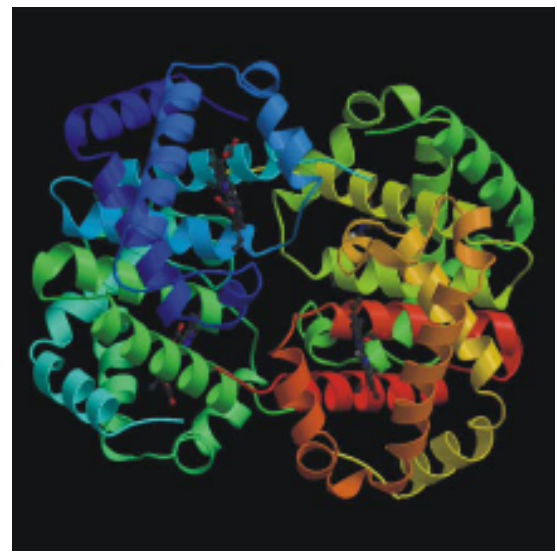

Figura 8: Estrutura terciária e quaternária da Deoxibemoglobina humana obtida por Difração de Raios Xe depositada no PDB. A

molécula é um tetrâmero, composta por 4 cadeias, e ligada a 4 átomos de ferro

A modelagem molecular é um método alternativo, não experimental, que permite, com base nos conhecimentos da estereoquímica dos aminoácidos e nas informaçoes adquiridas das estruturas terciárias já resolvidas, prever a conformação de proteínas a partir da seqüência primária dos aminoácidos.

Uma das formas de se realizar a modelagem de proteínas é utilizar como referência uma ou mais protéinas homólogas e de estrutura terciária já conhecida. Este tipo de modelagem é conhecido como modelagem por homologia ou modelagem comparati$v a$, e, por enquanto, é a abordagem que obtém melhores resultados. O primeiro passo do processo é a pequisa de proteínas homólogas em bancos de dados de estruturas terciárias de proteínas. O PDB (Protein Database Bank) é o mais utilizado para este fim. A seguir, deve ser realizado o alinhamento das seqüências de aminoácidos das protéinas homólogas e a proteínaalvo (o programa Clustal, citado anteriormente no artigo, pode ser usado). A modelagem, propriamente dita, é realizada através de softwares como o Modeller, SWISS-MODEL, 3D-PSSM, dentre outros. Esses programas normalmente procuram encontrar a estrutura terciária que melhor se aproxime da disposição dos átomos das proteínas utilizadas como modelo, e ao mesmo tempo atenda às restrições este- reoquímicas. Após a definição de uma estrutura candidada, esta pode ser avaliada através de outros softwares de verificação de restrições estereoquímicas, como o programa Procheck.

A modelagem por homologia é um processo iterativo de ajuste de parâmetros e verificação dos resultados. Normalmente é necessário que o processo seja repetido várias vezes até que uma estrutura terciária adequada seja obtida. Além disso, a modelagem de proteínas, como um todo, é uma técnica heurística: mesmo que a estrutura obtida concorde perfeitamente com todas as restrições impostas, não há garantias de que esteja correta. Deve-se lembrar que uma estrutura bastante semelhante à real pode ser o suficiente para formulação de novas hipóteses e atingir as expectativas do usuário desta técnica.

Uma abordagem recente, que possui um crescente números de adeptos e acumula bons resultados, é a modelagem através de threading de proteína. Esta técnica é baseada na comparação da proteína em questão com modelos descritivos dos enovelamentos de proteínas homólogas. Nesses modelos são descritas: a distância entre os resíduos de aminoácidos, a estrutura secundária de cada fragmento e as características fisico-químicas de cada resíduo.

Entretanto, um grande desejo dos que trabalham com proteínas é o desenvolvimento de programas realmente eficientes para a modelagem $a b$ initio, ou seja, que sejam capazes de predizer a estrutura terciária de uma proteína, tendo como informação apenas a seqüência dos resíduos de aminoácidos e suas interações fisico-químicas, entre si e com o meio. Programas assim existem hoje mas têm muito a melhorar para que possamos confiar unicamente no seu resultado.

No geral, a modelagem de proteínas através de programas de computador é um campo de pesquisa recente e ainda não gerou softwares de eficiência comprovada. Para estimular o desenvolvimento de programas de molelagem molecular de proteínas, foi criado um evento para a avaliação desses softwares denominado CASP (Critical Assesment of Structural Prediction). A cada dois anos este evento reúne os mais conhecidos pesquisadores desta área, que são desafiados e suas diferentes metodologias avalia-

\section{BOX10 - Programas e sites relacionados com modelagem e estrutu- ras de proteínas}

PDB http://www.rcsb.org/pdb/

Mais famoso e completo banco de dados de estrutura de proteínas.

Protein explorer http://molvis.sdsc.edu/protexpl/

Programa derivado do RasMol para a visualização de estruturas de proteínas.

SWISS-PDBviewer http://www.expasy.org/spdbv/

Programa para a visualização e análise da estrutura de várias proteínas ao mesmo tempo. Permite a realização de mutações de aminoácidos, alterações em pontes de hidrogênio, ângulos de torção e distâncias entre átomos.

Modeller http://guitar.rockefeller.edu/modeller

Um dos programas mais utilizados para a modelagem de proteínas por homologia.

SWISS-MODEL http://www.expasy.org/swissmod Programa via web para a modelagem de proteínas por homologia.

PROCHECK http://www.biochem.ucl.ac.uk/ roman/procheck/procheck.html Programa que checa a qualidade estereoquímica de uma estrutura de proteína, gerando análises gráficas sobre a geometria espacial da proteína, resíduo por resíduo.

Libra http://www.ddbj.nig.ac.jp/E-mail/libra/LIBRA_I.html

Programa on-line que utiliza threading para encontrar uma seqüência de resíduos de aminoácidos que melhor se adequem a uma estrutura terciária conhecida e vice-versa.

CASP http://predictioncenter.llnl.gov/Center.html Critical Assesment of Structural Prediction. Competição que avalia os softwares de predição de estrutura de proteínas. 
das. Nesta competição cada grupo recebe seqüências de proteínas tiveram sua estrutura resolvida experimentalmente por NMR e/ou cristalografia por difração de raios $\mathrm{X}$, mas que ainda não foram publicadas. Vence o grupo que conseguir prever ab initio, com maior exatidão, a estrutura do maior número proteínas. Apesar dos esforços, até hoje não houve 100\% de acerto.

\section{Métodos em filogenética molecular}

Uma das aplicações mais antigas da bioinformática é a de desenvolvimento de programas que, a partir das seqüências de DNA ou de proteínas de diferentes organismos, sejam capazes de reconstruir a relação de parentesco entre as espécies, o que chamamos de sistemática molecular, ou de reconstruir o parentesco entre as espécies associando essas informações a uma escala temporal, o que chamamos de filogenia molecular. A representação gráfica desses resultados é feita na forma de árvores filogenéticas.

Atualmente, árvores filogenéticas são extremamente comuns em artigos que abordam assuntos de biologia molecular, refletindo o reconhecimento de que estas árvores representam uma maneira legítima de entender os processos biológicos e a evolução dos mais diversos caracteres. Estes estudos e as ferramentas criadas para este fim têm aplicações tão diversas como procurar entender a origem do homem ou reconstituir a história epidemiológica da AIDS a partir de dados do genoma do vírus HIV.

Para realizar inferências a respeito das relações de parentesco entre organismos, tomando como base seqüências de DNA ou proteínas, o primeiro passo é identificar seqüências de interesse que apresentem ancestralidade comum, ou seja, que sejam homólogas. Para isto, muitas vezes estas seqüências são escolhidas por similaridade nos grandes bancos de dados disponíveis na rede, sem que tenhamos, sobre elas, dados das funções bioquímicas e biológicas que possam confirmar sua homologia. Por isso, é importante ressaltar que, ao fazermos uma reconstrução filogenética, a escolha de seqüências homólogas é fundamental para gerar uma árvore confiável, pois só assim teremos certeza de que esta- remos comparando um mesmo marcador que apresenta similaridades entre vários organismos a partir de uma origem comum, garantindo que eles compartilham um mesmo ancestral. Quando não se comparam caracteres homólogos, pode-se incidir no erro de considerar similaridades sem origem comum e, portanto, com histórias evolutivas diferentes. Uma das formas de avaliar esta escolha é incluir nas análises, seqüências de grupos externos (organismos com historia evolutiva conhecida em relação ao grupo em estudo), que funcionam como controles no processo de reconstrução de parentescos.

Uma vez selecionadas as seqüências homólogas dos organismos de interesse e de grupos externos, será necessário realizar o alinhamento múltiplo entre elas e então gerar árvores filogenéticas a partir de métodos de distância ou de caracteres discretos (máxima parcimônia ou máxima verossimilhança) para podermos realizar a inferência filogenética desejada. Para tanto, os seguintes métodos são freqüentemente utilizados pelos softwares:

\section{Métodos de Distância}

Funcionam basicamente em dois passos, sendo que o primeiro deles é a redução das variações entre seqüências alinhadas a valores de distância dispostos em uma matriz. No segundo passo, estes valores são utilizados na reconstrução filogenética. Um dos métodos de distância mais comuns é a chamada distância p, que expressa o número de sítios variáveis entre duas seqüências com relação ao total de sítios comparados. Além deste, existem também muitos outros modelos evolutivos utilizados para o cálculo de distâncias genéticas, como o Jukes-Cantor, Kimura 2 parâmetros, Tajima e Nei e Tamura 3 parâmetros. Na reconstrução filogenética, os algoritmos mais utilizados são o UPGMA (Unweighted Pair Group Method with Arithmetic means) e o Neighbor-joining, que realizam uma série de cálculos com a matriz de distância gerada a partir do alinhamento para estimar a árvore filogenética.

\section{Máxima Parsimônia (MP)}

Este método baseia-se na teoria de que a melhor hipótese para explicar um processo é aquela que requer o menor número de passos. Para a análise filogenética, isto significa que a árvore que possuir um menor número de mudanças (substituições) para explicar os dados do alinhamento é a mais próxima da real. Na MP não há a fase de cálculo de distância, sendo que as árvores são calculadas diretamente dos dados do alinhamento. Entretanto, esta metodologia requer muito mais tempo quando se usa a busca exaustiva de árvores, uma vez que o computador precisa reconstruir todas as árvores possíveis para "escolher" aquelas com um número mínimo de mudanças, que são chamadas de árvores mais parcimoniosas. Para contornar este problema do tempo, existem também algoritmos heurísticos de reconstrução filogenética, mas é preciso lembrar que, nestes casos, a árvore final pode ser subótima.

\section{Máxima Verossimilhança (MV)}

Este método baseia-se na reconstrução filogenética através da busca por uma árvore que maximize a probabilidade dos dados observados. Neste sentido, o método de MV calcula as probabilidades associadas a diferentes topologias e cada uma delas com as variações nos tamanhos dos ramos, considerando o modelo evolutivo escolhido. Portanto, encontrar a árvore mais verossímil envolve não somente a análise das topologias possíveis, mas também das variações de comprimento de ramos para cada topologia. Deste modo, o emprego de algoritmos heurísticos pode auxiliar enormemente na busca pela árvore ideal, já que o tempo computacional aumenta de acordo com o número de espécies e de parâmetros considerados na análise.

A cada vez que um programa de filogenia molecular é rodado para gerar uma árvore sobre o conjunto de dados escolhidos, o resultado pode ser diferente. Por isso, para validar uma árvore filogenética, o que se faz é rodar repetidas vezes o programa escolhido e, estatisticamente, testar cada ramo para escolher um a um aqueles com maior probabilidade de ocorrência para a composição final da árvore. O método estatístico mais usado nessas análises é o chamado bootstrap.

O bootstrap funciona gerando conjuntos modificados de dados, obtidos aleatoriamente a partir dos dados do alinhamento. Para cada conjunto aleató- 
BOX11 - Programas mais utilizados na análise filogenética Clustal

Programa para o alinhamento múltiplo de seqüências

Acesso on line - http://www.ebi.ac.uk/clustalw/

Download do clustal X para diversas plataformas - http://inn-

prot.weizmann.ac.il/software/ClustalX.html

PAUP 4.0 (Phylogenetic Analysis Using Parsimony and other methods) http://paup.csit.fsu.edu/

Análises filogenéticas utilizando métodos de distância, máxima parcimônia e máxima verossimilhança

PHYLIP (Phylogeny Inference Package) - inferências filogenéticas

http://evolution.genetics.washington.edu/phylip.html

MEGA (Molecular Evolutionary Genome Analysis) - http://

www.megasoftware.net/

Inferências filogenéticas com métodos de distância e parcimônia.

Download gratuito.

Treeview http://taxonomy.zoology.gla.ac.uk/rod/treeview

Software gratuito para edição gráfica e impressão de árvores filogenéticas

rio de dados obtidos é estimada uma árvore. As novas árvores, geradas a partir dos conjuntos modificados dos dados de entrada, são comparadas. Cada um dos ramos da árvore final recebe então um valor de probabilidade, que é obtido do número de novas árvores onde esse ramo ocorreu dividido pelo número total de novas árvores estimadas. Probabilidades altas indicam que, mesmo com algumas alterações, os dados suportam o ramo ao qual essa probabilidade se refere e probabilidades baixas significam que, com a amostra analisada, não se pode ter certeza de que determinado ramo seja correto.

\section{CONSIDERAÇÕES FINAIS}

Tentamos abordar nesse artigo os principais tópicos desenvolvidos em bioinformática. Este artigo não pretende esgotar cada um dos assuntos abordados, mas imaginamos que os leitores interessados poderão encontrar mais informações e trilhar seu próprio caminho visitando os links e observando as referências sugeridas.

\section{Agradecimentos}

Sendo este trabalho fruto do aprendizado obtido no II Curso de Especialização em Bioinformática, realizado de agosto a novembro de 2002 em Petrópolis - RJ, os autores gostariam de agradecer principalmente ao $\mathrm{CNPq}$ pelo suporte financeiro concedido para a realização do curso e ao LNCC (Laboratório Nacional de Computação Científica) por sediar este evento, em especial à coordenadora do curso, Ana Tereza Vasconcelos. Agradecemos também a todos os nossos professores: Darcy de Almeida, Richard Garratt, Glaucius Oliva, Patricia Palagi, Marie Anne Van Sluys, Cláudia Russo, Anamaria Camargo, Helena Brentani, Sandro de Souza, Jorge de Souza, Luiz Gonzaga, Frank Alarcon, Fernanda Raupp, Daniele Quintella, Helio Barbosa, Alexandre Plastino, Dorival Leão, Marcos Grivet, Simone Martins e a todo o pessoal do Laboratório de Bioinformática do LNCC.

Agradecemos também a nossos orientadores e às instituições e órgãos de financiamento nacionais e estaduais pelo apoio dado a cada um de nós para a participação no Curso de Especialização em Bioinformática do LNCC.

\section{REFERÊNCIAS BIBLIOGRÁFICAS}

1. Altschul SF et al. Gapped BLAST and PSI-BLAST: a new generation of protein database search programs. Nucleic Acids Res 25: 3389-3402. 1997.

2. Baxevanis AD, Ouellette BFF. Bioinformatics: A practical guide to the analysis of genes and proteins. Ed. Wiley-interscience. 2nd ed. 2001. 470p

3. Clote P, Backofen R. Computatio- nal Molecular Biology: An introduction. John Wiley \& Sons, LTD. 2000. 286p.

4. Ewing B, Green P. Base-calling of automated sequencer traces using phred. II. Error probabilities. Genome Res 8:186-94. 1998.

5. Frishman D et al. Comprehensive, comprehensible, distributed and intelligent databases: current status. Bioinformatics Review, 14, 551-561. 1998.

6. Huang X, Madan A. CAP3: A DNA Sequence Assembly Program. Genome Biol 9: 868-877. 1999.

7. Hunt SP, Livesey FJ. Functional genomics. Oxford University Press. 2000. 253p.

8. Matioli RM. Biologia Molecular e Evolução. Ed. Ribeirão Preto: Holos, 2001. 202 p.

9. Nei M, Kumar S. Molecular evolution and phylogenetics. $1 \mathrm{Ed}$. New York: Oxford, 2000. 333 p.

10. Lander ES et al. Initial sequencing and analysis of the human genome. Nature 409:860-921. 2001.

11. Li WH, Graur D. Fundamentals of molecular evolution. 2. Ed. Sunderland: Sinauer Associates, 2000.480p.

12. Prosdocimi $\mathrm{F}$ et al. Clustering of Schistosoma mansoni mRNA sequences and analysis of the most transcribed genes: implications in metabolism and biology of different developmental stages. Mem Inst Oswaldo Cruz 97: 61-69. 2002.

13. Schena M. Microarray Analysis. Ed. John Wiley \& Sons. 2002.

14. Setubal JC, Meidanis J. Introduction to Computational Molecular Biology. Brooks Cole Publishing Company. 1997. 296p.

15. Stein L. Genome annotation: from sequence to biology. Nat Reviews 2: 493-505. 2001.

16. Strohman R. Five stages of the Human Genome Project. Nat. Biotechnol 17, 112. 1999.

17. Schwartz RL. Learning Perl. Ed. O'Reilly \& Associates, Inc. 1993. $247 \mathrm{p}$.

18. Tisdall JD. Beginning Perl for Bioinformatics. Ed. O'Reilly \& Associates, Inc. 2001. 368p.

19. Venter JC et al. The sequence of the human genome. Science 29:1304-51. 2001. 


\section{Genes em indivíduos e famílias}

Ricardo de Godoi Mattos Ferreira

Carlos Eduardo Malvezzi Kawamata

Henrique Krieger

\section{INTRODUÇÃO}

Atualmente, na época chamada de "pósgenômica”, o enfoque dos estudos em genética humana, de uma maneira geral, tem-se voltado para os fenômenos de causa e efeito de genes conhecidos na produção de certas características nosológicas particulares. Por outro lado, muitas características humanas não possuem um mecanismo etiológico simples e são causadas pelo efeito simultâneo de vários fatores biológicos e do ambiente. Essas características são chamadas "complexas", pois não existe um mecanismo (genético ou ambiental) simples que explique o desenvolvimento da característica em estudo. Como exemplo de característica complexa podem ser citadas as doenças cardiovasculares, em que um número grande de fatores afeta o fenótipo (tipo de alimentação, exercícios, hábito de fumar, excesso de peso e um componente genético importante, porém de natureza ainda não esclarecido).

No presente capítulo, serão tratados apenas aspectos importantes nos métodos e nas abordagens específicas do estudo de características complexas. Existem bons livros dedicados ao tratamento de dados sobre características monogênicas e que o leitor buscando informações mais complexas deve-se valer (conferir Beiguelman, "A interpretação genética da variabilidade humana" na página http://www.desvirtual.com/bbeiguel/ ebook03.htm).

Com o fabuloso desenvolvimento da biologia molecular e conseqüente desenvolvimento de métodos e técnicas, equipamentos e treinamento de profissionais competentes, no começo do presente milênio, estabeleceu-se com quase absoluta precisão, o genoma humano com todos os genes que compõem esse patrimônio hereditário e suas seqüências de nucleotídeos (ver Capítulo 2 - Genes e cromossomos).

Porém, deve-se salientar que o gene não possui apenas essa propriedade (i.e. uma determinada seqüência), mas também outras que são de extrema importância para os estudiosos de características complexas e, na maioria, bastante simples e conhecidas há muitas décadas. Essas propriedades, apesar de poderem ser enunciadas e entendidas facilmente, possuem especificidades matemáticas bastante claras e vêm, com o constante aprimoramento de métodos, colaborando para o conhecimento das contribuições relativas de várias causas em características normais e patológicas da espécie.

A primeira propriedade do gene que será tratada aqui é a transmissão da característica de 
uma geração para a geração subseqüente. Como se sabe da genética clássica, existem apenas três situações distintas de um gene passar ou não passar de um genitor para sua prole.

a) O referido genitor é homozigoto para o gene. Nesse caso, toda a prole receberá, o referido gene. Pode-se simbolizar essa transmissão em termos probabilísticos da seguinte forma: $\mathrm{P}(\mathrm{AA} \rightarrow \mathrm{A})=1$, ou seja, a probabilidade de um indivíduo $\mathrm{AA}$ transmitir o gene A é um, desde que tenha descendência.

b) O genitor é heterozigoto para o gene A (genótipo AA'). Nesse caso, a probabilidade de transmissão do gene A é 0,5. Simbolicamente: $\mathrm{P}\left(\mathrm{AA}^{\prime} \rightarrow \mathrm{A}\right)=0,5$.

c) $\mathrm{O}$ genitor não possui o gene $\mathrm{A}$. Obviamente podemos dizer que $\mathrm{P}\left(\mathrm{A}^{\prime} \mathrm{A}^{\prime} \rightarrow\right.$ A) $=0$.

Nos trabalhos que tratam de analisar o comportamento dos genes em famílias, essas três probabilidades possuem geralmente, as seguintes notações $\mathrm{P}(\mathrm{AA} \rightarrow \mathrm{A})=\tau_{\mathrm{AA}}$, $\mathrm{P}\left(\mathrm{AA}^{\prime} \rightarrow \mathrm{A}\right)=\tau_{\mathrm{Aa}}$ e $\mathrm{P}\left(\mathrm{A}^{\prime} \mathrm{A}^{\prime} \rightarrow \mathrm{A}\right)=\tau_{\mathrm{aa}}$

A segunda propriedade que será abordada é o efeito. Para se visualizar a maneira pela qual é quantificado o efeito, utiliza-se uma abstração relativamente simples: imagina-se que o indivíduo homozigoto AA produz, em média, um efeito $t$ sobre o fenótipo em estudo, ao passo que o indivíduo A'A' não produz nenhum efeito visível no fenótipo $(t=0)$. O efeito produzido pelo heterozigoto (AA') é igual a $d t$, em que $d$ é o que se denomina de dominância. Dessa forma o gene A humano é dominante quando $d=1$, e portanto, o efeito do gene no heterozigoto (AA') é igual ao efeito no homozigoto (AA). Quando o valor de $d$ é zero, diz-se que o gene A é recessivo, uma vez que os fenótipos de A'A' e AA' são iguais. Existe dominância parcial quando $0<d<1$. Quando $d=0,5$, há co-dominância.

Uma outra propriedade importante do gene é sua freqüência populacional (q). Essa propriedade é definida por um parâmetro clássico estabelecido no começo do século XX por Hardy \& Weinberg e que costuma ser estimada por simples contagem gênica ou por intermédio de simplificações algébricas quando existe dominância.

Esses parâmetros $(\tau, t, d$ e $q)$ são geralmente estimados simultaneamente no que hoje se denomina análise de segregação complexa, conjuntamente com outro parâmetro $(H)$ que é a herdabilidade no sentido tradicional que mede a combinação total do componente multifatorial que inclui o conjunto de poligenes que atuam sobre a característica em estudo. Finalmente, mais uma propriedade do gene de importância capital para os estudos de epidemiologia genética é a recombinação, que é medida pela taxa de recombinação $(\theta)$ e definida como a relação entre o gene em estudo e um determinado marcador. Essa última propriedade será tratada com mais pormenores a seguir.

\section{LIGAÇÃO GÊNICA}

\section{Breve perspectiva histórica}

Após a publicação dos trabalhos de Charles Darwin em meados do século XIX, pesquisadores de diversas áreas das Ciências Naturais, especialmente aqueles interessados em melhoramento vegetal, demonstraram grande interesse em uma abordagem prática da Teoria da Evolução. O trabalho de Mendel, publicado em fevereiro de 1866, intitulado Versuche über Pflanzen-Hybriden - Experimentos na Hibridação de Plantas, foi recebido com entusiasmo pela comunidade científi$\mathrm{ca}$, depois de traduzido para o inglês por Willian Bateson (1901). O artigo original de Mendel, assim como a tradução de Bateson e outros textos muito interessantes sobre o início da Genética Moderna podem ser encontrados na página http://www.mendelweb.org/.

Logo depois da sua redescoberta, as Leis de Mendel foram testadas por diversos pesquisa- 
dores, e alguns deles começaram a encontrar proporções entre dois fenótipos dominantes que segregam independentemente quando analisados separadamente, diferentes das esperadas na geração F2 de acordo com a Segunda Lei de Mendel (9:3:3:1), quando analisados de forma conjunta. Como exemplo, tem-se o estudo de Bateson e Punnet (1911) que utilizaram ervilhas. Apesar das observações, os dois pesquisadores não forneceram uma explicação para o fenômeno, chamado no momento de coupling e repulsion. Estudando drosófilas, Thomas Hunt Morgan publicou uma série de trabalhos sobre os mecanismos hereditários, entre eles o livro Mechanism of Mendelian Heredity (1915), no qual propõe que os genes estão organizados linearmente em cromossomos, e desse modo, fornecendo uma explicação sobre as divergências das freqüências fenotípicas observadas quando comparadas àquelas esperadas pelas Leis de Mendel.

Considerando os trabalhos de Morgan e sua escola, ficou claro que nem todos os genes segregam de forma independente. Genes que estão em um mesmo cromossomo podem estar ligados uns aos outros. Uma visão probabilística da ligação entre os genes deu origem ao conceito de ligação gênica.

Em humanos, um exemplo clássico de ligação entre os genes é o que forma o sistema principal de histocompatibilidade (MHC).

\section{Conceito atual de ligação gênica}

Do ponto de vista celular, os genes de um mesmo cromossomo estão ligados entre si. Em cada célula somática, um indivíduo possui duas cópias homólogas (2n) de cada cromossomo, uma proveniente de seu pai e outra de sua mãe. Durante a meiose, a divisão celular que leva à formação dos gametas, cada um dos cromossomos homólogos é duplicado, formando quatro cromátides (duas paternas e duas maternas). Posteriormente, essas cromátides são pareadas; nesse momento, freqüente- mente as cromátides pareadas não se separam completamente em alguns pontos, formando os quiasmas. Nos pontos onde ocorrem os quiasmas, segmentos do cromossomo de origem paterna são trocados por maternos, formando um cromossomo com uma nova combinação de alelos, chamado de recombinante. As recombinações ocorrem nos pontos onde ocorrem os quiasmas. Depois das duas divisões da meiose, os gametas terminam com uma cópia de cada cromossomo (n), porém essas cópias normalmente são diferentes daquelas encontradas em células somáticas, devido aos cromossomos recombinantes.

Uma vez que a formação de um quiasma inibe a formação de outro muito próximo, sua formação ocorre em posições semi-aleatórias (Watson et al., 1987). Isso torna possível a construção de mapas genéticos. Genes próximos uns aos outros têm, portanto, uma menor chance de recombinação entre si. Por definição, uma unidade de distância em um mapa genético é igual a $1 \%$ de recombinação entre dois genes. Essas unidades são comumente chamadas de centimorgan (cM), em homenagem ao pesquisador Morgan. Nos grandes cromossomos humanos, é freqüente a ocorrência de mais de uma recombinação. No cromossomo 1, por exemplo, ocorrem em média quatro recombinações por meiose, o que possibilita uma distância de mais de $100 \mathrm{cM}$ entre dois genes que se encontram nos extremos desse cromossomo.

Existem diversos métodos para detecção de ligação entre dois ou mais genes. Classicamente, o parâmetro $\theta$, que pode variar de 0 a $0,5 \mathrm{cM}$ é calculado medindo-se o número de recombinações entre dois genes na formação dos gametas. $\mathrm{O}$ parâmetro $\theta$ assume $\mathrm{o}$ valor máximo de $0,5 \mathrm{cM}$ porque uma célula dá origem a quatro gametas, dos quais apenas dois podem ser recombinantes.

A ligação é, portanto, uma propriedade do gene, assim como a seqüência, que se refere às relações entre os genes. O mapa de ligação traz os genes ordenados com suas respec- 
tivas distâncias $x$ baseadas na recombinação. A distância entre genes sucessivos é aditiva, ou seja, dado quatro genes A, B, C e D localizados nessa ordem em um único cromossomo, a distância $x$ entre A e D é $\sim\left(x_{\mathrm{AB}}+x_{\mathrm{BC}}\right.$ $\left.+x_{\mathrm{CD}}\right)$. A equação mais simples para a construção de mapas de ligação é $x=\theta$, onde $x$ é a distância entre os genes. Essa equação, conhecida como função de mapeamento de Morgan (Morgan, 1928), tende a superestimar a distância entre genes mais distantes.

$\mathrm{Na}$ tentativa de resolver as superestimativas de distância decorrentes da equação proposta por Morgan e levar em conta os fenômenos que alteram a linearidade de $x$, foram sugeridas outras equações. Dentre as mais usadas, pode-se citar a de Haldane (1919), binomial (Karlin, 1984) e a de Kosambi (Kosambi, 1944). Na página http://www.ncbi. nlm.nih.gov/projects/genome/guide/ human/, pode-se encontrar mapas de ligação de todos os cromossomos humanos, além dos mapas físicos e muitas outras informações sobre o genoma humano.

Nos casos de genes humanos, os estudos de ligação têm uma complicação adicional, pois não é possível realizar cruzamentos entre indivíduos com características "interessantes", além de haver maior intervalo entre gerações. Para isso foram criados diversos métodos de estudo baseados principalmente na obtenção de dados familiares. Com o uso de dados de indivíduos relacionados é possível, em condições favoráveis, inferir a ocorrência de recombinações e até determinar a localização de um gene relacionado ao fenótipo em estudo delimitado por genes marcadores. Os marcadores são genes de localização conhecida, nos quais o genótipo pode ser inferido com razoável precisão a partir dos fenótipos.

Antes dos avanços trazidos pela biologia molecular nos últimos 25 anos, os pesquisadores contavam com cerca de 60 marcadores genéticos clássicos, por meio dos quais realizavam a busca por novos genes. Nesse cenário, pesquisadores como Victor McKusick, que iniciou em 1966 um dos maiores bancos de dados de genes humanos, o livro Mendelian Inheritance in Man (MIM) atualmente conta com uma versão on-line, o OMIM (On-line Mendelian Inheritance in Man). A Tabela 4.1 retirada do portal do OMIN (http:// www.ncbi.nlm.nih.gov/entrez/query. fcgi?db=OMIM), mostra as estatísticas atuais sobre os genes catalogados nessa página.

Entre os métodos de análise de ligação propostos, um dos pioneiros e que vem sendo amplamente utilizado é o método do lod score proposto por Newton E. Morton (1955), um dos pesquisadores teóricos mais importantes na proposição de métodos de análise genética em humanos.

Atualmente, com a disponibilidade de diversos painéis de marcadores de STRs (short tandem repeats) ou SNPs (single nucleotide polymorphisms) que cobrem desde regiões específicas do genoma até o genoma inteiro, a informação genética dos indivíduos e das populações ficou muito mais acessível.

A facilidade de obtenção de dados criou uma demanda por novos métodos de análise de ligação. O principal problema a ser contornado decorre do grande número de testes aplicados sobre uma mesma amostra. Imaginado um estudo do tipo de escaneamento genômico (genome scan) com cerca de 400 marcadores de STRs e uma análise de ligação de dois pontos, encontram-se pelo menos 400 testes. Se o nível de significância $\alpha$ de 0,05 for adotado, esperaria-se cerca de 20 resultados positivos espúrios, um erro do tipo I muito alto. Por outro lado, a adoção de uma correção simples como a de Bonferroni, que basicamente é a divisão de $\alpha$ pelo número de testes realizados para obtenção de um $\alpha_{c}$, que nesse exemplo seria igual a 0,000125 , tornaria praticamente impossível a obtenção de um lod score com essa significância, tornando o erro do tipo II muito alto.

As estratégias para a resolução desses problemas começam desde o planejamento do estudo, como o uso de projetos de dois está- 
Tabela 4.1 Estatísticas do OMIM em 21 de novembro de 2006 - números de registros

\begin{tabular}{|c|c|c|c|c|c|}
\hline Genes & Autossômicos & Ligados ao X & Ligados ao Y & Mitocondriais & Total \\
\hline $\begin{array}{l}\text { Genes com } \\
\text { seqüência } \\
\text { conhecida }\end{array}$ & 10542 & 488 & 48 & 37 & 11115 \\
\hline $\begin{array}{l}\text { Genes com } \\
\text { seqüência e } \\
\text { fenótipos } \\
\text { conhecidos }\end{array}$ & 354 & 33 & 0 & 0 & 387 \\
\hline $\begin{array}{l}\text { Descrição de } \\
\text { fenótipo, bases } \\
\text { moleculares } \\
\text { conhecidas }\end{array}$ & 1821 & 161 & 2 & 26 & 2010 \\
\hline $\begin{array}{l}\text { Fenótipo } \\
\text { mendeliano, bases } \\
\text { moleculares } \\
\text { desconhecidas }\end{array}$ & 1415 & 137 & 4 & 0 & 1556 \\
\hline $\begin{array}{l}\text { Outros, } \\
\text { principalmente } \\
\text { fenótipos com } \\
\text { suspeita de } \\
\text { segregação } \\
\text { mendeliana }\end{array}$ & 2019 & 144 & 2 & 0 & 2165 \\
\hline Total & 16151 & 963 & 56 & 63 & 17233 \\
\hline
\end{tabular}

gios, em que uma parte da amostra é testada com todos os marcadores e a outra é testada apenas com os marcadores com resultados significativos no primeiro estágio. Outras estratégias envolvem confirmação em outras amostras e metanálises. É sempre bom lembrar que resultados obtidos em um experimento de ligação devem ser confirmados com outro tipo de estudo ou em mais de uma amostra.

\section{O método lod score}

O método lod score foi proposto por Morton em 1955 e foi uma contribuição muito importante e duradoura desse pesquisador. Lod score vem do inglês logarithm of an odds ratio. Sendo odd ratio definida como a razão entre a probabilidade de um genótipo específico ser observado em determinada família, em uma determinada fração de recombinação diferente de 0,5 contra a mesma probabilidade computada, considerando segregação independente. O logaritmo é aplicado por ser mais conveniente, já que traz os valores a uma escala mais adequada, assim como permite que os valores obtidos em diversas famílias possam ser somados entre si. Quanto maior o lod score, maior a evidência a favor de ligação e, sem levar em conta múltiplos testes e outras complicações, lod scores com valores acima de três são altamente indicativos de ligação. O fato de os lod scores poderem ser somados é especialmente interessante quando se pretende realizar uma metanálise. Com o algoritmo que permite o cálculo do lod score em pedigrees mais complexos proposto por Elston e Stewart (1971) e posteriormente com o programa de Ott (1974), que permitia a realização desses cál- 
culos de maneira mais amistosa, o método lod score ganhou popularidade e vem sendo amplamente utilizado.

\section{Outros métodos de estudo de ligação gênica}

O livro de Jurg Ott, Analysis of Human Genetic Linkage, apresenta uma revisão extensa e abrangente sobre ligação e os métodos empregados para o seu estudo. O método lod score vem sofrendo diversas modificações e aperfeiçoamentos que tentam levar em conta as particularidades das populações e características estudadas.

De forma geral, os métodos de análise de ligação consideram a proporção de alelos em marcadores compartilhados entre parentes devido à descendência (em inglês, $I B D$-identity by descend) contra a proporção dos alelos compartilhados devido ao acaso (em inglês, IBS - identity by state) e a concordância da característica estudada com essas proporções.

Partindo de mapas de IBD, os métodos de análise de ligação podem ser divididos em dois grandes grupos: análise paramétrica e análise não-paramétrica. A diferença principal entre os dois tipos de análise é que na análise paramétrica, baseada principalmente no lod score, é necessário estabelecer um modelo de herança para a característica em estudo, ao passo que na análise não-paramétrica esse modelo não é necessário. As vantagens e desvantagens de cada método são motivos de discussão entre especialistas da área e dependem muito da amostra a ser estudada, bem como da característica. De maneira breve, pode-se dizer que os métodos paramétricos têm maior poder estatístico quando utilizado em características com herança bem determinada. Em características complexas, freqüentemente os métodos não-paramétricos são preferidos. De qualquer maneira a escolha do método depende de muitos outros fatores além dos descritos aqui.

\section{ASSOCIAÇÃO}

Estudos de associação visam a identificar um marcador que tenha relação com um fenótipo no nível populacional. Isso se deve a um possível desequilíbrio de ligação entre dois genes. Dizemos que dois genes estão em desequilíbrio de ligação quando as freqüências simultâneas dos alelos forem diferentes daquelas esperadas por acaso. Quanto mais próximos estiverem os polimorfismos no cromossomo, menor será a probabilidade de recombinação e maior será a probabilidade dos dois genes estarem em desequilíbrio de ligação.

Isso se deve ao fato de que quanto mais próxima for a ligação, maior será o tempo que o desequilíbrio permanecerá na população. Em uma amostra em que o casamento é ao acaso, a tendência ao equilíbrio é igual a uma parte da taxa de recombinação $(\theta)$; e decresce um valor igual a $\theta$ em cada geração. Em loci não-ligados, a freqüência dos haplótipos percorre metade do caminho para o equilíbrio a cada geração; quando $\theta=0,10$, serão necessárias sete gerações; quando $\theta=0,01$, serão 69 gerações; e quando $\theta=0,001$, serão necessárias 693 gerações. Isto é, quanto menor a taxa de recombinação $(\theta)$, maior a probabilidade de dois genes estarem em desequilíbrio de ligação e um número maior de gerações será necessário para a população chegar ao equilíbrio. Com isso, as perspectivas para se detectar um desequilíbrio de ligação são menores para mutações mais antigas do que para mutações mais recentes, porém outros fatores evolucionários como deriva genética, migração e mistura, por exemplo, podem amplificar a visibilidade do desequilíbrio ou mesmo mimetizá-lo (Rao e Province, 2001).

Muitos estudos de associação com doenças infecciosas são feitos com a utilização de SNP, STR e marcadores clássicos de sistemas sangüíneos (como ABO, Rh e Duffy, por exemplo). Nesses estudos são usados métodos do tipo caso-controle, nos quais indiví- 
duos doentes são comparados com indivíduos sadios pertencentes à mesma população, e testes do tipo TDT (transmission/disequilibrium-test), nos quais é analisada a transmissão dos alelos entre os indivíduos afetados e não afetados.

A forma mais utilizada para estudar associação, devido à facilidade na obtenção de amostras apropriadas, é por meio da utilização de testes do tipo caso-controle, que se dá pela genotipagem dos indivíduos dentro de uma população. Compara-se o marcador ou as freqüências genotípicas de STR ou SNP nos indivíduos que apresentam a característica em estudo (afetados) com as freqüências dos indivíduos do restante da amostra (não afetados). Se o desequilíbrio de ligação entre os marcadores for significativo, diferenças entre caso e controle, caracterizarão uma associação entre marcador e fenótipo (Nilesen e Weir, 2001).

Em 2003, estudos desse tipo revelaram que existe uma associação entre indivíduos do grupo sangüíneo Duffy negativo e o número de episódios de malárias em Portuchuelo, RO (Beiguelman et al, 2003). Nesse trabalho, uma população composta por 182 indivíduos foi analisada. Testes com marcadores de grupos sangüíneos realizados entre indivíduos afetados e indivíduos não afetados comprovaram a associação entre o grupo sangüíneo Duffy negativo e a resistência pela infecção por $P$. vivax, fato já conhecido e presente na literatura científica.

Para o teste TDT é necessária a informação genotípica e trios de indivíduos - pai, mãe e filho - e pelo menos um dos pais deve ser heterozigoto para que o teste seja informativo. A grande vantagem desse tipo de teste, que vem ganhando cada vez mais importância, é que ele não é influenciado pela estratificação da amostra e nem por casos de mistura étnica. Pesquisadores têm contribuído bastante para estender o teste TDT para outras situações, como marcadores com mais de um alelo (Sham e Curtis,
1995; Bickeboeller e Clerget-Darpoux, 1995; Rice et al., 1995), casos em que se tem apenas um dos pais para o estudo (Sun et al., 1999), casos em que não se tem nenhum dado dos pais usando pares de irmãos (Spielman e Ewens, 1998; Hovarth e Laird, 1998; Boehnke e Langefeld, 1998), o que traz informações sobre alelos que não segregam em indivíduos afetados.

Tanto no teste de caso-controle quanto no teste TDT, o que deve ser analisado é o marcador depois de a população estar corretamente organizada por fenótipo da doença em questão. A principal barreira nos estudos de associação é que não existe garantia da presença de um desequilíbrio de ligação na região de interesse; sendo assim, se não há desequilíbrio de ligação, os testes de associação não terão alto poder estatístico, fato que torna ainda mais importante a escolha da população a ser estudada (Rao e Province, 2001).

Um dos problemas nos estudos de associação surge quando temos que fazer a análise com marcadores multialélicos. Alguns métodos, como aumentar o número de classes, além de aumentar o número de graus de liberdade podem causar perda de poder estatístico. Outro mecanismo seria diminuir o número de alelos, o que pode levar a um problema estatístico quando se tenta comparar todos os alelos possíveis. O melhor modelo seria baseado na verossimilhança para os testes de desequilíbrio de ligação que pode utilizar vários alelos (Terwilliger, 1995); o teste se torna mais conservador à medida que se aumenta o número de alelos sem perder o poder estatístico (Rao e Province, 2001).

Quando se examina um gene candidato, vários sítios polimórficos podem existir próximos ao gene, do qual uma parte pode ser escolhida para a genotipagem. Cada um desses sítios pode ser funcional ou pode estar associado a outro sítio funcional. Examinando individualmente SNP dessa região não se obtém um grande poder para detec- 
ção de associações quando se compara com o uso de haplótipos (Rao e Province, 2001).

Uma importante fonte de estudos de associação são os haplótipos, isto é, segmentos dos cromossomos que são transmitidos através das gerações como regiões de seqüências de DNA que são compartilhados por muitos indivíduos sem sofrer recombinação. Sendo assim, permitem a busca de genes candidatos associados a doenças e outras características relevantes.

Para isso alguns geneticistas utilizam o HapMap, que é um catálogo de variantes genéticas comuns que ocorrem nos seres humanos. Nesse catálogo podem ser encontradas as descrições das variantes, o local onde ocorrem e como estão distribuídas nos indivíduos dentro das populações e entre as populações em diferentes partes do mundo. O Projeto HapMap tem o objetivo de fornecer informações a respeito da relação de genes com o possível risco a algumas doenças para que outros pesquisadores possam concluir novas descobertas e, assim, proporcionar novos métodos de tratamento, diagnóstico e prevenção de doenças (International HapMap Project).

Procurou-se nos tópicos anteriormente resumidos dar uma idéia das ferramentas que os modernos programas computacionais empregam no tratamento de características complexas e na separação de mecanismos monogênicos que podem afetar essas características.

\section{REFERÊNCIAS BIBLIOGRÁFICAS}

1. Bateson W. G. Mendel: Experiments in Plant Hybridisation. J Royal Hort Soc 1901; 26:1-32.

2. Bateson W. Hybridisation and cross-breeding as a method of scientific investigation. Journal of the Royal Horticultural Society 1900; 24:59-66.

3. Bateson W, Punnet RC. On the inter-relations of genetic factors, Vol 6, Number 1 / December, 1911 http://www.springerlink.com/index/ L80H71270 0246G85.pdf Bateson, W, Punnet, RC. On the Inter-relations of Genetic Factors.
Proceedings of the Royal Society, 84, B. 1911, S. 3

4. Beiguelman B, Alves FP, Moura MM, Engracia V, Nunes ACS, Heckmann MIO et al. The association of genetic markers and malaria infection in the Brazilian Western Amazonian region. Mem Inst Oswaldo Cruz 2003; 98. [cited 2006 Nov 17]. Available at: <http:// www.scielo.br/scielo.php?script=sci_arttext\&pid $=$ S0074-02762003000400004\&lng= en\&nrm $=$ iso $>$.

5. Bickeboeller H, Clerget-Darpoux F. Statistical properties of the allelic and genotipic transmission/disequilibrium test for multiallelic markers. Genet Epidemiol 1995; 12:865-70.

6. Boehnke M, Langefeld CD. Genetic association base don discordant sib pairs: The discordantallelic test. Am J Hum Genet 1998; 62:950-61.

7. Elson RC, Stwart J. A general model for the genetic analysis of pedigree data. Hum Hered 1971; 21(6):523-42.

8. Hovarth S, Laird MN. A discordant-sibship test for disequilibrium and linkage: no need for parental data. Am J Hum Genet 1998; 63:1886-97.

9. International HapMap Project. [cited 2006 nov 10]. Available at: http://www.hapmap.org/ index.html.

10. Karlin S. Theoritical aspects of genetic map functions in recombination processes. In: Chakravarti A (ed.). Human population genetics: The Pittsburgh Symposium. New York: Van Nostrand Reinhold, 1984. p. 209-28.

11. Kosambi DD. The estimation of map distances from recombination values. Ann Eugen 1944; 12:172-5.

12. Li L, Wang QK, Rao S, LINKAGE programs: linkage analysis for monogenic cardiovascular diseases. Methods Mol Med. 2006; 128:41-60.

13. Mendel G. Versuch über Plfazen-Hybriden. Verh Naturforsch Ver Brünn 1866; 4:3-47.

14. Nielsen DM, Weir BS. Association studies under general disease models. Theorical population biology 2001; 60:253-63.

15. Rao DC, Province MA. Genetic dissection of complex traits. In: Borecki IB, Suarez BK. Linkage and associaton: basic concepts. San Diego: Academic Press, 2001. p. 45-66.

16. Rice JP, Neuman RJ, Hoshaw SL, Daw EW, Gu C. TDT with covarietes and genomic screen 
with mod scores: their behavior on simulated data. Genet Epidemiol 1995; 12:659-64.

17. Sham PC, Curtis D. An extended transmission/disequilibrium test (TDT) for multiple allele marker loci. Ann Hum Genet 1995; 59: 323-36.

18. Spielman RS, Ewens WJ. A sibship test for linkage in the presence of association: the sib transmission/disequilibrium test. Am J Hum Genet 1998; 62:450-8.

19. Stewart WC, Thompson EA. Improving estimates of genetic maps: a maximum likelihood approach. Biometrics 2006 Sep;62(3):728-34.

20. Sun F, Flanders WD, Yang Q, Khoury MJ. Transmission disequilibrium test (TDT) when only one parent is avaliable: the 1-TDT. Am J Epidemiol 1999; 150:97-104.
21. Tapper W, Collins A, Gibson J, Maniatis N, Ennis S, Morton NE. A map of the human genome in linkage disequilibrium units. Proc Natl Acad Sci USA 2005 Aug 16; 102(33): 11835-9. Epub 2005 Aug 9.

22. Terwilliger JD. A powerful likelihood method for the analysis of linkage disequilibrium between trait loci and one or more polymorphic marker loci. Am J Hum Genet. 1995; 65:777-87.

23. Watson JD, Hopkins NH, Roberts JW, et al. Molecular biology of the gene. vol II: Specialized aspects. $4^{\text {th }}$ ed. Menlo Park California: Benjamin Cummings Publishing Company, 1987. 